\title{
Stability of Disposal Rooms During Waste Retrieval
}

Manuscript Completed: October 1988

Date Published: March 1989

\section{Prepared by}

T. Brandshaug

Itasca Consulting Group, Inc.

Suite 210, 1313 5th Street SE

Minneapolis, MN 55414

\section{Prepared for}

Division of High-Level Waste Management

Office of Nuclear Material Safety and Safeguards

U.S. Nuclear Regulatory Commission

Washington, DC 20555

NRC FIN D1016

\section{MASTER}

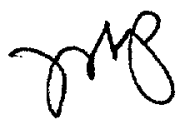




\section{DISCLAIMER}

This report was prepared as an account of work sponsored by an agency of the United States Government. Neither the United States Government nor any agency thereof, nor any of their employees, make any warranty, express or implied, or assumes any legal liability or responsibility for the accuracy, completeness, or usefulness of any information, apparatus, product, or process disclosed, or represents that its use would not infringe privately owned rights. Reference herein to any specific commercial product, process, or service by trade name, trademark, manufacturer, or otherwise does not necessarily constitute or imply its endorsement, recommendation, or favoring by the United States Government or any agency thereof. The views and opinions of authors expressed herein do not necessarily state or reflect those of the United States Government or any agency thereof. 


\section{DISCLAIMER}

Portions of this document may be illegible in electronic image products. Images are produced from the best available original document. 


\section{ABSTRACT}

This report presents the results of a numerical analysis to determine the stability of waste disposal rooms for vertical and horizontal emplacement during the period of waste retrieval. It is assumed that waste retrieval starts 50 years after the initial emplacement of the waste, and that access to and retrieval of the waste containers take place through the disposal rooms. It is further assumed that the disposal rooms are not backfilled. Convective cooling of the disposal rooms in preparation for waste retrieval is included in the analysis. Conditions and parameters used were taken from the Nevada Nuclear Waste Storage Investigation (NNWSI) Project Site Characterization Plan Conceptual Design Report (MacDougall et al., 1987).

Thermal results are presented which illustrate the heat transfer response of the rock adjacent to the disposal rooms. Mechanical results are presented which illustrate the predicted distribution of stress, joint slip, and room deformations for the period of time investigated.

Under the assumption that the host rock can be classified as "fair to good" using the Geomechanics Classification system (Bieniawski, 1974), only light ground support would appear to be necessary for the disposal rooms to remain stable. 

TABLE OF CONTENTS

PAGE

ABSTRACT

iii

LIST OF FIGURES • • • • • • • • • • • • • • • • • •

vii

1.0 INTRODUCTION . . . . . . . . . . . . . . . . . . . . 1

1.1 Background. . . . . . . . . . . . . . . . 1

1.2 Objective................... . . . . . . . . . 3

1.3 Scope . . . . . . . . . . . . . . 3

2.0 APPROACH . . . . . . . . . . . . . . . . . 4

2.1 Assumptions and Idealizations . . . . . . . . 4

2.2 Numerical Models. . . . . . . . . . . . . 7

2.3 Conceptual Considerations . . . . . . . . . 9

3.0 MODEL INPUT PARAMETERS . . . . . . . . . . . . . 15

3.1 Material Properties . . . . . . . . . . 15

3.2 Waste Form Characteristics. . . . . . . . . 17

4.0 DISCUSSION OF RESULTS. . . . . . . . . . . . . . . . 18

4.1 Thermal Results . . . . . . . . . . . . 18

4.1 .1 Vertical Emplacement . . . . . . . . 18

4.1 .2 Horizontal Emplacement . . . . . . . . 25

4.2 Mechanical Results. . . . . . . . . . . 32

4.2.1 Vertical Emplacement . . . . . . . . 32

4.2.2 Horizontal Emplacement . . . . . . . 38

5.0 SUMMARY AND CONCLUSIONS. . . . . . . . . . . . . 43 
TABLE OE CONTENTS

(continued)

PAGE

6.0 RECOMMENDATIONS FOR FUTURE STUDIES . . . . . . . . 45

7.0 REFERENCES . . . . . . . . . . . . . . . 4 46

APPENDIX A: DETERMINATION OF THE RADIUS OF THERMAL INELUENCE

APPENDIX, B: DETERMINATION OF THE THERMAL LOADING

APPENDIX C: DETERMINATION OF CONVECTIVE HEAT TRANSFER COEFFICIENTS

APPENDIX D: FLAC INPUT FILES 
vii

LIST OF EIGURES

$\underline{\text { PAGE }}$

Fig. 1 Retrieval Time Erame for Design Purposes

[MacDougall et al., 1987] . . . . . . . . . 2

Fig. 2 Range of Thermal Influence at Waste Panel Center After 50 Years. . . . . . . . . . . . . . 5

Fig. 3 Mohr-Coulomb Failure Criterion for a Rock Matrix. . 7

Fig. 4 Mohr-Coulomb Failure Criterion for a Rock Joint . . 8

Fig. 5 Plan and Cross-Sectional Views of the Vertical Commingled SF and DHLW Emplacement Configuration [MacDougall et al., 1987, Chapter 4]...... . 10

Fig. 6 Plan and Cross-Sectional Views of the Horizontal Commingled SF and DHLW Emplacement Configuration [MacDougall et al., 1987, Chapter 4]. . . . . . 11

Fig. 7 Conceptual Models of the Disposal Rooms for Vertical and Horizontal Waste Emplacement . . . . 13

Fig. 8 Waste Form Normalized Power Decay . . . . . . . . 17

Fig. 9 Predicted Temperature Contours $\left({ }^{\circ} \mathrm{C}\right)$ Around the Waste Disposal Room for Vertical Emplacement

1 Year After Initial Waste Emplacement. . . . . .

Fig. 10 Predicted Temperature Contours $\left({ }^{\circ} \mathrm{C}\right)$ Around the Waste Disposal Room for Vertical Emplacement 25 Years After Initial Waste Emplacement . . . .

Fig. 11 Predicted Temperature Contours $\left({ }^{\circ} \mathrm{C}\right)$ Around the Waste Disposal Room for Vertical Emplacement 50 Years After Initial Waste Emplacement . . . .

Fig. 12 Predicted Temperature Histories in the Floor, Wall and Roof of the Waste Disposal Room for Vertical Emplacement . . . . . . . . . . .

Fig. 13 Predicted Temperature Profiles into the Pillar of the Waste Disposal Room for Vertical Emplacement. 
viii

$\underline{\text { PAGE }}$

Fig. 14 Predicted Temperature Contours $\left({ }^{\circ} \mathrm{C}\right)$ Around the Waste Disposal Room for Horizontal Emplacement 10 Years After Initial Waste Emplacement . . . . 26

Fig. 15 Predicted Temperature Contours $\left({ }^{\circ} \mathrm{C}\right)$ Around the Waste Disposal Room for Horizontal Emplacement 25 Years After Initial Waste Emplacement . . . .

Fig. 16 Predicted Temperature Contours $\left({ }^{\circ} \mathrm{C}\right)$ Around the Waste Disposal Room for Horizontal Emplacement 50 Years After Initial Waste Emplacement . . . . . 28

Eig. 17 Predicted Temperature Histories in the Floor, Wall and Roof of the Waste Disposal Room for Horizontal Emplacement . . . . . . . . . . . . .

Fig. 18 Predicted Temperature Profiles in the Pillar of the Waste Disposal Room for Horizontal Emplacement Prior to Waste Retrieval. . . . . . . .

Fig. 19 Predicted Temperature Profiles Into the Pillar of the Waste Disposal Room for Horizontal Emplacement During Waste Retrieval . . . . . .

Fig. 20 Predicted Slip Along Vertical Joints as a Result of Excavation of the Waste Disposal Room for Vertical Emplacement . . . . . . . . . .

Fig. 21 Predicted Shear and Horizontal Stresses As a Result of Excavation of the Waste Disposal Room for Vertical Emplacement . . . . . . . . . .

Fig. 22 Predicted Slip Along Vertical Joints Around the Waste Disposal Room for Vertical Emplacement at the Time of Waste Retrieval and After Waste Retrieval. . . . . . . . . . . . . . . . .

Fig. 23 Predicted History of the Roof to Floor Closure and Wall to Wall Closure of the Waste Disposal Room for Vertical Emplacement. . . . . . . .

Fig. 24 Suggested Ground Support As a Function of Induced Stresses and Rock Mass Quality [after Hoek, 1979]. 
Eig. 25 Predicted Slip Along Vertical Joints Around the Waste Disposal Room for Horizontal Emplacement After Excavation and at the Time of Waste Retrieval.... . . . . . . . . . . . .

Fig. 26 Predicted Slip Along Vertical Joints Around the Waste Disposal Room for Horizontal Emplacement After 120 Days of Ventilation. . . . . . . .

Fig. 27 Predicted Shear and Horizontal Stresses As a Result of Excavation of the Waste Disposal Room for Horizontal Emplacement . . . . . . . . .

Fig. 28 Predicted History of the Roof to Floor Closure and the Wall to Wall Closure of the Waste Disposal Room for Horizontal Emplacement . . . . 


\subsection{INTRODUCTION}

This report addresses the subject of structural stability of disposal rooms in a geologic radioactive waste repository. This subject is important because of requirements to retrieve any of the emplaced waste if this should become necessary. In this report, it is assumed, strictly for the purpose of analysis, that waste retrieval will take place 50 years after initial waste emplacement, access to and retrieval of the waste will take place through the disposal rooms, and the disposal rooms are not backfilled prior to waste retrieval.

\subsection{Background}

The Nuclear Waste Policy Act of 1982 (NWPA) which mandates the development of repositories for disposal of high-level waste and spent nuclear fuel also requires the repository to be designed and constructed to permit the retrieval of any emplaced radioactive waste. Regulations concerning waste retrieval are also issued by the Nuclear Regulatory Commission (NRC) in $10 \mathrm{CFR} 60$, and by the Environmental Protection Agency (EPA) in 40 CFR 191.14 ( $f$ ). These regulations dictate specific requirements which affect repository design and performance objectives.

If access to and retrieval of the waste take place through the disposal rooms, the two most important elements in complying with the regulations are the unobstructed access to the waste container boreholes, and the unobstructed access to the waste containers inside the boreholes. This means the disposal rooms and the container boreholes must remain structurally stable for the time period required to complete the retrieval process. This report addresses only the issue of room stability.

The candidate repository site is at Yucca Mountain, Nevada, where the repository horizon is proposed to be located in a densely welded tuff. The site is being evaluated by the Nevada Nuclear Waste Storage Investigation (NNWSI) Project as potentially the first radioactive waste repository in the United States. The NNWSI project's position paper on waste retrieval is given by Flores (1986) and concludes that the disposal rooms are likely to be stable, but may require a minimal amount of maintenance.

The Site Characterization Plan Conceptual Design Report for Yucca Mountain (MacDougall et al., 1987), subsequently referred to as the SCP-CDR, and the Consultation Draft Site Characterization PIan (U.S. DOE, 1988), subsequently referred to as the CD-SCP, 
outline a waste retrieval philosophy and provide a list of design criteria. The retrieval time frame considered in both these documents is shown in Fig. 1. The "retrievability period" is defined as "the time during which the ability to initiate retrieval will be maintained". This period is set to 50 years [U.S. DOE (1986), Appendix D]. The "retrieval period" is defined as "the time period required for removal of the emplaced waste from the underground repository, if a decision to retrieve the waste is made". This period is set to 34 years (Flores, 1986).

\section{FIRST WASTE \\ EMPLACEMENT}

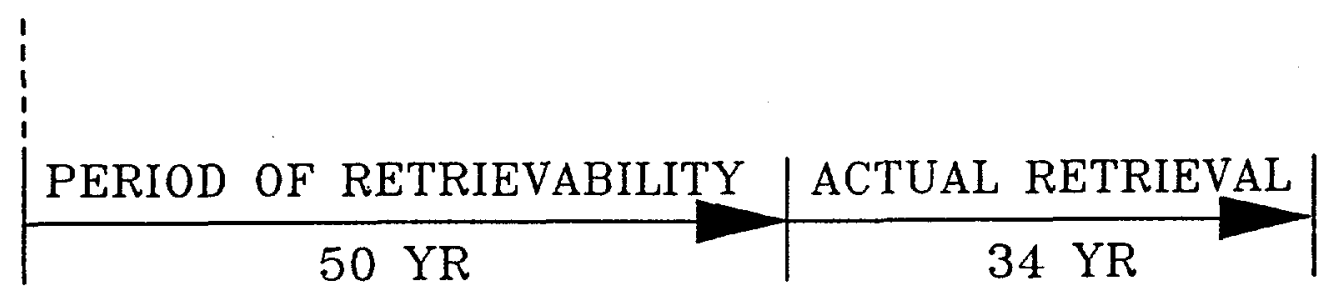

Fig. 1 Retrieval Time Frame for Design Purposes [MacDougall et al., 1987]

The results of the present study will contribute to the evaluation of compliance to some of the design criteria listed in the SCP-CDR and CD-SCP. These are:

- The access and emplacement drifts will remain usable for at least 84 years.

- The rock displacement in the drifts will be less than $0.152 \mathrm{~m}$ ( $6 \mathrm{in}$ ).

- In the horizontal emplacement concept, the temperature in the emplacement drifts will not exceed $50^{\circ} \mathrm{C}$ for 50 years after waste emplacement.

- In the horizontal emplacement concept, the minimum allowable radius of curvature for the horizontal axis of the borehole liner is $34 \mathrm{~m}$ (110 ft). 


\subsection{Objective}

The objective of this report is to provide a document which, by example, may serve as a procedure to the type of numerical analyses that are helpful in evaluating the particular issue of stability/instability of waste disposal rooms during the period of retrievability, and if necessary, the period of actual waste retrieval. Access to and retrieval of the waste are assumed to take place through the disposal rooms.

\subsection{Scope}

The subject of room stability involves the evaluation of inelastic rock behavior such as the creation of new fractures in the intact rock caused by excessive shear stresses, and activities along pre-existing joints such as slip (caused by excessive shear stress along the joints) or opening (caused by tensile stresses across the joints or by a reduction in the compressive stresses). These activities may result from the excavation of the disposal rooms, the continuous heating of the rock because of the presence of the radioactive waste, and from the effects of forced ventilation which may be required to cool the rooms before entry for the purpose of inspection or waste retrieval if necessary.

The present study includes both vertical and horizontal waste emplacement concepts, meaning that single waste containers are placed in vertical boreholes along the disposal room floor, or that multiple waste containers are placed in long horizontal boreholes perpendicular to the room walls. The heat transfer associated with the first 50 years (the retrievability period) of heating is predicted along with the induced thermal stresses, displacements, and inelastic rock behavior. At 50 years (the beginning of the retrieval period), forced convective cooling of the disposal room is initiated to prepare for the retrieval of any emplaced waste. For both the vertical and horizontal emplacement concepts, the convective cooling is continued for a time period sufficient to retrieve all the waste containers from one disposal room. Rock stresses, displacements, and inelastic behavior is also predicted during this period. 


\subsection{APPROACH}

\subsection{Assumptions and Idealizations}

The effective use of numerical models to predict the thermal/mechanical behavior of rock in the vicinity of a waste disposal room requires a number of assumptions and idealizations. Because the results of the numerical models may effect the repository design, it is important that the assumptions and idealizations, if affecting the outcome of the model, contribute to conservative results. With respect to the heat transfer model, "higher" temperatures are conservative. With respect to the mechanical model, "higher" deviatoric stresses are conservative. In this study, assumptions and idealizations are such that "conservative" or "worst case" conditions are reflected in the results.

The assumptions and idealizations are:

- Instantaneous waste emplacement is used.

Emplacing all the waste instantly results in higher predicted temperatures throughout the rock than if sequential waste emplacement is performed. This is because more energy (in the form of heat generating waste) is immediately present to elevate the rock temperature.

- The disposal room cross-section considered is at the center of a waste emplacement panel.

Choosing a cross-section of a disposal room at the center of a waste emplacement panel ensures that maximum temperatures will be predicted with minimum effect from the stand-off distance between emplacement panels (refer to Fig. 2). If the method suggested by St. John (1985) is applied to determine the radius of influence of a single waste container on rock temperatures as a function of time, it is found to be $164 \mathrm{~m}$ after approximately 50 years for the present problem (see Appendix A for this calculation). This means the predicted rock temperatures are not likely to be affected by the panel stand-off distance in the present problem. 


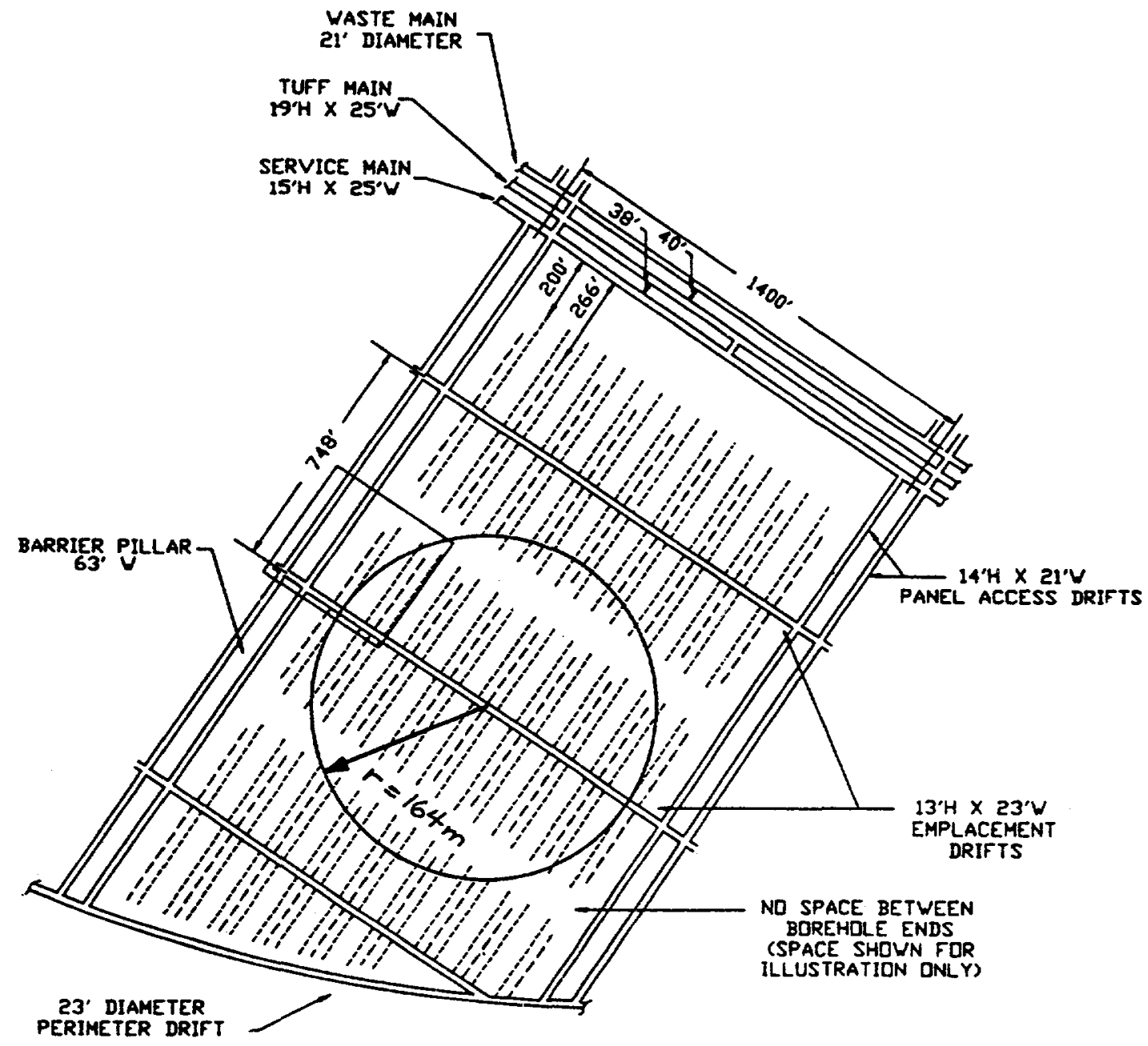

Eig. 2 Range of Thermal Influence at Waste Panel Center After 50 Years 
- Boiling of pore water is not included.

The welded tuff at the proposed repository horizon is expected to be about $80 \%$ saturated (MacDougall et al., 1987, Chapter 2). Therefore, when the rock temperatures reach $100^{\circ} \mathrm{C}$, the pore water can be expected to boil (assuming atmospheric boiling). If pore water boiling is not included in the model, the predicted rock temperatures will be conservative, because the energy that would have been expended in the phase change (liquid to vapor) is available to elevate the rock temperatures instead.

- Waste retrieval takes place at the latest possible time.

To assume that waste retrieval will take place at the end of the retrievability period (i.e., 50 years after initial waste emplacement), allows the rock to be heated for a maximum amount of time. This results in the highest possible rock temperatures relative to starting waste retrieval earlier.

- Access to and retrieval of the nuclear waste will take place through the disposal rooms.

This assumption implies that a particular waste retrieval scenario is used.

- The disposal rooms are not backfilled prior to waste retrieval.

If the disposal rooms are backfilled, waste retrieval would require the backfill to be removed to provide access to the waste containers. The effects of backfill are not considered in this study.

Being conservative in the predictions of the rock temperatures results (because of thermal expansion of the rock) in conservative estimates of rock displacements and deviatoric stresses. In addition, when convective cooling of the disposal rooms begin, the largest possible thermal gradients will develop, bringing about the largest possible deviatoric stresses in the rock around the room periphery, and thus, the greatest potential for room instability. 


\subsection{Numerical Models}

The finite difference computer code FLAC [Fast Lagrangian Analysis of Continua, (ITASCA, 1988)] is used to simulate the thermal/ mechanical response of the rock. A plane strain model is used, and the rock is characterized as an elastic perfectly plastic material with ubiquitous vertical joints (planes of weakness). A Mohr-Coulomb failure criterion is used to determine if new fractures are created in the rock matrix (e.g., Brady and Brown, 1985). Figure 3 illustrates the Mohr-Coulomb failure criterion for the rock matrix for an arbitrary state of stress.

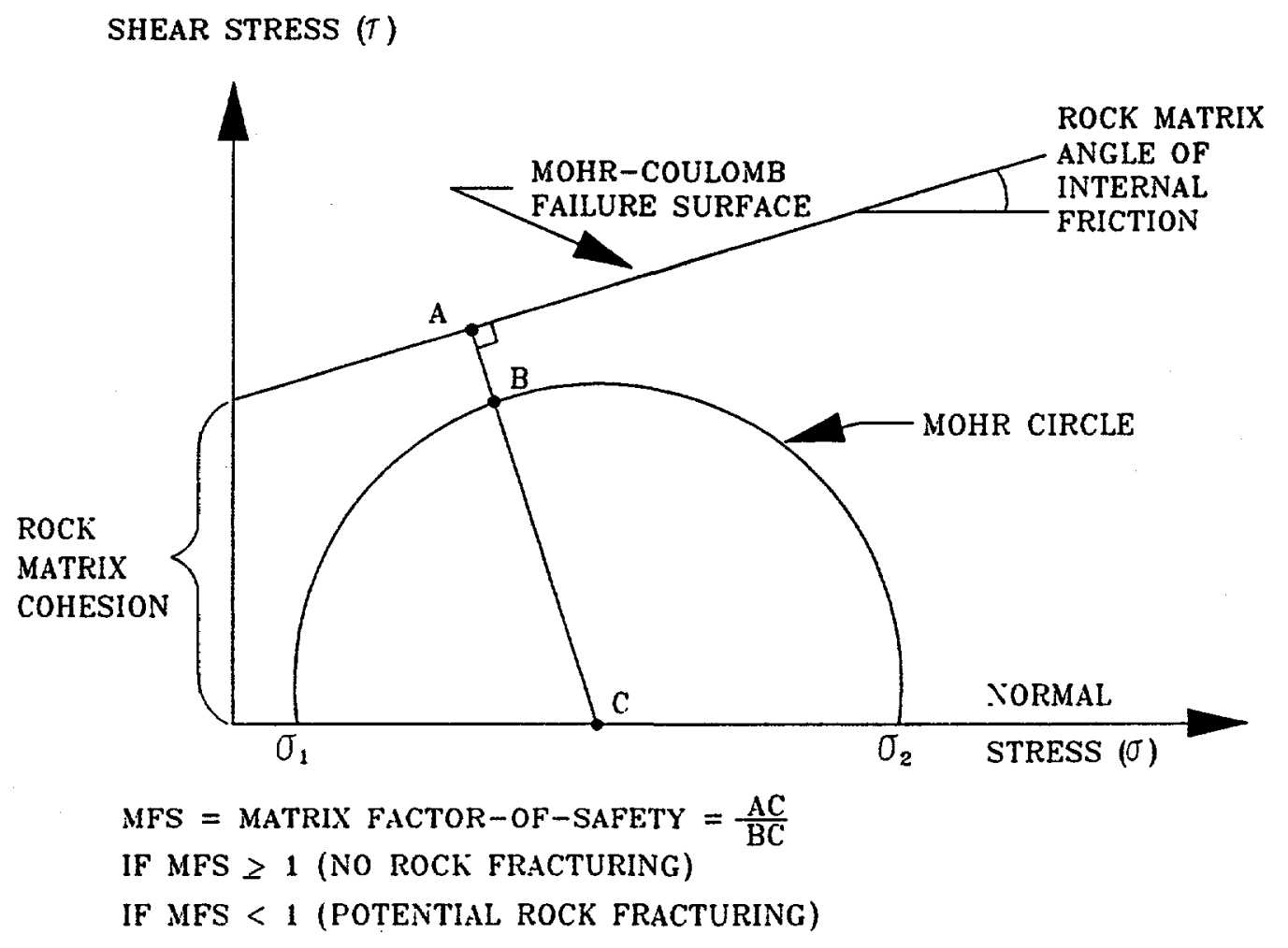

Fig. 3 Mohr-Coulomb Failure Criterion for a Rock Matrix 
Slip or opening along the vertical planes of weakness is determined by a Mohr-Coulomb criterion for joints [e.g., Goodman $(1980)$ ]. Figure 4 illustrates the Mohr-Coulomb criterion for the ubiquitous vertical joints. By allowing inelastic rock behavior to occur, the potential and extent of room instability may be evaluated.

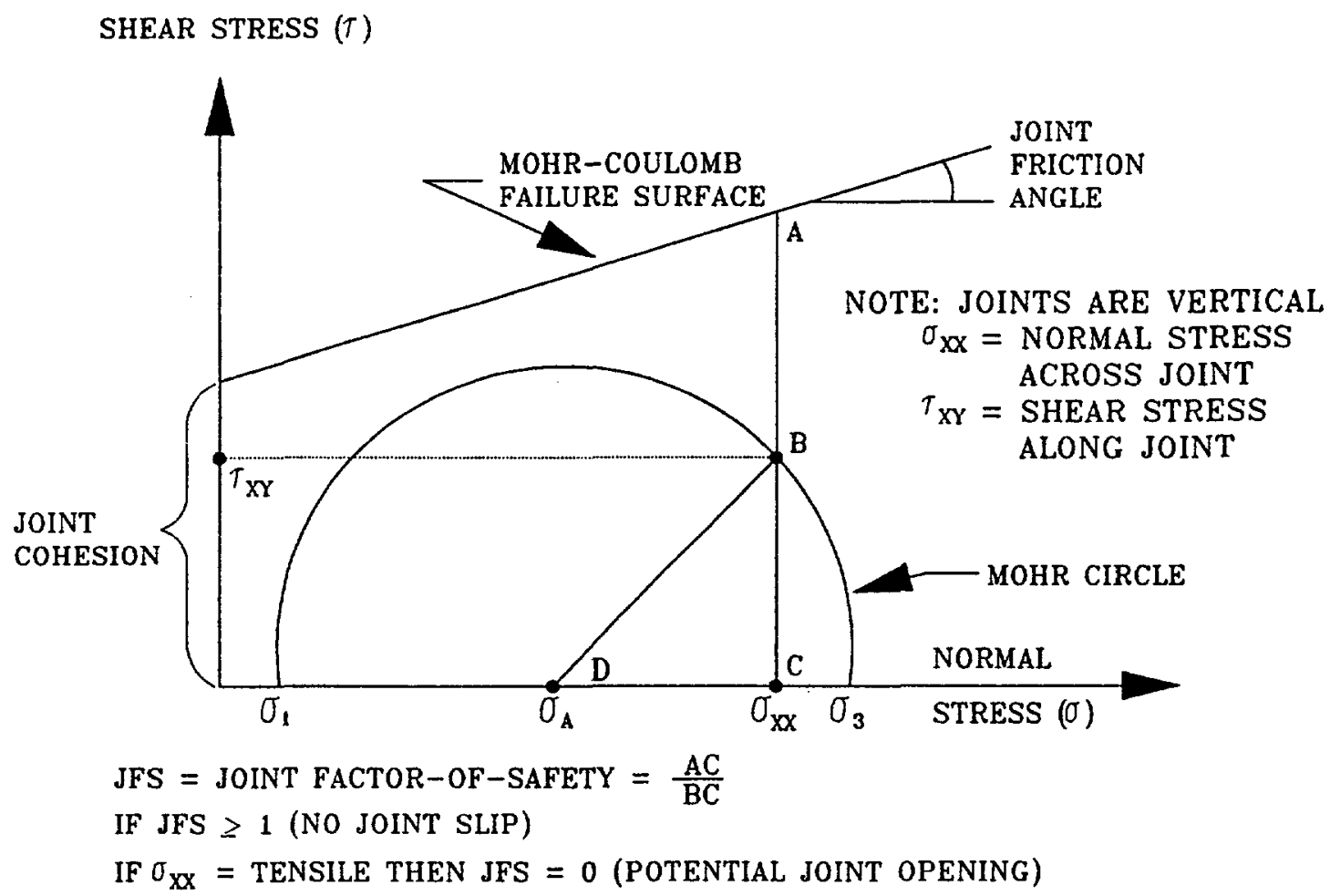

Fig. 4 Mohr-Coulomb Failure Criterion for a Rock Joint 
The simultaneous mass and heat transfer (coupled convection/diffusion process) which occurs in forced ventilation of a waste disposal room is not included in ELAC. However, FLAC allows the use of convective boundaries by applying Newton's law of cooling (e.g., Pitts and Sissom, 1977). This requires the specification of a convective heat transfer coefficient and a temperature of the cooling "fluid", which in this case is air. Svalstad and Brandshaug (1981) compared the thermal response of a waste disposal room during forced ventilation, using separately, coupled convection/diffusion heat transfer and Newton's law of cooling. They found the thermal response to be similar when properly specifying the heat transfer coefficient and the temperature of the ventilating air.

\subsection{Conceptual Considerations}

Emplacement of waste in vertical or horizontal boreholes are alternatives considered in the SCP-CDR for Yucca Mountain; therefore, both concepts are included in this report. Figures 5 and 6 illustrate the vertical and the horizontal emplacement concepts, respectively.

Because two-dimensional models are used, the waste containers and emplacement boreholes cannot be modeled explicitly. Therefore, the discrete thermal power of the waste containers is distributed uniformly along the disposal room. In the case of vertical emplacement, this means the presence of a heat generating vertical plane along the axis of the room at the center of the floor. For the horizontal emplacement, the heat generating plane is horizontal along the axis of the room at the mid-height of both walls. The potential problem of room instability results from the compounded effect of heat transfer from individual waste containers at some distance. Because of the distance, the heat transfer effect of the individual waste containers to the rock around the room will be damped. Therefore, the concept of using a heat generating plane is an adequate idealization for both emplacement concepts. 

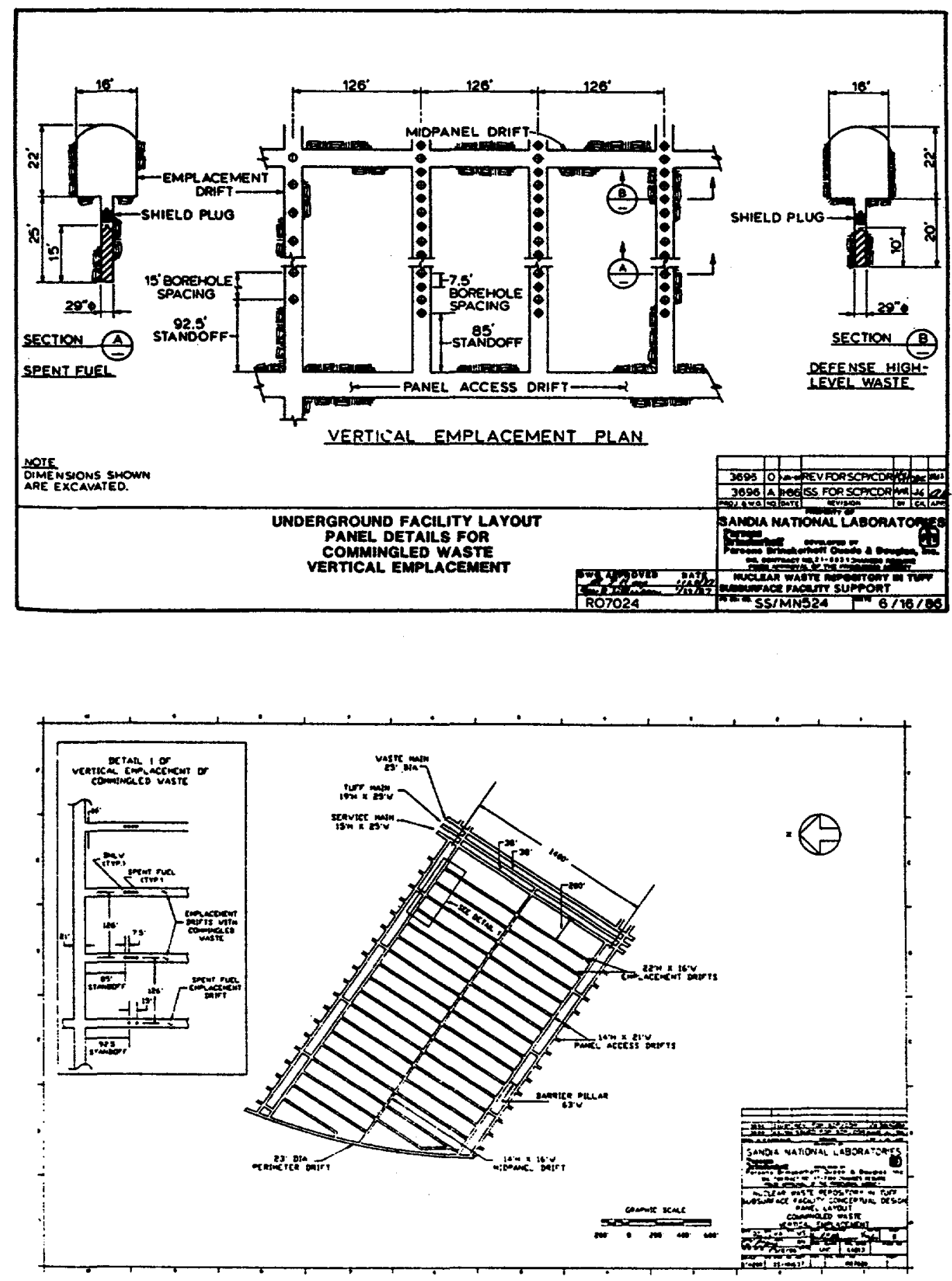

Fig. 5 Plan and Cross-Sectional Views of the Vertical Commingled $\mathrm{SF}$ and DHLW Emplacement Configuration [MacDougall et al., 1987, Chapter 4] 

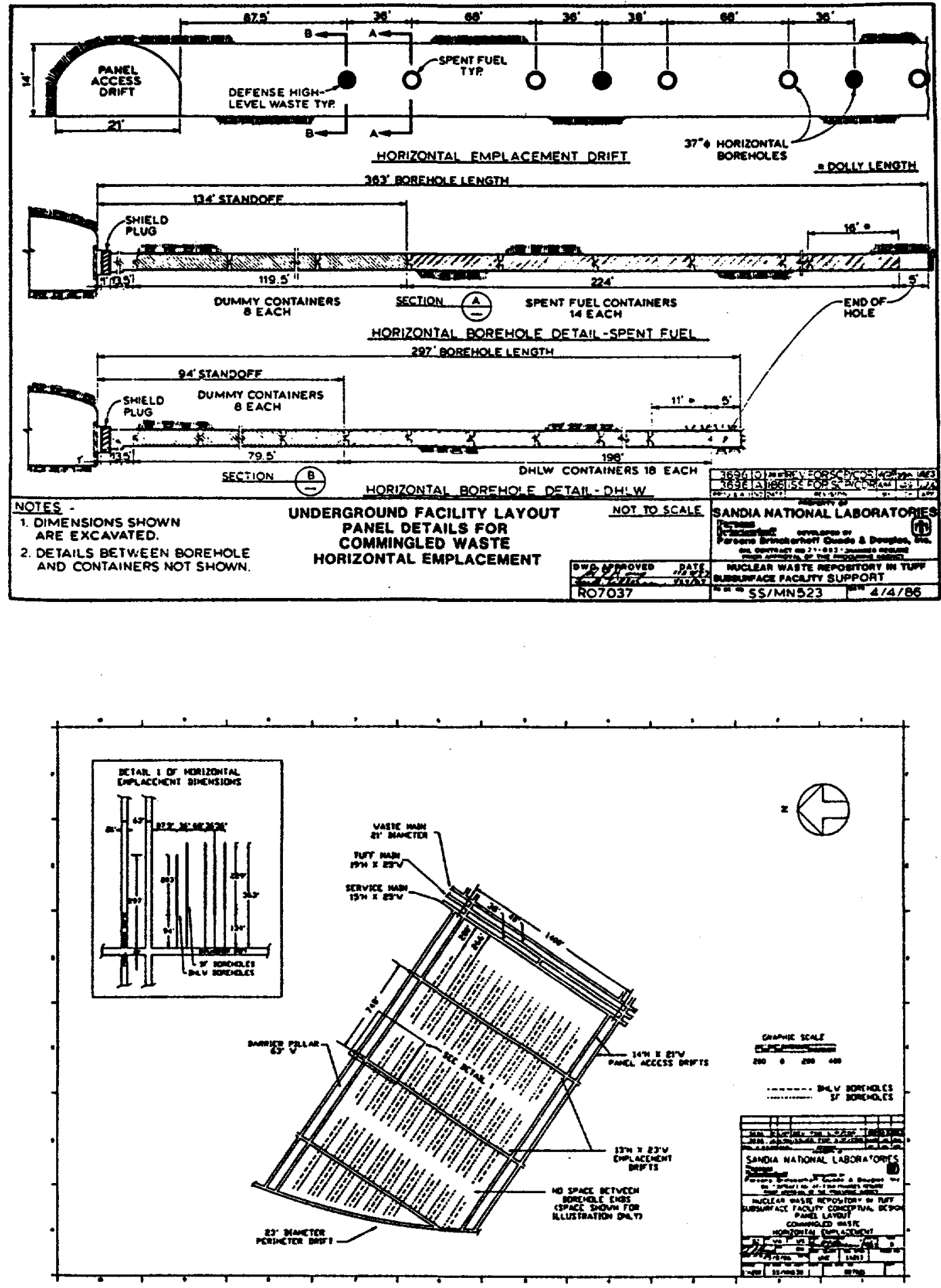

Fig. 6 Plan and Cross-Sectional Views of the Horizontal Commingled SE and DHLW Emplacement Configuration [MacDougall et al., 1987, Chapter 4] 
The Areal Power Density (APD), also called thermal loading (dimensions used are $\mathrm{W} / \mathrm{m}^{2}$ and $\mathrm{kW} /$ acre), may vary depending on the geometric scale of the numerical model being considered. On a far-field scale, which includes the total repository area, the APD being considered is $14.1 \mathrm{~W} / \mathrm{m}^{2}$ (57 kW/acre) (Johnstone et al., 1984). On the scale of the present model (one waste emplacement panel), the APD is approximately $20 \mathrm{~W} / \mathrm{m}^{2}$ (81 $\mathrm{kW} /$ acre) for the current layout of commingled SF and DHLW (MacDougall et al., 1987, Chapter 4). Because waste emplacement panel stand-off distances are not included in the present model, the APD is higher than in the far-field model. Appendix B describes in detail the calculation used to determine the thermal loading for both the vertical and horizontal emplacement concepts.

Eigure 7 illustrates the conceptual models of the vertical and horizontal waste emplacement. Because of symmetry, only one half of the disposal room and pillar needs to be included. The thermal boundary conditions are adiabatic. The two horizontal boundaries have been removed sufficiently far from the heat generating waste to remain at the initial temperature of $26^{\circ} \mathrm{C}$ for the time period simulated.

The kinematic boundary conditions are also shown in Fig. 7, and are such that the two vertical boundaries are restricted from moving in the horizontal direction, while free to move in the vertical direction. The lower horizontal boundary is restricted from moving in the vertical direction, while free to move in the horizontal direction. The upper horizontal boundary is a freeto-move pressure boundary. The initial vertical and horizontal stresses applied to the models are $-7 \mathrm{MPa}$ and $-3.5 \mathrm{MPa}$, respectively (MacDougall et al., 1987, Chapter 2). Note, that compressive stresses are negative.

The following describes the sequence of events which are simulated, and explains some of the specifics related to the heat transfer in the disposal rooms. 

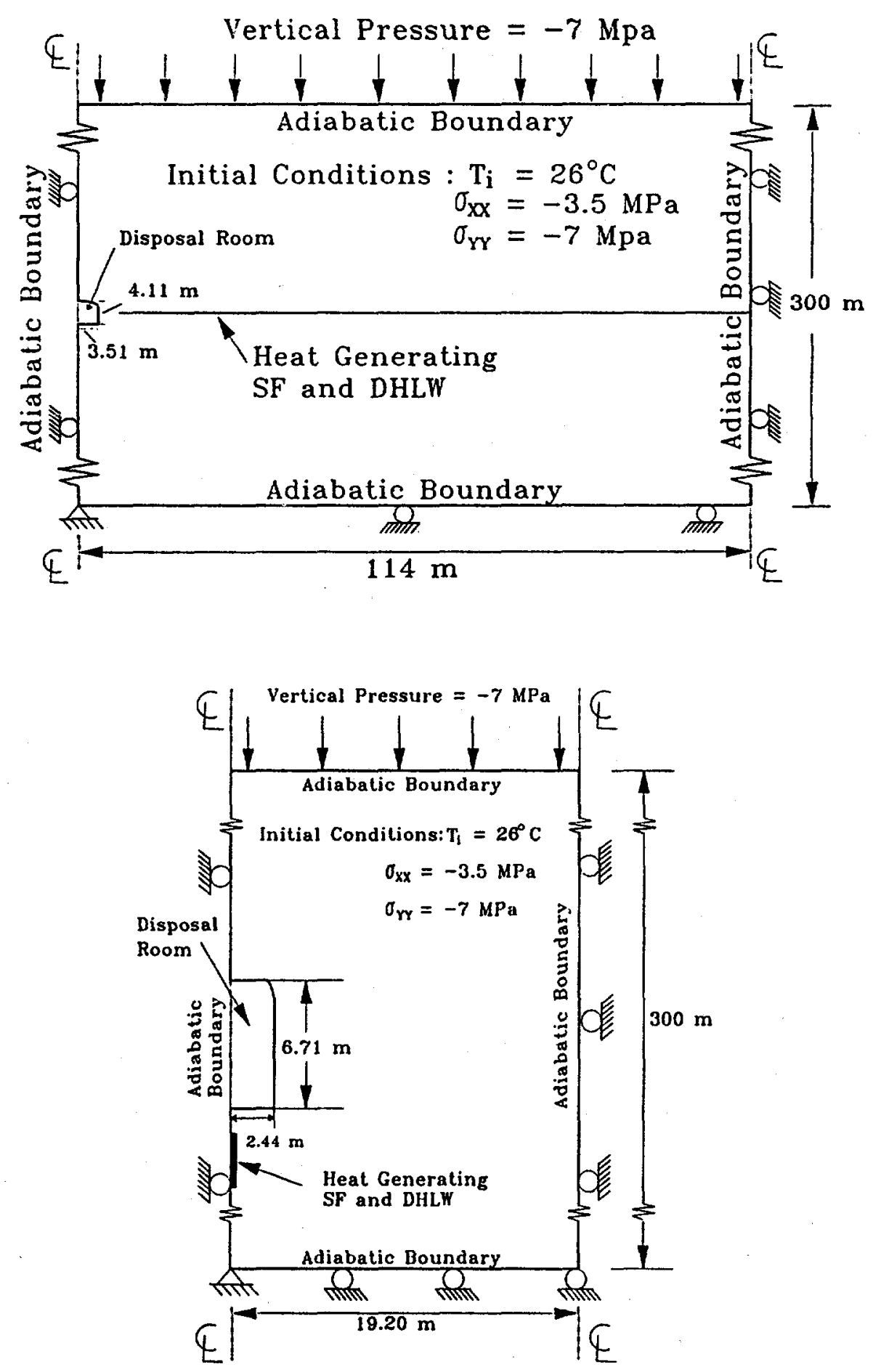

Fig. 7 Conceptual Models of the Disposal Rooms for Vertical and Horizontal Waste Emplacement 
- eXCAVATION OF THE DISPOSAL ROOM AT TIME $=0$

Deformations and stresses are determined throughout the rock.

- initial waste emplacement at time $=0$

Heat transfer calculations start.

- WASTE ISOLATION FROM 0 TO 50 YEARS

The thermal/mechanical response of the rock is predicted, and results are recorded at selected times frequently enough to provide a perspective of the transient behavior of the temperatures and stresses in the rock. The disposal room is not ventilated during this period; therefore, the heat transfer in the room is by thermal radiation, and some probably by free convection. FLAC does not include simulation of explicit thermal radiation; therefore, to simulate some of these effects by conduction heat transfer, the material in the room is modeled (only with respect to heat transfer) as tuff from the repository horizon, except the thermal conductivity is increased from $2.29 \mathrm{~W} / \mathrm{m}-\mathrm{K}$ to $50 \mathrm{~W} / \mathrm{m}-\mathrm{K}$.

- WASTE RETRIEVAL FROM 50 YEARS TO 50 yEARS PLUS THE TIME REQUIRED TO RETRIEVE ALI THE WASTE FROM ONE DISPOSAL ROOM

The thermal/mechanical response of the rock is predicted during the period of forced convective cooling of the disposal room and the period of actual waste retrieval. It is only necessary to consider waste retrieval from one disposal room, because retrieval from subsequent rooms is identical. Forced ventilation to cool the disposal room starts at 50 years by applying Newton's law of cooling with the room periphery as a convective boundary. Determination of the convective heat transfer coefficient used is shown in Appendix C. If 12 waste containers can be removed per day (MacDougall et al., 1987, Appendix L-2), it will take approximately 14 days to complete the waste retrieval of a disposal room for vertical emplacement, and about 65 days for horizontal emplacement. To be conservative, the convective cooling of the disposal rooms is continued for 120 days. 


\subsection{MODEL INPUT PARAMETERS}

\subsection{Material Properties}

The material properties used in the numerical models are taken from Chapter 2 of the SCP-CDR and are specific to the rock at the repository horizon (designated as thermal/mechanical unit TSw2 in the SCP-CDR, Chapter 2).

The mean value of the thermal properties and a range (where available) of one standard deviation from the mean are given in Table 1. Determination of the convective heat transfer coefficient is shown in Appendix $C$.

\section{Table 1}

THERMAL PROPERTIES

[MacDougall et al., 1987]

\section{PROPERTY}

$\underline{\text { ROCK }}$

DISPOSAL ROOM

Thermal Conductivity $(W / m-K)$

$2.29 \pm 0.17$

50.

Specific Heat Capacity $(\mathrm{J} / \mathrm{kg}-\mathrm{K})$

Convective Heat Transfer

coefficient $\left(W / m^{2}-K\right)$

Coefficient of Thermal

8.8

Expansion $\left(x 10^{-6} \mathrm{~K}^{-1}\right)$

(a) Refer to Appendix C for the value of this parameter. 
The mechanical properties of the rock mass are given in Table 2 . The mean property value and a range (where available) of one standard deviation from the mean are given. Note, that only the mean values are used for the thermal and mechanical properties in these analyses.

$$
\text { Table 3-2 }
$$

MECHANICAL PROPERTIES

[MacDougall et al., 1987]

\begin{tabular}{lcc}
\multicolumn{1}{c}{ PRORERTY } & ROCK & JOINTS \\
Density (kg/m $\left./ \mathrm{m}^{3}\right)$ & 2320. & - \\
Deformation Modulus (GPa) & $15.2 \pm 4.2$ & - \\
Poisson's Ratio & $0.22 \pm 0.05$ & $0.1 \pm 0.1$ \\
Cohesion (MPa) & $17.8 \pm 5.7$ & 28.4 \\
Angle of Internal & $23.5 \pm 0.15$ & $(11.8$ to 38.7$)$ * \\
Friction (degrees) & & -- \\
Uniaxial Compressive & $166 \pm 65$ & \\
Strength (MPa) & &
\end{tabular}

${ }^{*}$ This is a range. 


\subsection{Waste Form Characteristics}

The initial power of a SF container at the time of emplacement may range from $2.3 \mathrm{~kW}$ to $3.4 \mathrm{~kW}$ (O'Brian, 1985). In this study, the initial power is set conservatively to $3.2 \mathrm{~kW}$. The initial power of the DHLW container is chosen as $0.42 \mathrm{~kW}$ after Peters (1983).

The thermal decay characteristics of SF and DHLW are given by Peters (1983) for waste ten years out of the reactor:

$$
\begin{aligned}
& \text { Spent Fuel } \quad P(t)=\begin{aligned}
& 0.54 \exp (\ln (0.5) t / 89.3)+ \\
& 0.44 \exp (\ln (0.5) t / 12.8)
\end{aligned} \\
& \text { DHLW } \quad \mathrm{P}(\mathrm{t})=0.86 \exp (\ln (0.5) t / 34.2)+ \\
& 0.14 \exp (\ln (0.5) 7 / 15.2)
\end{aligned}
$$

where $P(t)$ = normalized power, and

$$
t=\text { time in years. }
$$

The normalized power as a function of time, as described from the above equations as well as that given by Mansure (1985) for SF are shown in Fig. 8. As seen, the two approximations for SF are very similar.

Comparison of Power Decay Characteristics For Spent Fuel and Defense High Level
Waste

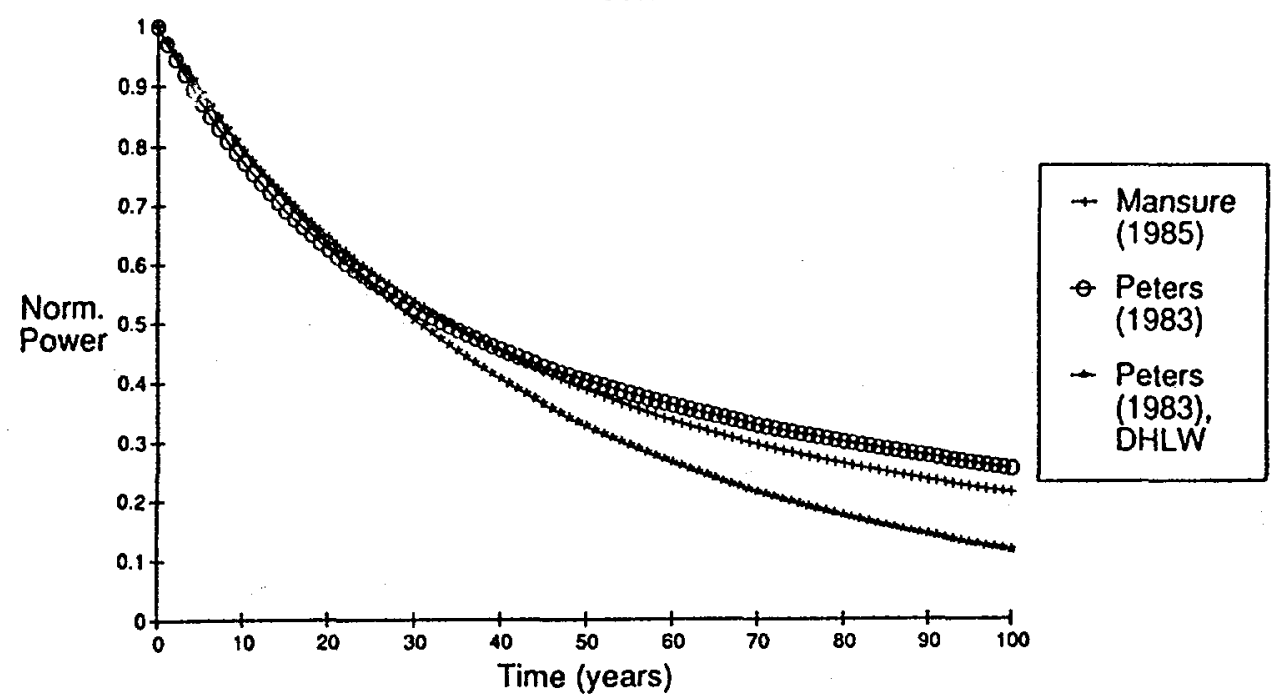

Fig. 8 Waste Form Normalized Power Decay 


\subsection{DISCUSSION OF RESULTS}

In preparation for waste retrieval, convective cooling of the disposal room is started 50 years after waste emplacement. In this study, it is assumed that waste retrieval will start when the disposal room floor temperature has decreased to less than $50^{\circ} \mathrm{C}$. To be conservative, the convective cooling of a disposal room (horizontal or vertical emplacement) continues during and beyond the period assumed to be necessary for retrieval of the waste. If twelve waste containers can be removed per day

(MacDougall et al., 1987, Appendix L-2), it will require about 14 days to completely remove the waste from a disposal room with vertical emplacement, and about 65 days for a room with horizontal emplacement. In the results that follow, the convective cooling of the disposal room has been continued for a period of 120 days.

\subsection{Thermal Results}

Rock temperatures are predicted at every nodal location throughout the time period simulated. Results are presented as temperature contours and straight line temperature profiles at different times, and as temperature histories for specific locations. The initial temperature of the rock is $26^{\circ} \mathrm{C}$.

\subsubsection{Vertical Emplacement}

Figures 9 to 11 show the predicted temperatures in the rock surrounding the waste containers and the disposal room. The temperatures are illustrated as contours (isotherms) at 1, 25, and 50 years after waste emplacement. During this period, more and more of the rock is heated by the nuclear waste, and temperatures are increasing. Because of the short distance between the waste containers and the disposal room, the temperature of the rock around the room starts to increase soon after waste emplacement. There is no ventilation of the disposal room until the end of 50 years. When ventilation is initiated, it has a dramatic effect on the room surface temperature as seen in Fig. 12. The immediate and substantial reduction of the temperature of the room floor, wall, and roof is consistent with the results obtained by Svalstad and Brandshaug (1981). The results in Fig. 12 are shown for ventilation air temperatures of $10^{\circ} \mathrm{C}$ and $20^{\circ} \mathrm{C}$. Figure 12 also shows that the maximum temperature reached in the floor prior to ventilation is $126^{\circ} \mathrm{C}$. 


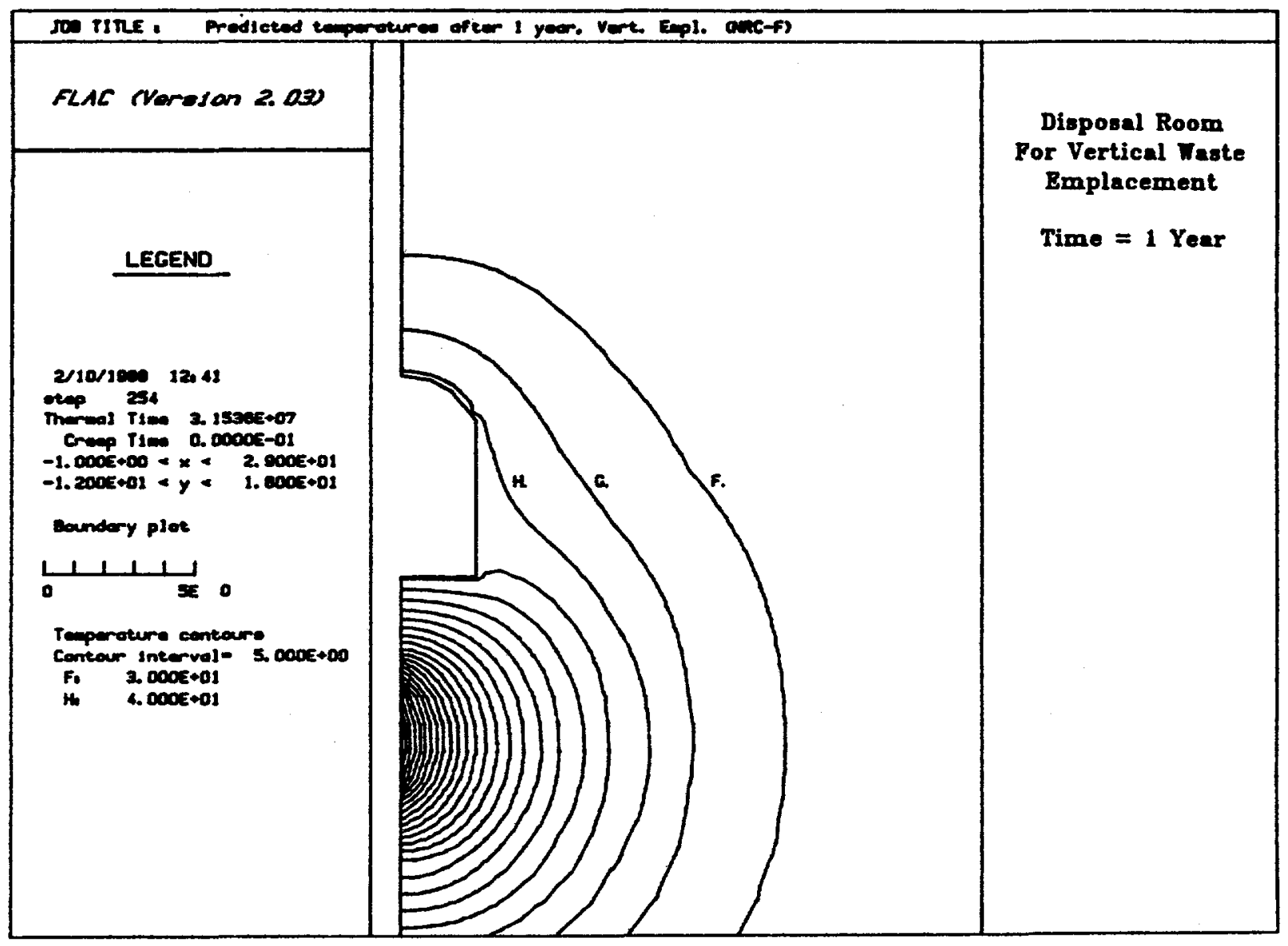

Fig. 9 Predicted Temperature Contours $\left({ }^{\circ} \mathrm{C}\right)$ Around the Waste Disposal Room for Vertical Emplacement 1 Year After Initial Waste Emplacement 


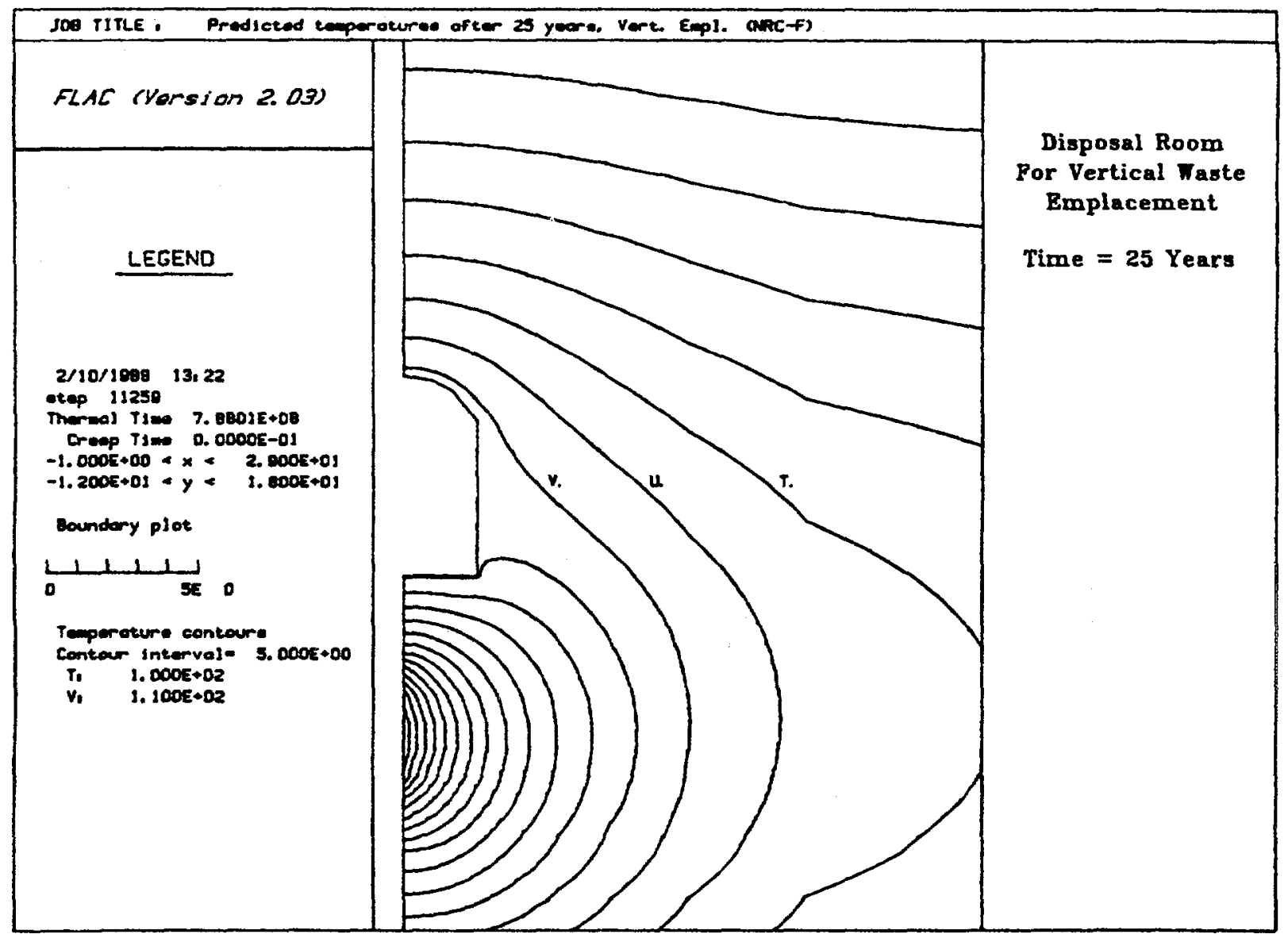

Fig. 10 Predicted Temperature Contours $\left({ }^{\circ} \mathrm{C}\right)$ Around the Waste Disposal Room for Vertical Emplacement 25 Years After Initial Waste Emplacement 


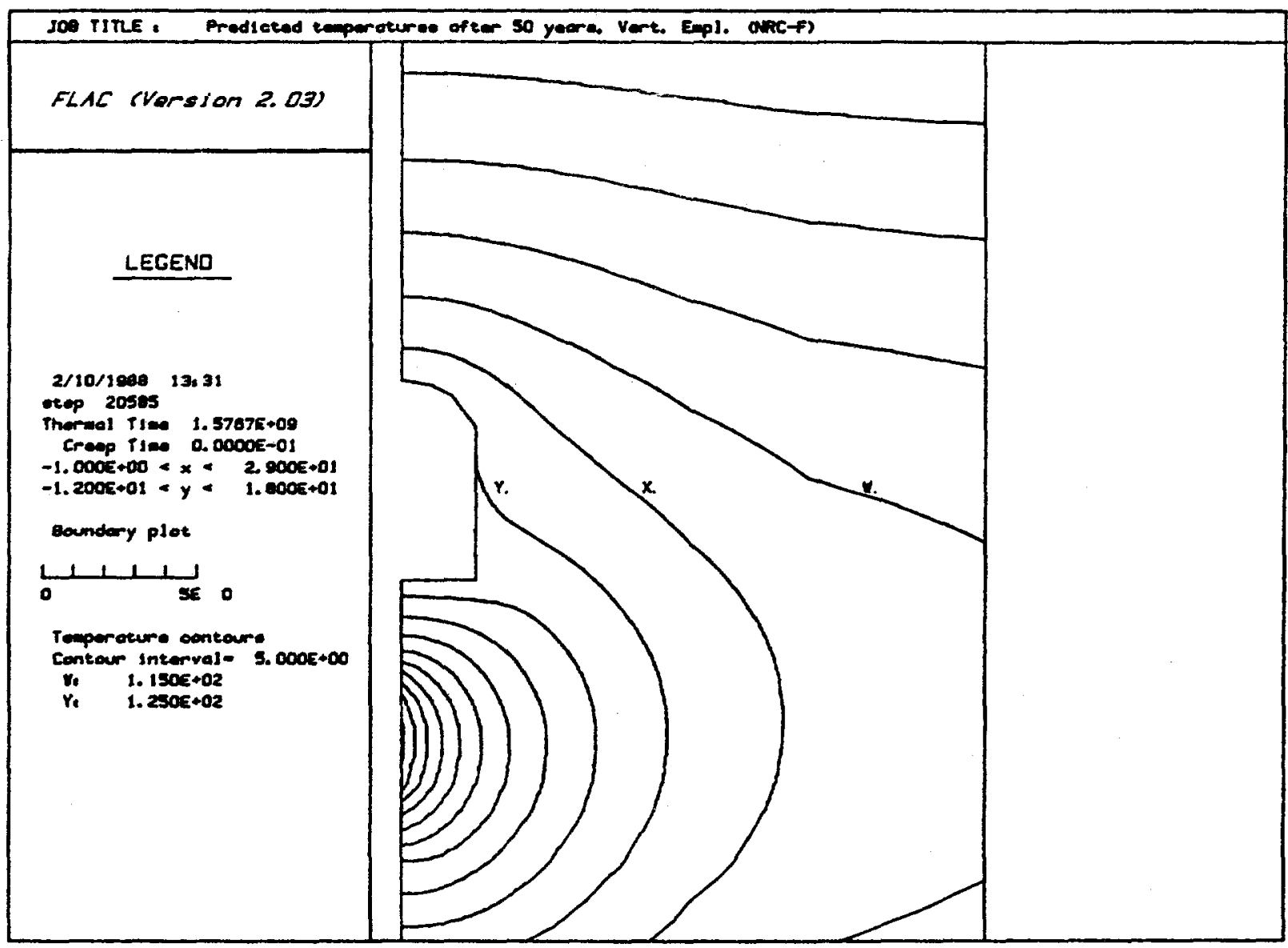

Fig. 11 Predicted Temperature Contours $\left({ }^{\circ} \mathrm{C}\right)$ Around the Waste Disposal Room for Vertical Emplacement 50 Years After Initial Waste Emplacement 
50 Year Thermal History

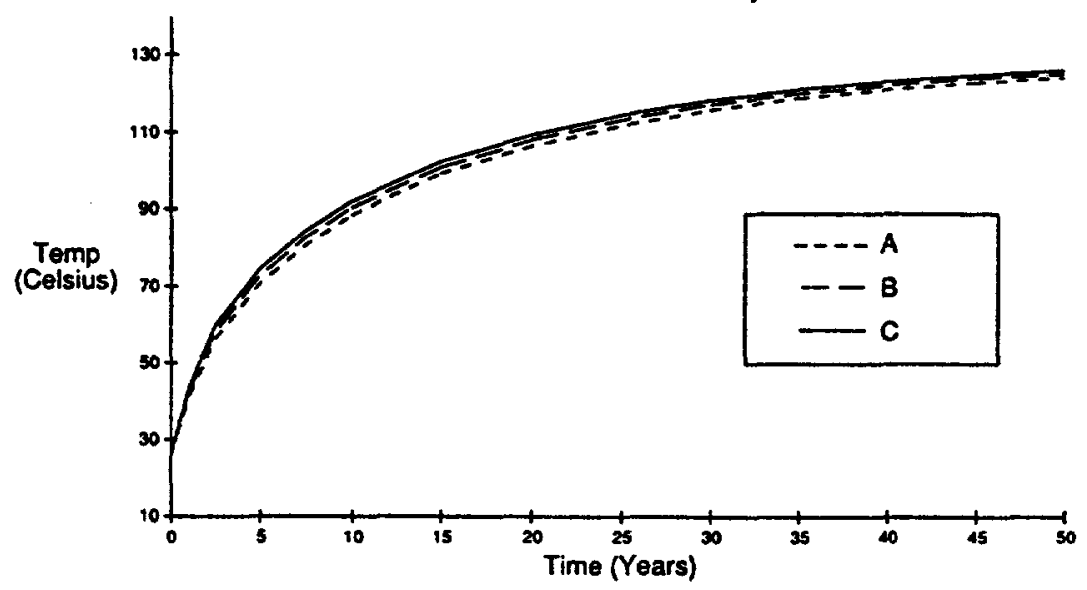

Ventilation for 120 Days After 50 Years of Heating
Air Temperature $=10$ Deg.
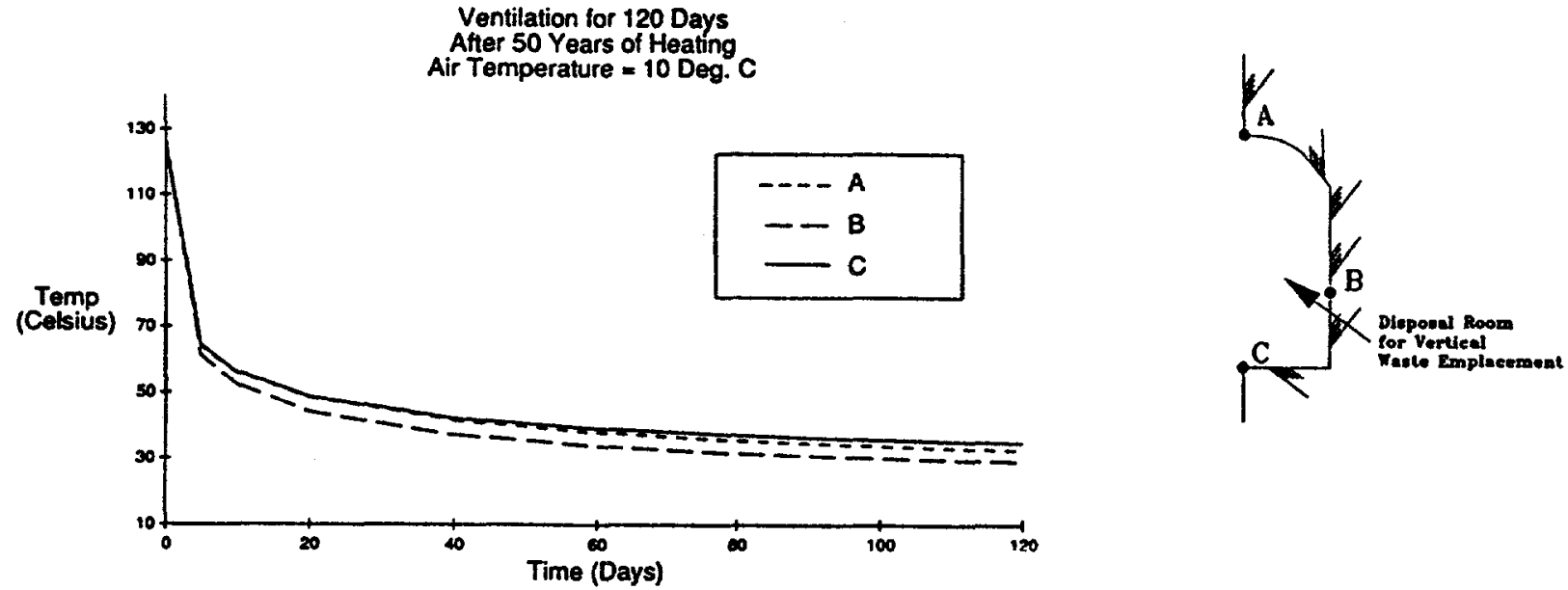

Ventilation for 120 Days

After 50 Years of Heating

Air Temperature $=20$ Deg. C

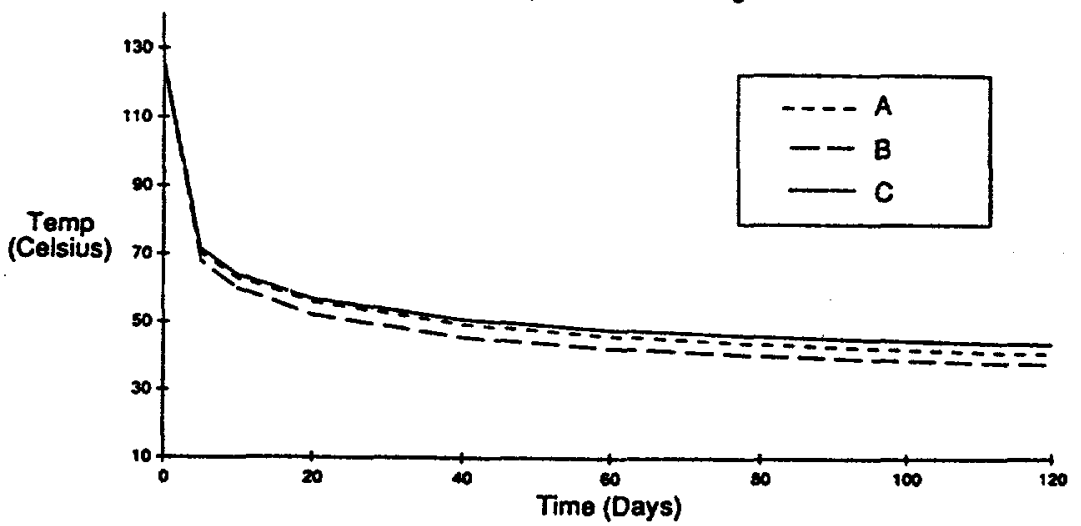

Fig. 12 Predicted Temperature Histories in the Floor, Wall and Roof of the Waste Disposal Room for Vertical Emplacement. 
A different perspective of the predicted heat transfer in the rock is provided in Fig. 13, as temperatures along a horizontal straight line from the room wall into the pillar are shown at various times. It is obvious from Fig. 13 that high thermal gradients develop in the rock adjacent to the disposal room from the time when ventilation starts. The cool rock at the room surface and the high thermal gradients may result in a differential thermal contraction of the rock adjacent to the room. Therefore, the potential for falling rocks exists at the time of ventilation and waste retrieval. 

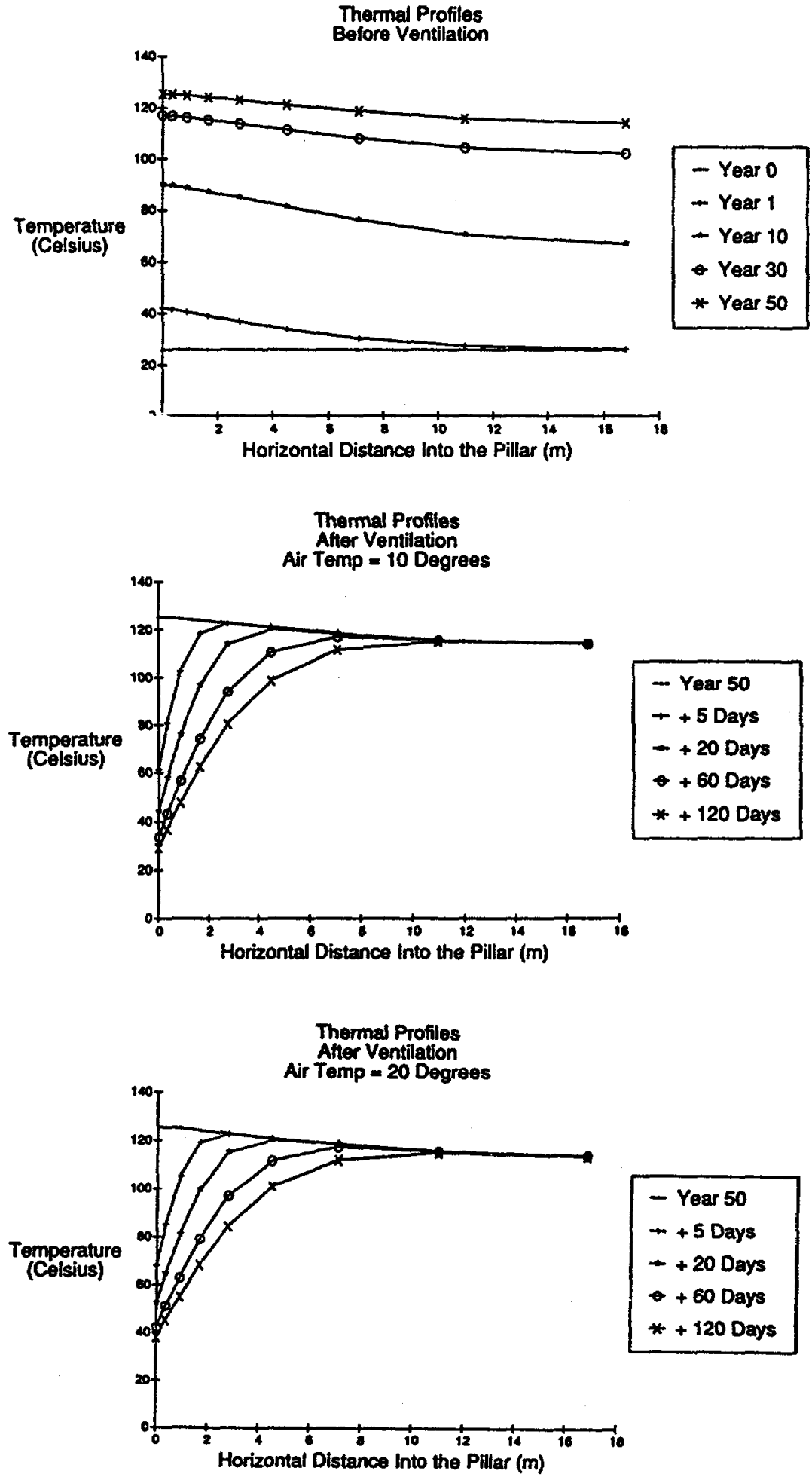

Fig. 13 Predicted Temperature Profiles into the Pillar of the Waste Disposal Room for Vertical Emplacement 


\subsubsection{Horizontal Emplacement}

For horizontal waste emplacement, the containers are located at much greater distance from the disposal room than for vertical emplacement. Because of the distance and the horizontal waste lay-out, more of the thermal energy diffuses in the vertical direction, and therefore, does not reach the disposal room. This results in lower temperatures of the rock around the disposal room than in the case of vertical emplacement.

Figures 14 to 16 illustrate the predicted temperatures as isotherms in the rock around the disposal room after 10, 25, and 50 years (i.e., prior to the initiation of forced ventilation). After 50 years, a considerable region of rock has been heated because of the presence of the waste. Figure 17 shows the predicted thermal history of the disposal room floor, wall, and roof. The results indicate that the room surface temperature will exceed the maximum temperature criterion of $50^{\circ} \mathrm{C}$ after 50 years, as listed in Chapter 2 of the SCP-CDR, and repeated in Chapter 1 of this report. However, the forced ventilation starting at 50 years substantially reduces the room surface rock temperature.

Temperatures are shown in Fig. 18 for various times up to 50 years along the horizontal straight line from the room wall into the pillar. The different curves illustrate the effect of the transient heat transfer.

Figure 19 shows the substantial thermal gradients in the rock around the room as a result of convective cooling for 120 days beyond 50 years. The results of ventilation air temperatures of 10 and $20^{\circ} \mathrm{C}$ are included. 


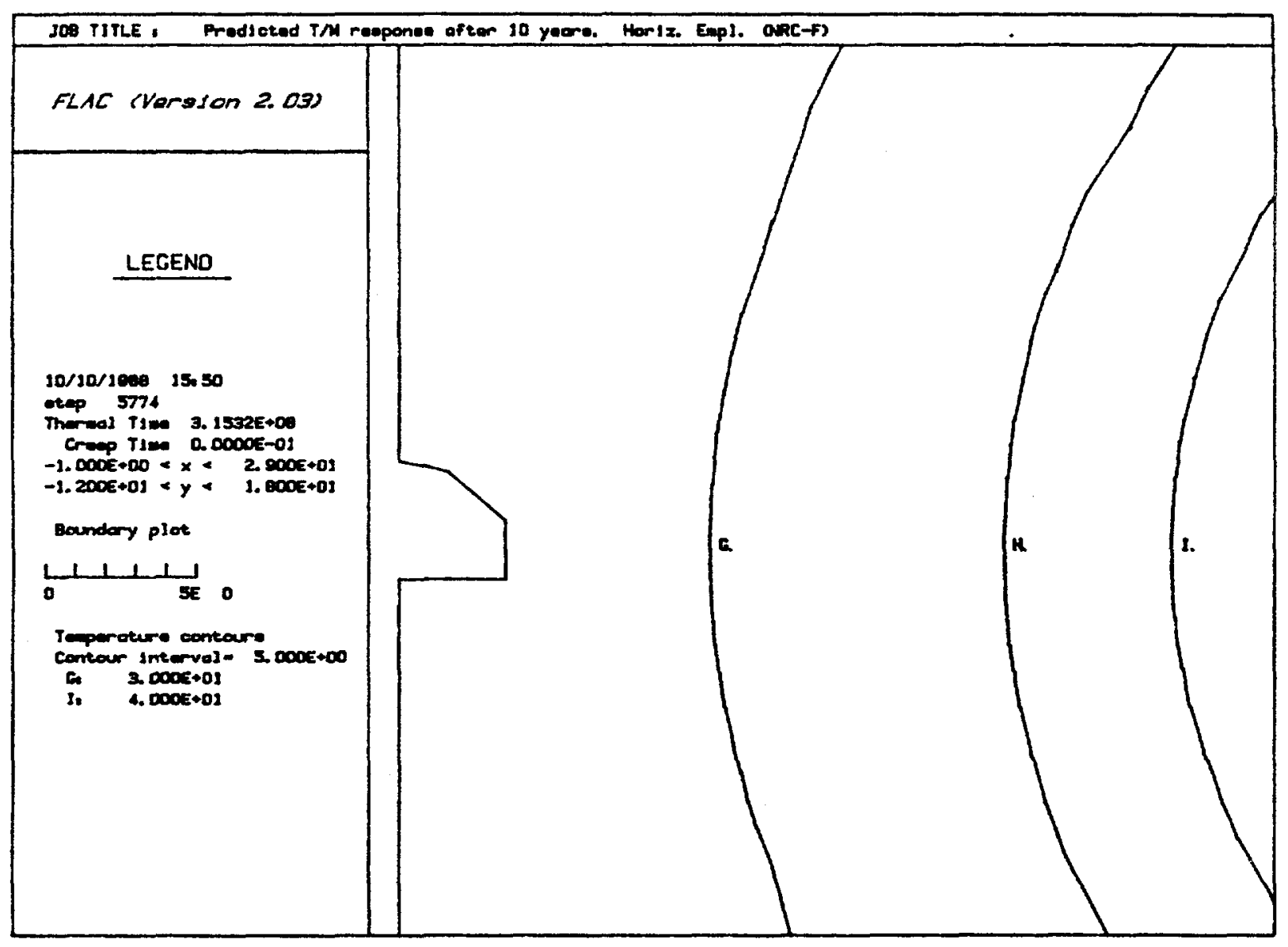

Fig. 14 Predicted Temperature Contours $\left({ }^{\circ} \mathrm{C}\right)$ Around the Waste Disposal Room for Horizontal Emplacement 10 Years After Initial Waste Emplacement 


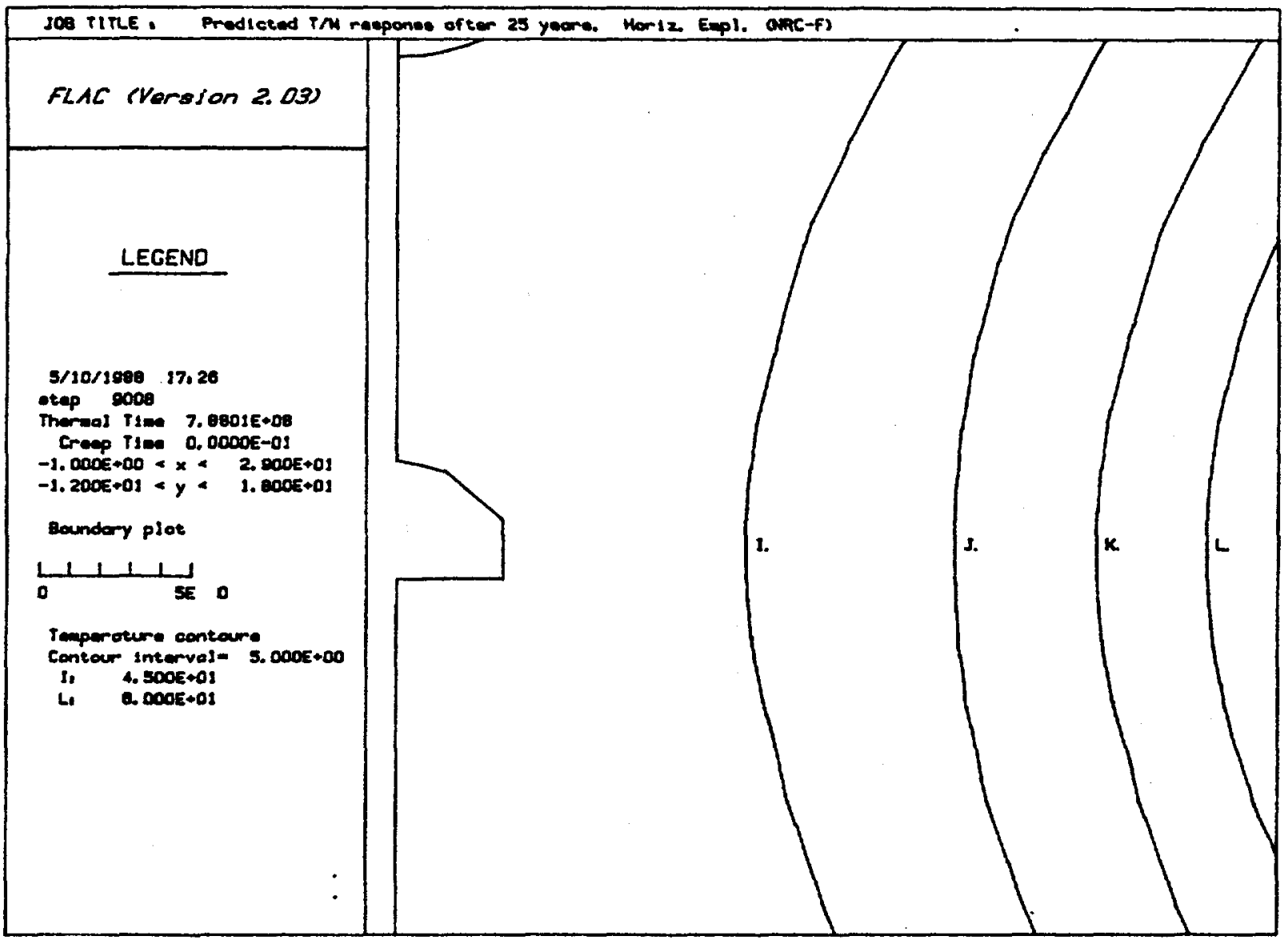

Fig. 15 Predicted Temperature Contours $\left({ }^{\circ} \mathrm{C}\right)$ Around the Waste Disposal Room for Horizontal Emplacement 25 Years After Initial Waste Emplacement 


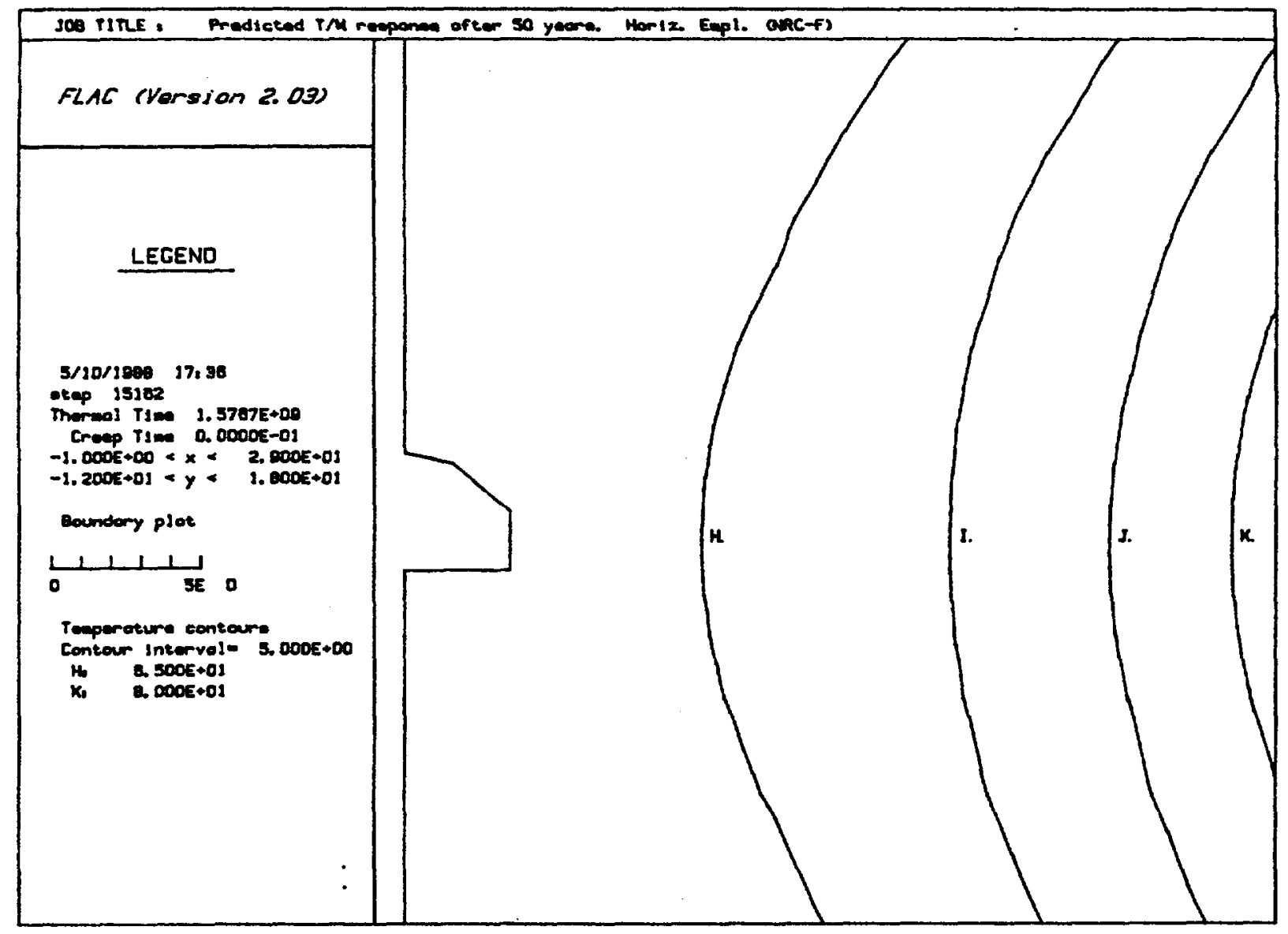

Fig. 16 Predicted Temperature Contours $\left({ }^{\circ} \mathrm{C}\right)$ Around the Waste Disposal Room for Horizontal Emplacement 50 Years After Initial Waste Emplacement 


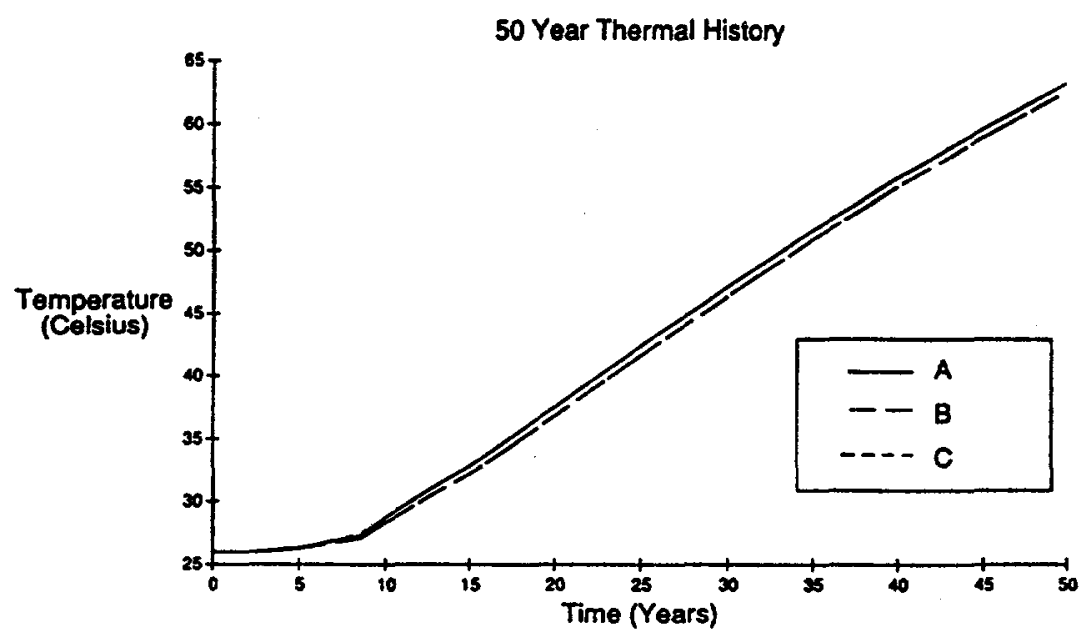

Ventilation for 120 Days
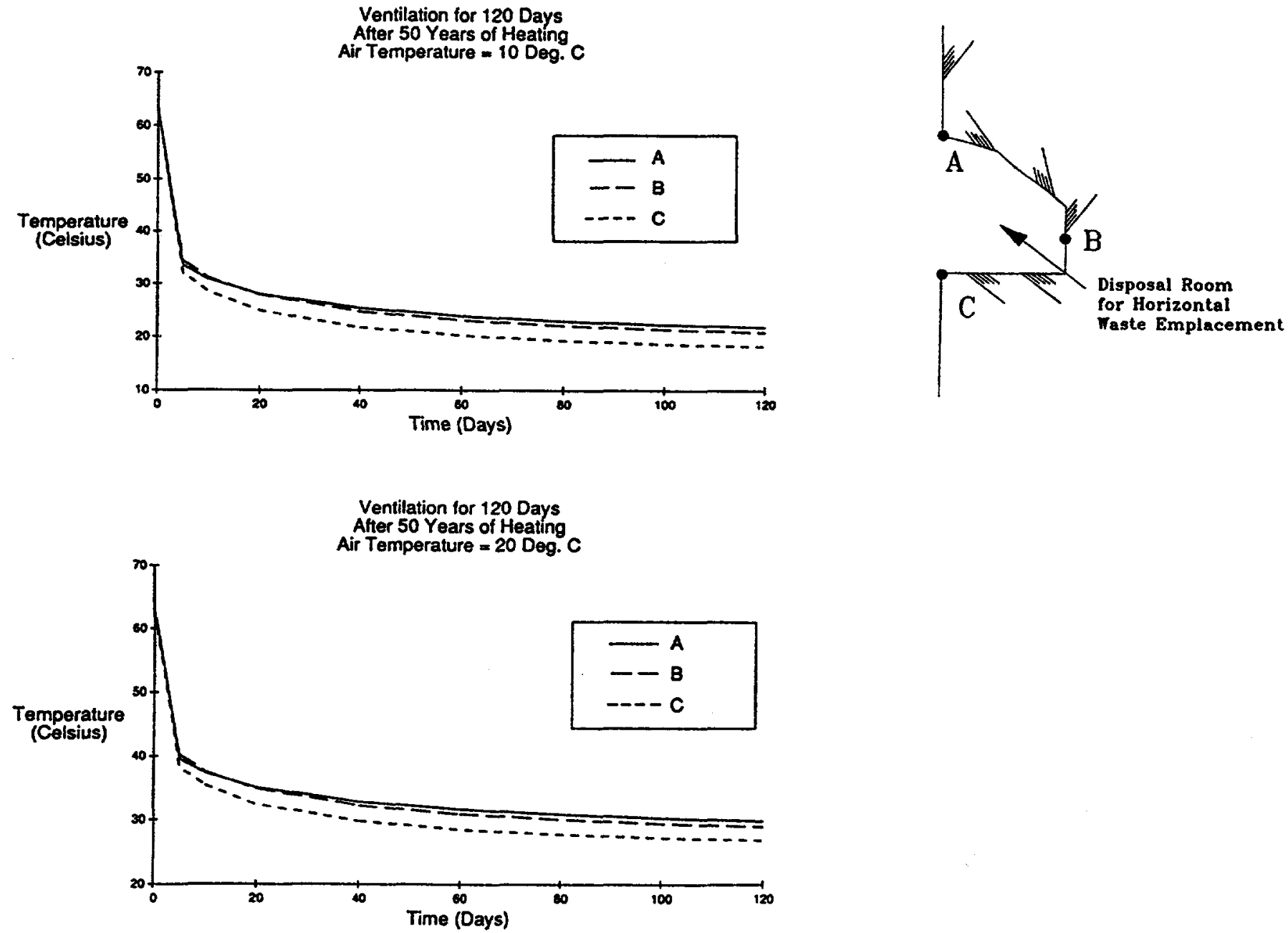

Fig. 17 Predicted Temperature Histories in the Floor, Wall and Roof of the Waste Disposal Room for Horizontal Emplacement 


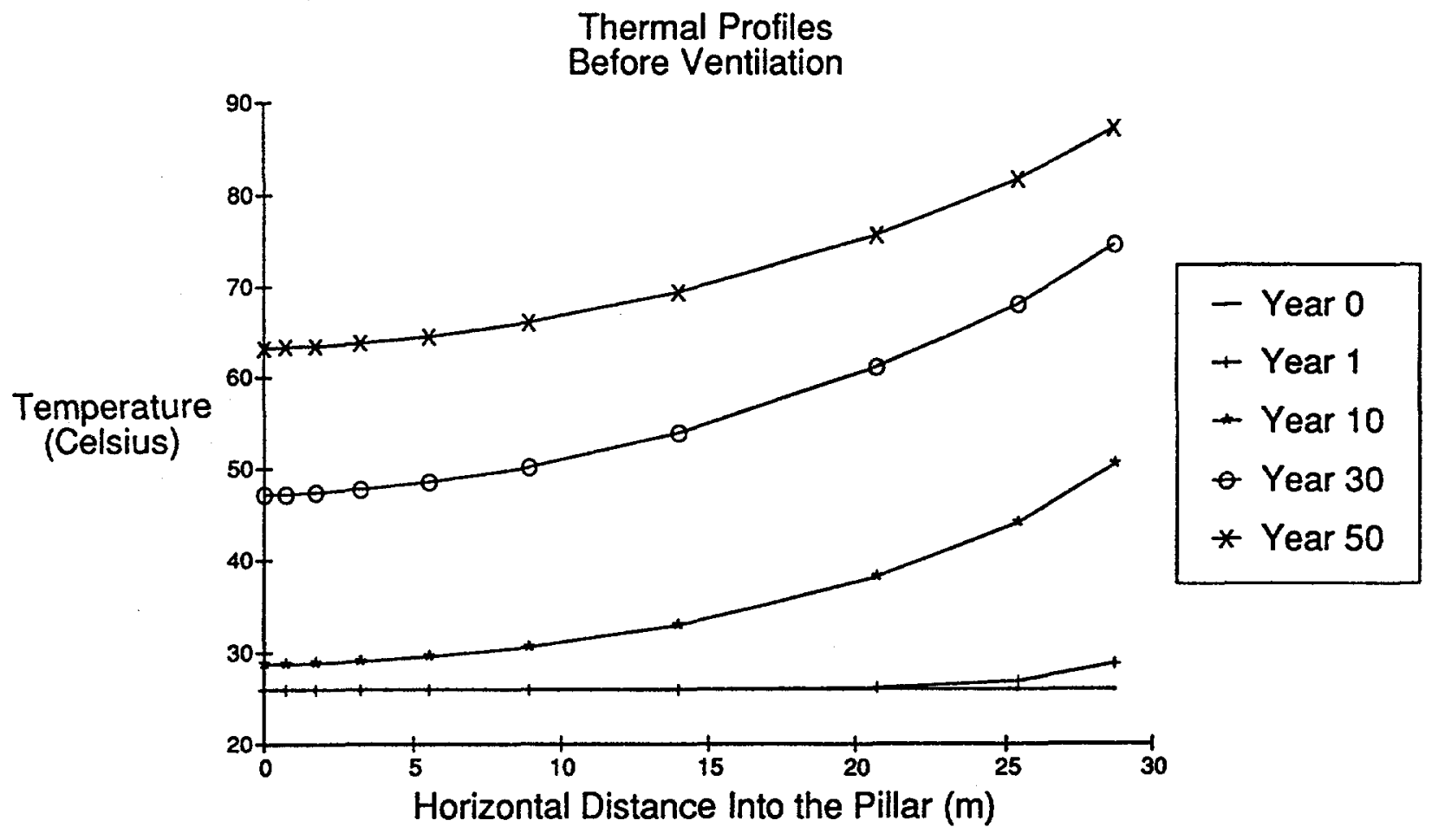

Fig. 18 Predicted Temperature Profiles in the Pillar of the Waste Disposal Room for Horizontal Emplacement Prior to Waste Retrieval 

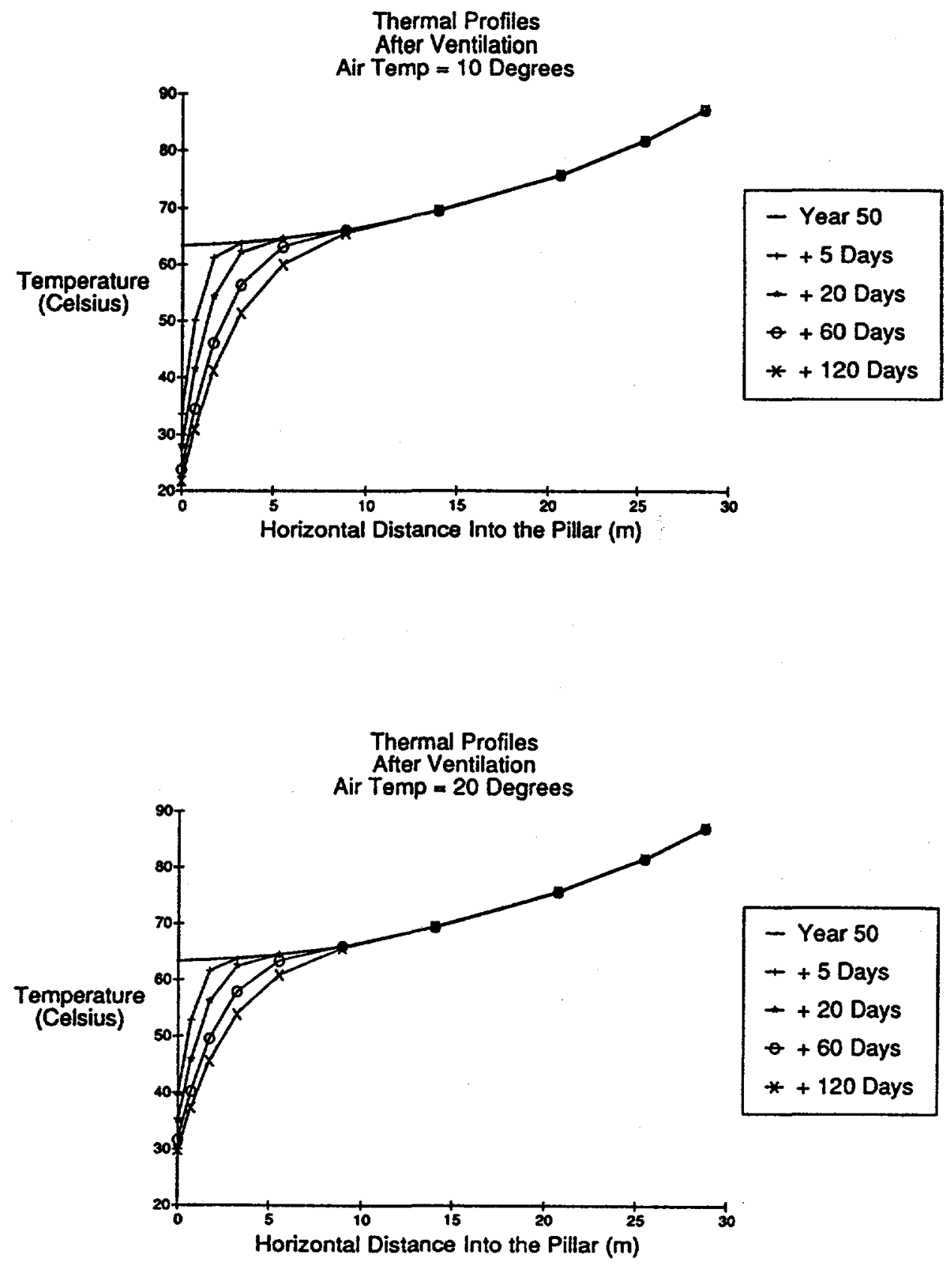

Fig. 19 Predicted Temperature Profiles. Into the Pillar of the Waste Disposal Room for Horizontal Emplacement During Waste Retrieval 


\subsection{Mechanical Results}

Displacements, stresses, and joint slip are predicted in the mechanical model. Results are presented, which show portions of the rock around the room where the vertical joints have slipped (failed in shear). Contours of predicted horizontal and shear stresses are shown, as well as the predicted roof to floor closure and wall to wall closure.

\subsubsection{Vertical Emplacement}

The results of the mechanical model show that no new fractures are created in the rock around the disposal room as a result of room excavation or thermal expansion of the rock in the period following the emplacement of the waste. Figure 20 illustrates the predicted slip along pre-existing vertical joints as a result of room excavation. The slip is initiated because the shear stresses induced by excavating the room exceed the shear strength of the joints. Figure 21 illustrate the predicted shear and horizontal stresses in the rock as a result of excavation. Because the joints are vertical, these stresses are the same as the shear and normal stresses acting on the joints.

In Fig. 22, the predicted slip along the pre-existing vertical joints is shown after 50 years, and also after an additional 120 days of forced ventilation. There is very little additional joint slip induced as a result of the thermomechanical response of the rock for 50 years after room excavation and 120 days of forced ventilation beyond the 50 years. Using air of $10^{\circ} \mathrm{C}$ or $20^{\circ} \mathrm{C}$ during ventilation has the same effect on the predicted joint slip.

The predicted 50 year history of roof to floor closure, and wall to wall closure are shown in Figure 23. Both the roof/floor and wall/wall close as a result of excavation. The deformations predicted are very small, and far below the maximum amount of $0.152 \mathrm{~m}$ currently listed as a criterion in the SCP-CDR, Chapter 2. 


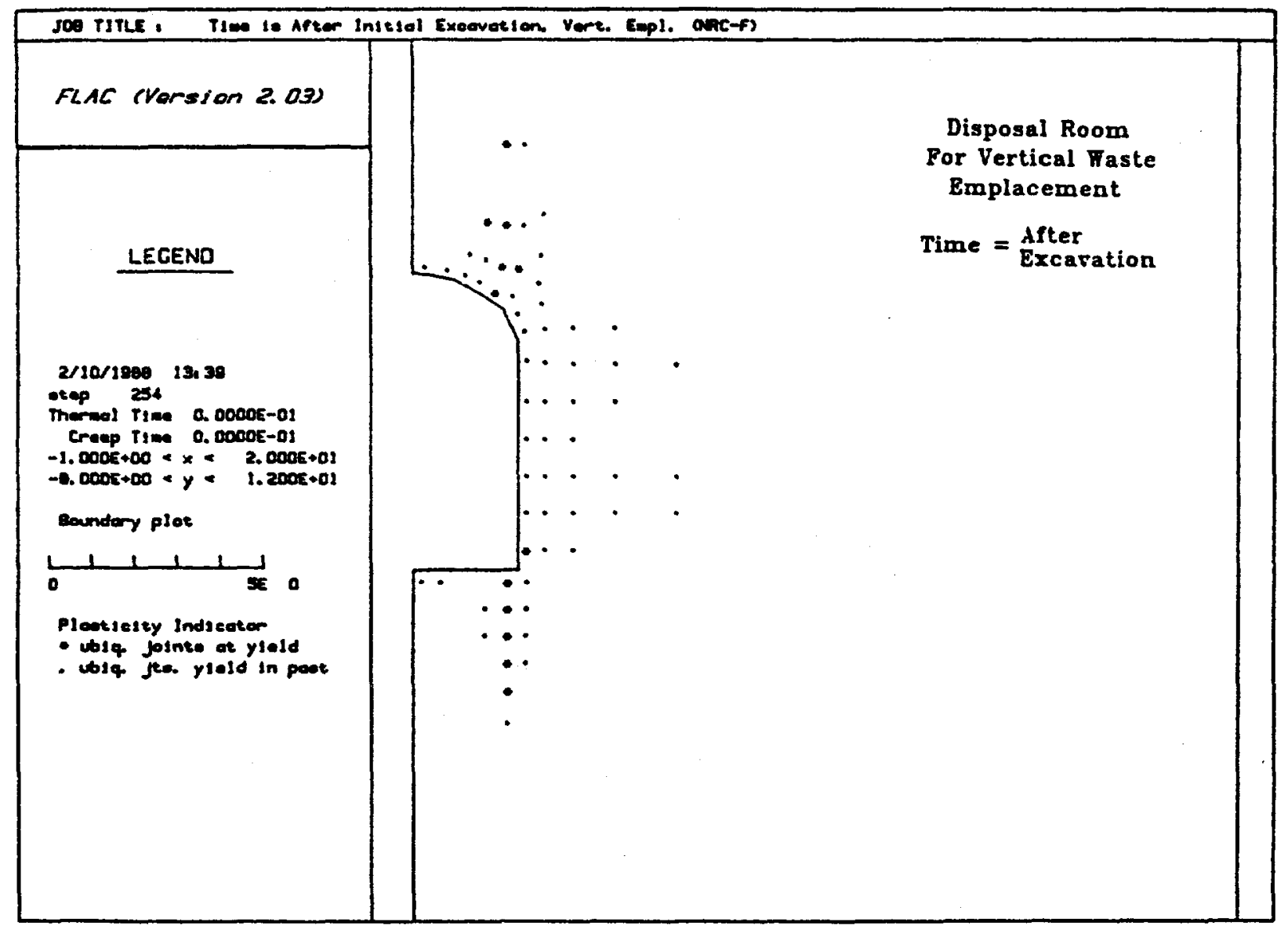

Fig. 20 Predicted Slip Along Vertical Joints as a Result of Excavation of the Waste Disposal Room for Vertical Emplacement 

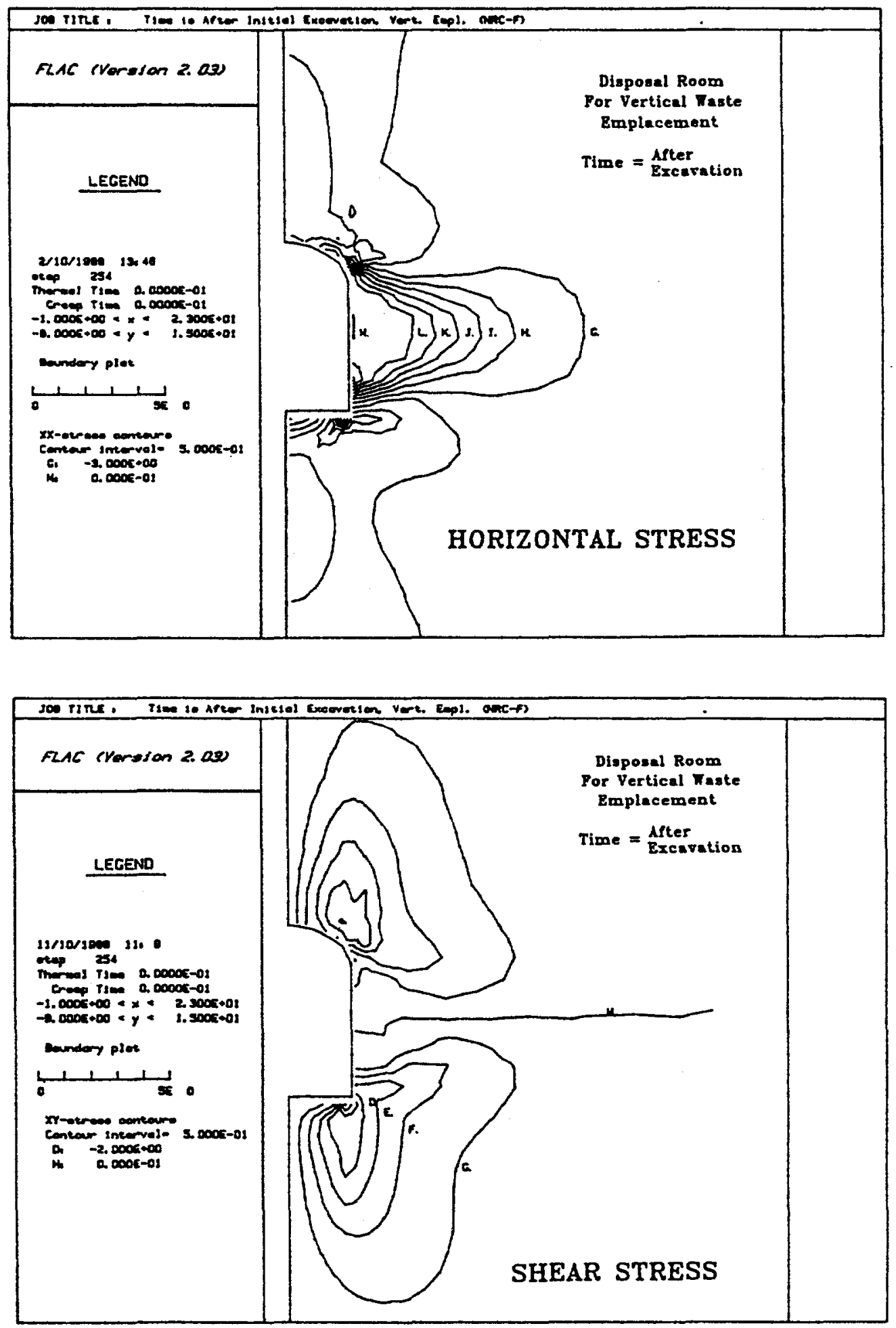

Fig. 21 Predicted Shear and Horizontal Stresses As a Result of Excavation of the Waste Disposal Room for Vertical Emplacement 

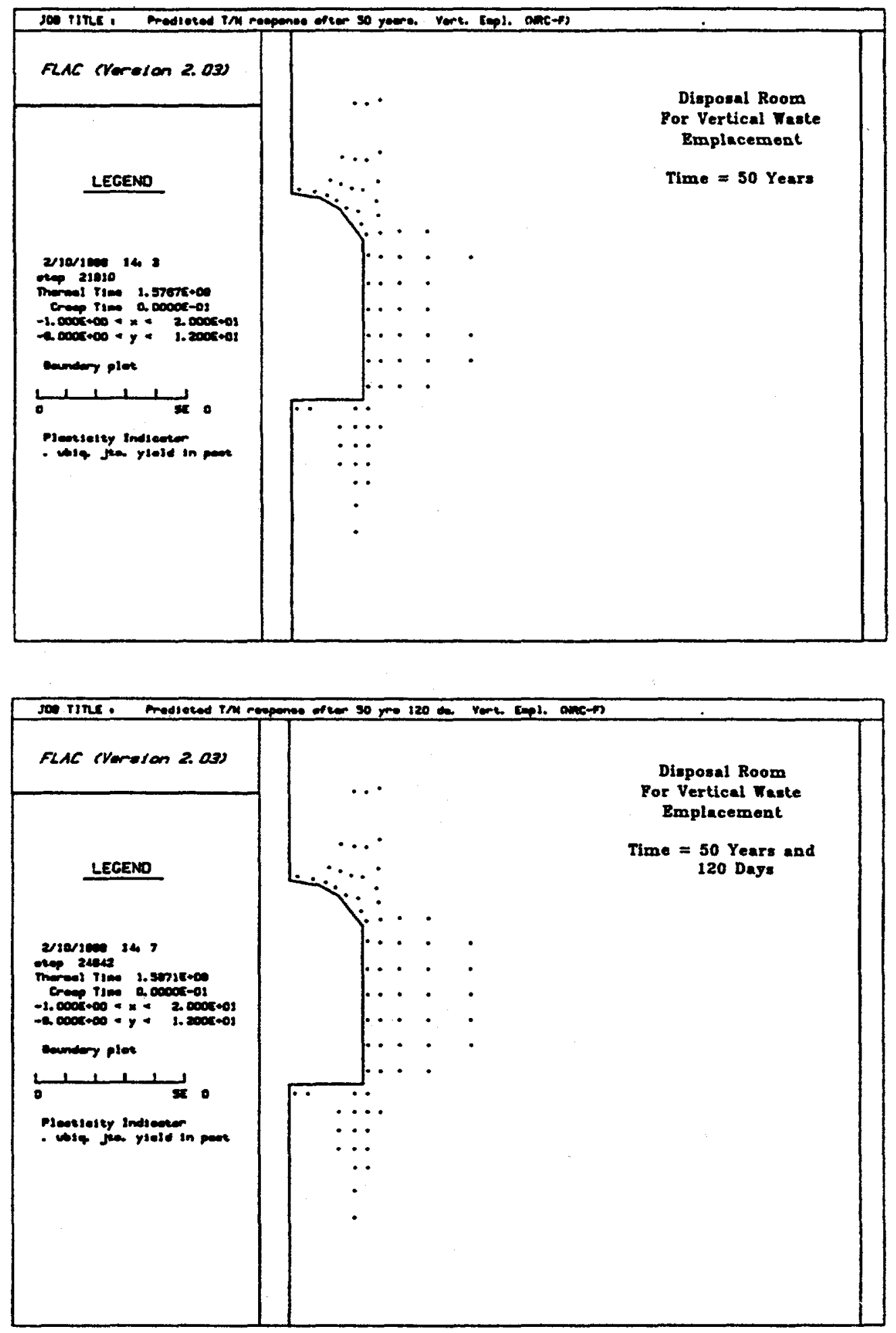

Fig. 22 Predicted Slip Along Vertical Joints Around the Waste Disposal Room for Vertical Emplacement at the Time of Waste Retrieval and After Waste Retrieval 


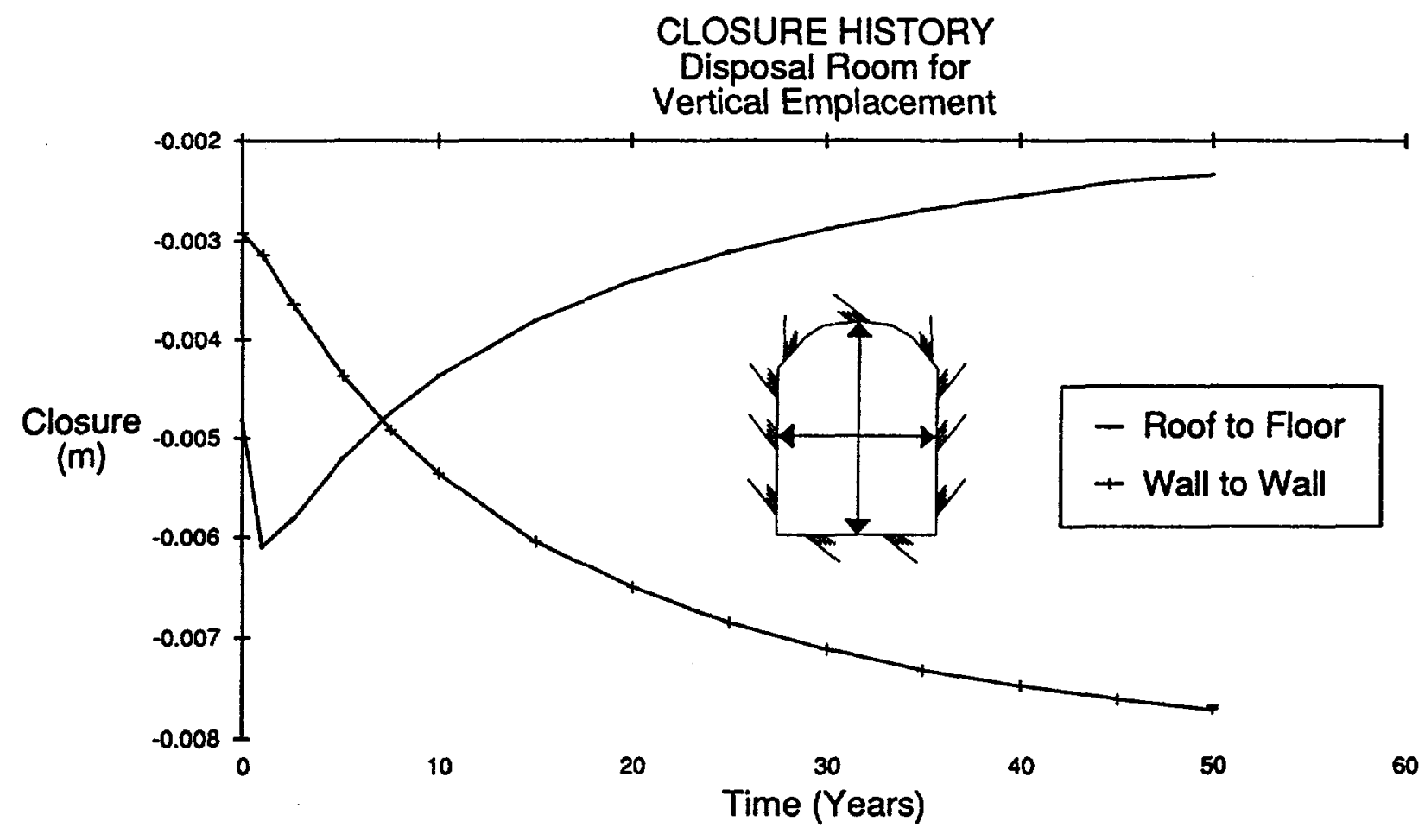

Fig. 23 Predicted History of the Roof to Floor Closure and Wall to Wall Closure of the Waste Disposal Room for Vertical Emplacement 
As forced ventilation is initiated, the temperatures of the room surface rock decrease, resulting in thermal contraction of the rock. Depending on the system of rock fractures around the room, this effect may cause individual blocks of rock to become unstable. The kinematics of individual blocks of rock is not included in the mechanical model; thus, this phenomenon is not predicted in this study.

Joint movement may not result in room instability, however, it does result in the potential of such an event. Because most of the joint slip results from the effect of excavation, the chart in Fig. 24 (after Hoek, 1979) can be used to approximate the required ground support for the disposal rooms. When applied to the vertical emplacement rooms, assuming that the quality of the rock can be classified as "fair to good" according to the Geomechanics Classification system (Bieniawski, 1974), only light ground support such as rockbolts, wire mesh, or shotcrete is estimated to be required to maintain room stability.

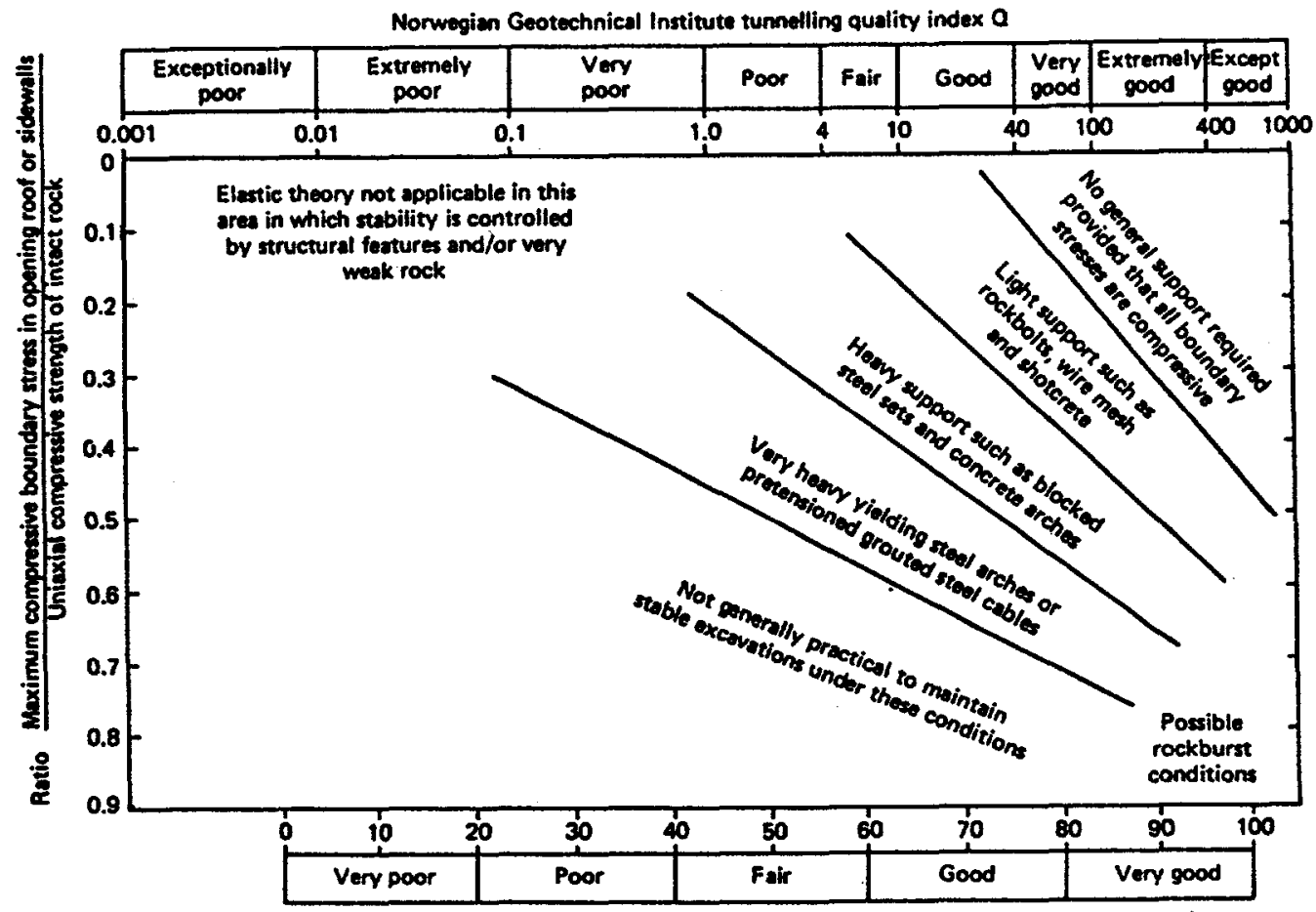

South African Council for Scientific and Industrial Research Geomechenics clessification

Fig. 24 Suggested Ground Support As a Function of Induced Stresses and Rock Mass Quality [after Hoek, 1979] 


\subsubsection{Horizontal Emplacement}

The results of the mechanical model show that no new fractures are created in the rock around the disposal room for horizontally emplaced waste as a result of room excavation or rock thermal expansion in the period following the emplacement of the waste. However, slip is predicted along the pre-existing vertical joints. Figure 25 illustrates the predicted joint slip as a result of room excavation (at time $=0$ ), and 50 years after initial waste emplacement. The amount of joint slip predicted is about the same as for the disposal room with vertically emplaced waste. There is very little additional joint slip induced as a result of 50 years of thermomechanical rock response.

Figure 26 illustrates the predicted joint slip after 120 days of ventilation for air temperatures of $10^{\circ} \mathrm{C}$ and $20^{\circ} \mathrm{C}$. Very little additional joint slip results from the effect of ventilation.

Figure 27 illustrates the predicted shear and horizontal stresses in the rock after excavation. Because the joints are vertical, these stresses are the same as the shear and normal stresses that act on the joints.

The predicted closure history between the roof and floor as well as that of the walls is illustrated in Fig. 28. The deformations predicted are very small, and below the maximum amount of $0.152 \mathrm{~m}$ currently listed as a criterion in the SCP-CDR, Chapter 2.

Assuming that the quality of the rock can be classified as "fair to good" according to the Geomechanics Classification system (Bieniawski, 1974), the chart in Fig. 24 (after Hoek, 1979). can be used to estimate the required ground support. When applied to the rooms for horizontal waste emplacement, only light ground support such as rockbolts, wire mesh, or shotcrete is likely to be required to maintain room stability. 

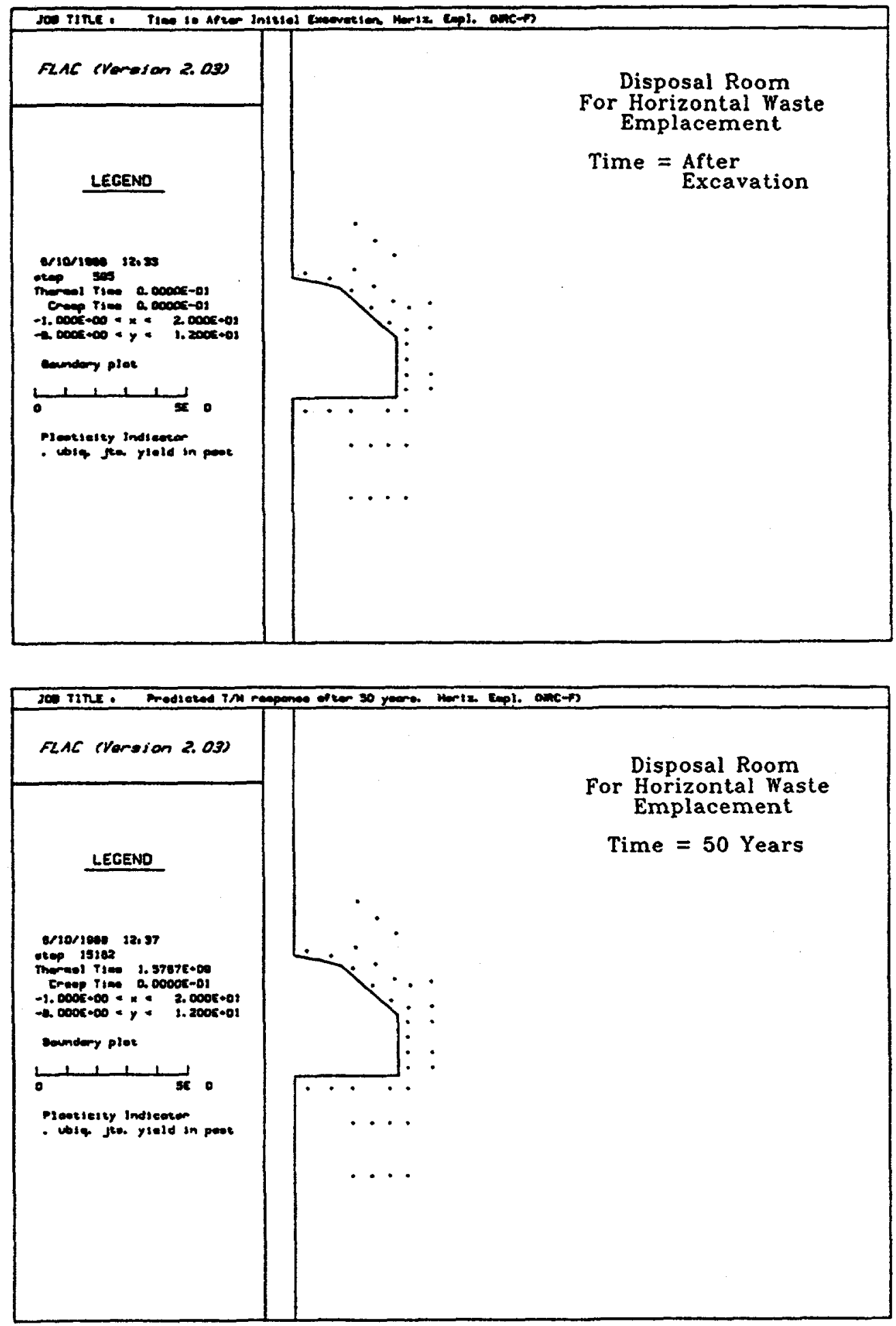

Fig. 25 Predicted Slip Along Vertical Joints Around the Waste Disposal Room for Horizontal Emplacement After Excavation and at the Time of Waste Retrieval 

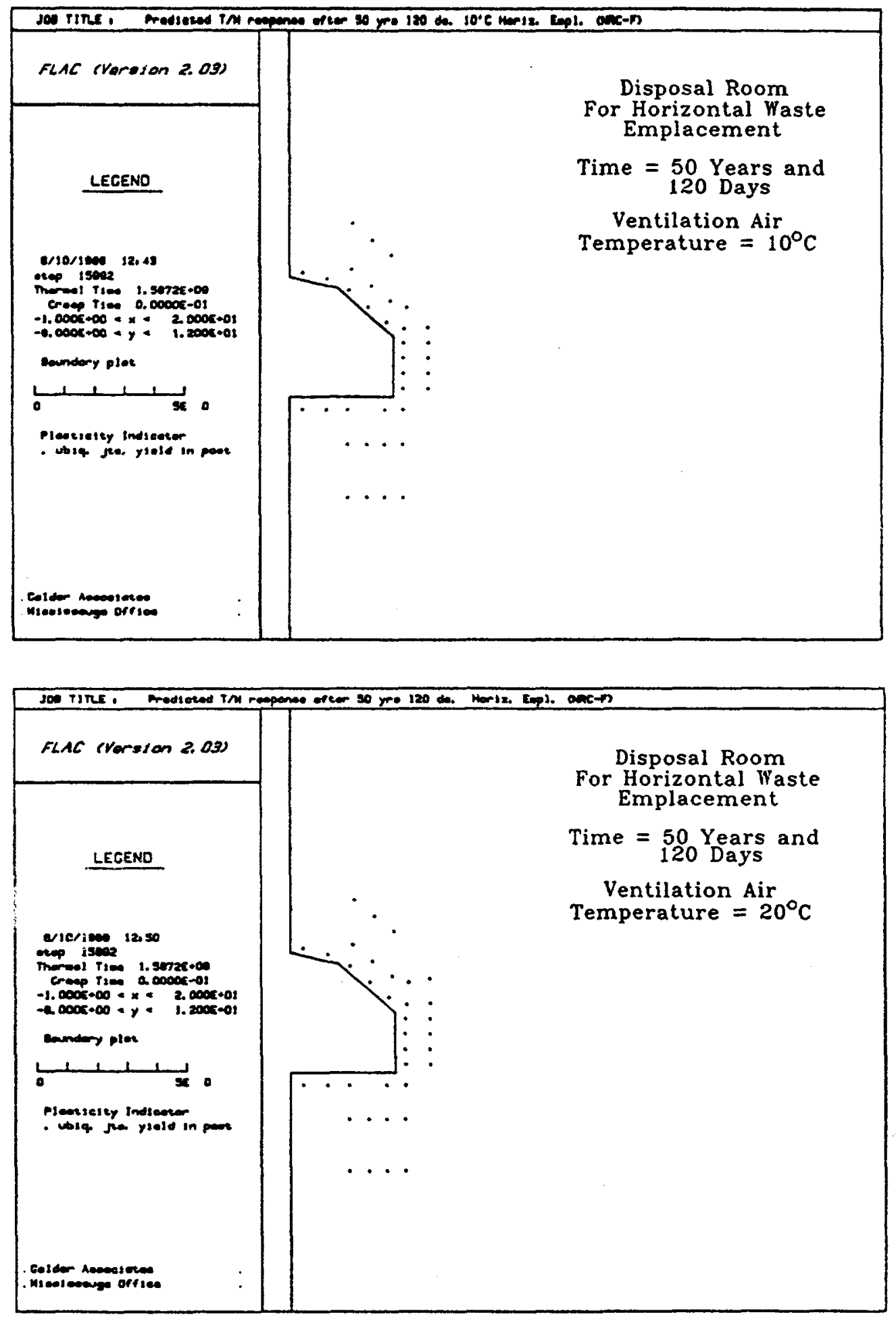

Fig. 26 Predicted Slip Along Vertical Joints Around the Waste Disposal Room for Horizontal Emplacement After 120 Days of Ventilation 

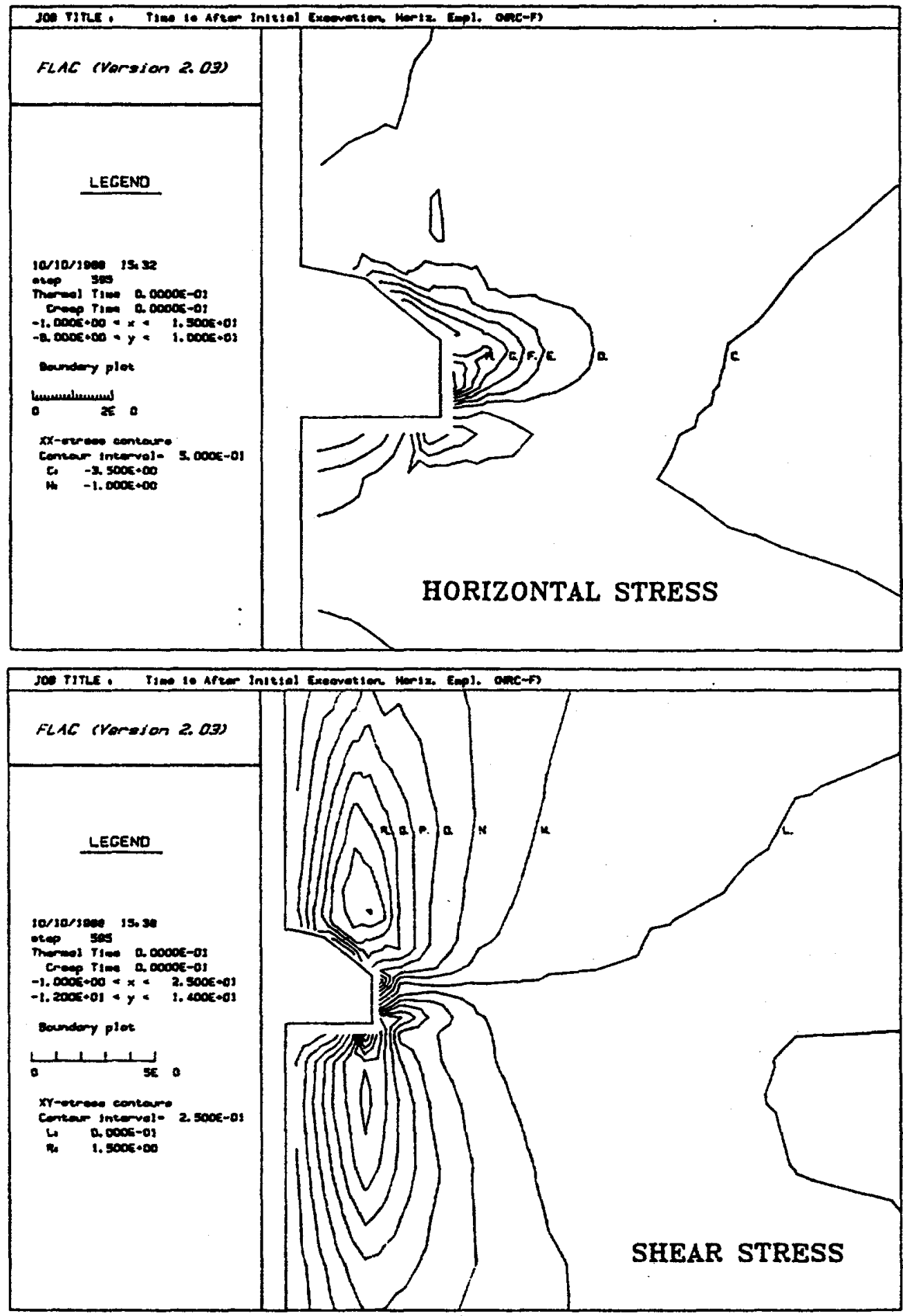

Fig. 27 Predicted Shear and Horizontal Stresses As a Result of Excavation of the Waste Disposal Room for Horizontal Emplacement 


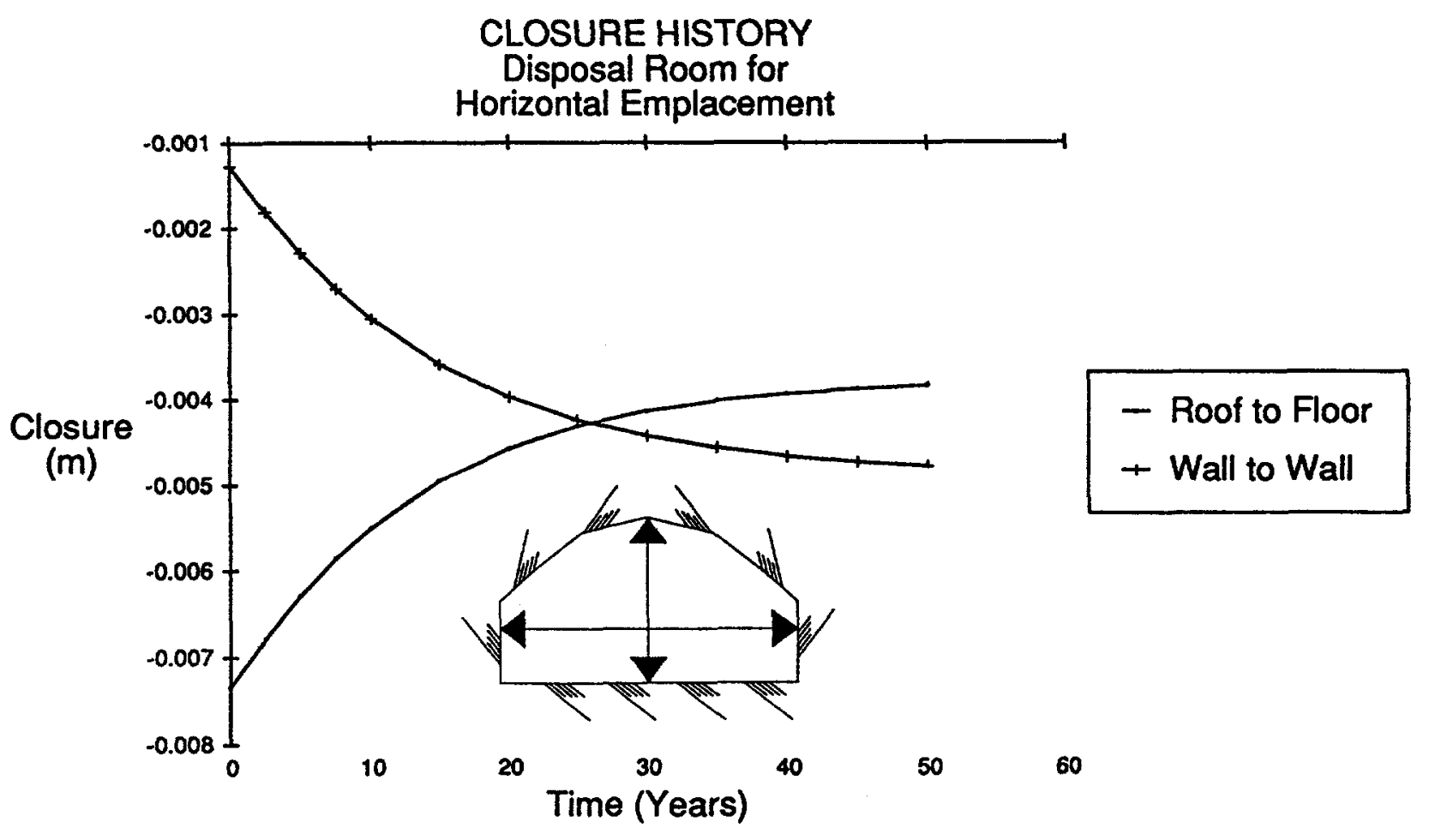

Fig. 28 Predicted History of the Roof to Floor Closure and the Wall to Wall Closure of the Waste Disposal Room for Horizontal Emplacement 


\subsection{SUMMARY AND CONCLUSIONS}

The response of the rock to the excavation of the disposal rooms, heating by the nuclear waste, and cooling by forced ventilation has been investigated, considering separately vertical and horizontal emplacement of the waste. The focus of the analyses has been toward effects that may compromise the structural stability of the rooms. Because two-dimensional models were used, the stability of individual container boreholes could not be investigated. The effects of particular interest, therefore, have been the predictions of any inelastic behavior of the rock around the disposal room, such as the creation of new fractures from excessive shear stresses, and also slip or opening of pre-existing vertical joints.

From the results of the analyses a set of conclusions can be made which apply to both disposal rooms (i.e., vertical or horizontal waste emplacement) investigated, unless specifically stated otherwise.

- No new fractures are created from excessive shear stresses in the rock around the disposal room as a result of room excavation, 50 years of thermomechanical rock response, or 120 days of convective cooling in preparation for waste retrieval. Fracturing may occur around the boreholes, but this could not be examined in this study.

- Slip along pre-existing vertical joints in the rock is predicted around the disposal room as a result of room excavation.

- Fifty (50) years of thermomechanical rock response has little effect on the development of joint slip beyond that predicted from room excavation alone.

- Assuming that the rock can be classified as "fair to good" according to the Geomechanics Classification system (Bieniawski, 1974), only light ground support such as rockbolts, wire mesh, or shotcrete is estimated to be necessary to maintain rock stability. 
Conclusions which relate specifically to some of the design criteria listed in the SCP-CDR, Chapter 2, can also be stated:

- After 50 years, the maximum predicted rock surface temperature of the disposal room for horizontal waste emplacement is $60^{\circ} \mathrm{C}$, which exceeds the allowable maximum of $50^{\circ} \mathrm{C}$ according to the design criterion.

- The maximum predicted deformation of the disposal room is of the order of $0.005 \mathrm{~m}$, which is substantially below the maximum of $0.152 \mathrm{~m}$, according to the design criterion.

- The radius of curvature of the axis of the horizontal borehole is significantly larger than the minimum of $34 \mathrm{~m}$ allowed by the design criterion.

Note that all of the above conclusions reflect the current understanding of the in-situ conditions, thermal and mechanical properties, and structure of the rock at the proposed repository site as reported in the SCP-CDR. Should any of these parameters change, the results of this study will change, which may affect the conclusions. No attempt was made in this study to determine the effects of uncertainties in the parameters on the predicted thermal/mechanical rock response.

The input files used for FLAC in these analyses are included in Appendix $D$. 


\subsection{RECOMMENDATIONS FOR FUTURE STUDIES}

In this study, the thermal/mechanical response of the rock was determined using an average set of input parameters. However, uncertainties are associated with the input parameters to the numerical model (e.g., thermal rock properties, mechanical rock properties, initial conditions). To provide for a repository design that has a high probability of meeting the performance objectives, it is necessary to understand what the effects of parameter uncertainties are with respect to the thermal/mechanical response of the rock. Future studies, therefore, should include an assessment of the effect of these uncertainties on the rock response and ability to isolate the nuclear waste.

The current study characterizes the rock as a continuum. Although ubiquitous vertical joints are included, the presence of these joints is initiated only by a critical state of stress (i.e., a state of stress that exceeds the strength of the joints according to a Mohr-Coulomb criterion). Future studies should also include discontinuum models (e.g., Shi and Goodman, 1988; Cundall, 1980; Cundall, 1988; Williams et al., 1985), which are capable of explicitly characterizing the intact rock and the rock joints and, therefore, provide additional information that may help to resolve the issue of stability/instability of the rock around the disposal rooms. 


\subsection{REFERENCES}

Bieniawski, Z. T. "Geomechanics Classification of Rock Masses and Its Application in Tunnelling," Proc. Third International Conqress on Rock Mechanics (Denver, 1974), Vol. 11A, pp. 27-32. Denver: ISRM, 1974 .

Brady, B.H.G., and E. T. Brown. Rock Mechanics for Underground Mining. London: George Allen \& Unwin, 1985.

Cundal1, P. A. "UDEC - A Generalized Distinct Element Program for Modelling Jointed Rock," Report PCAR-1-80, Peter Cundall Associates; Contract DAJA37-79-C-0548, European Research Office, U.S. Army, March 1980.

Cundall, P. A. "Formulation of a Three-Dimensional Distinct Element Model - Part I: A Scheme to Detect and Represent Contacts in a System Composed of Many Polyhedral Blocks," Int. J. Rock Mech., Min. Sci. \& Geomech. Abstr., 25, 107-116 (1988).

Flores, Richard J. "Retrievability: Strategy for Compliance Demonstration," SAND84-2242, January 1986.

Goodman, R. E. Introduction to Rock Mechanics. New York: John Wiley \& Sons, 1980 .

Hoek, Evert. "The Role of Modeling in the Design of Nuclear Waste Repositories - The Design Engineer's Viewpoint, " Proceedings of a Workshop on Thermomechanical Modeling for a Hardrock Waste Repository (June 1979), pp. 33-43. Berkeley: Lawrence Livermore Laboratory, 1979.

Itasca Consulting Group, Inc. FLAC (Fast Lagrangian Analysis of Continua). Minneapolis: Itasca Consulting Group, 1988.

Johnstone, J. Keith, Ralph R. Peters, and Paul F. Gnirk. Unit Evaluation at Yucca Mountain, Nevada Test Site: Summary Report and Evaluation. SAND83-0372. June 1984 .

MacDougall, Hugh R., Leo W. Scully, and Joe R. Tillerson (Compilers). Site Characterization Plan Conceptual Design Report.

SAND84-2641. September 1987. 
Mansure, A. J. "Expected Temperatures for Spent Fuel Borehole Walls and Drifts," Memo to R. J. Flores, Sandia Keystone Memo 6310-85-8, April 15, 1985.

NWPA (Nuclear Waste Policy Act of 1982), Public Law 97-425, 96 Stat. 2201, 42 USC 10101, Washington, D.C., January 1983.

O’Brien, Paul D. "Reference Nuclear Waste Descriptions for a Geologic Repository at Yucca Mountain, Nevada," SAND84-1848, September 1985 .

Peters, Ralph R. "Thermal Response to Emplacement of Nuclear Waste in Long, Horizontal Boreholes," SAND82-2497, April 1983.

Pitts, Donald R., and Leighton E. Sissom. Schaum's Outline of Theory and Problems of Heat Transfer. New York: McGraw-Hill Book Company, 1977,

Shi, G.-H. and R. E. Goodman. "Discontinuous Deformation Analysis - A New Method for Computing Stress, Strain and Sliding of Block systems," in Key Questions in Rock Mechanics: Proceedings of the 29th U.S. Symposium (University of Minnesota, June 1988), pp. 381-393. Rotterdam: A. A. Balkema, 1988.

St. John, C. M. "Thermal Analysis of Spent Fuel Disposal in Vertical Emplacement Boreholes in a Welded Tuff Repository," SAND847207, November 1985.

Svalstad, D. K. and T. Brandshaug. "Forced Ventilation Analysis of a Commercial High-Level Nuclear Waste Repository in Tuff," SAND81-7206, December 1981.

Williams, J. R., G. Hocking and G. G. W. Mustoe. "The Theoretical Basis of the Discrete Element Method," Proceedings of the International Conference on Advances in Numerical Methods in Engineering (University of Swansea, U.K., 1985).

U. S. Department of Energy (DOE). Consultation Draft Site Characterization Plan Overview, Yucca Mountain Site, Nevada Research and Development Area, Nevada. Nuclear Waste Policy Act, Section 113. January 1988 .

U. S. Department of Energy (DOE). "Generic Requirements for a Mined Geologic Disposal System, Appendix D, 'Department of Energy Position on Retrievability and Retrieval for a Geologic Repository," OGR/B-2, DOE/RW-0090, Office of Civilian Radioactive Waste Management, Washington, D.C., September 1986. 
U. S. Environmental Protection Agency (EPA). Code of Federal Requlations: Title 40, Parts 190 to 399 (Protection of Environment). January 1988 .

U.S. Nuclear Regulatory Commission (NRC). Code of Federal Regulations: Title 10, Parts 0 to 199 (Energy); 10 CFR Part 60 , "Disposal of High-Leve1 Radioactive Wastes in Geologic Repositories." January 1988. 
St. John (1985) examined the radius of thermal influence of a single waste container as a function of time, so that the size of the area required in a model could be determined. The equation for temperature change at a distance, $R$, from a decaying point source of initial strength $Q_{0}$ is given by (Christianson, 1979):

$\Delta T=\frac{Q_{0}}{\pi^{3 / 2}} \exp (-A t) \frac{\sqrt{ } \pi}{4 K} \exp \left(-\frac{R^{2}}{4 K t}\right) \operatorname{Re}\left[w\left[\sqrt{ }(A t)+\frac{i R}{\sqrt{(4 K t)}}\right]\right] m$

where $A=$ decay constant,

$\kappa=$ thermal diffusivity,

$t=t i m e$, and

$w(z)=$ complex error function.

It is seen that the temperature change decays from the point source approximately proportional to

$$
\exp \left(-\frac{R^{2}}{4 \kappa t}\right)
$$

St. John (1985) suggests that $\mathrm{R}^{2} / 4 \mathrm{kt}=4$ is sufficient to ensure a small temperature change. This requires that

$$
R \geq 4(\kappa t)^{1 / 2}
$$

where $t$ is time in years.

Applying Equation $A-2$ to the present problem for a time period of 50 years, and a thermal diffusivity of tuff of $33.44 \mathrm{~m}^{2} /$ year, the radius of thermal influence, $R$, is determined to be approximately $164 \mathrm{~m}$. 


\section{REFERENCE}

Christianson, Mark. TEMP3D: A Computer Program for Determining Temperatures Around Sinqle or Arrays of Constant or Decaying Heat Sources-Users' Guide and Manual. University of Minnesota Report to BWIP. December 1979.

St. John, C. M. "Thermal Analysis of Spent Fuel Disposal in Vertical Displacement Boreholes in a Welded Tuff Repository," SAND84-7207, November 1985. 
Figure B-1 illustrates the lay-out of the waste containers for vertical emplacement (MacDougall et al., 1987). The appropriate thermal loading at the center of the waste panel for times of 50 years or less can be determined from this figure. The shaded area in Fig. B-1 represents a unit area, over which the initial power of one half SF and one half DHLW container should be averaged. The shaded area is $87.8 \mathrm{~m}^{2}$. With an initial power of 3200 $W$ per SF container and $420 \mathrm{~W}$ per DHLW container, the thermal loading is determined to be $20.6 \mathrm{~W} / \mathrm{m}^{2}$ or $83.3 \mathrm{~kW} /$ acre.

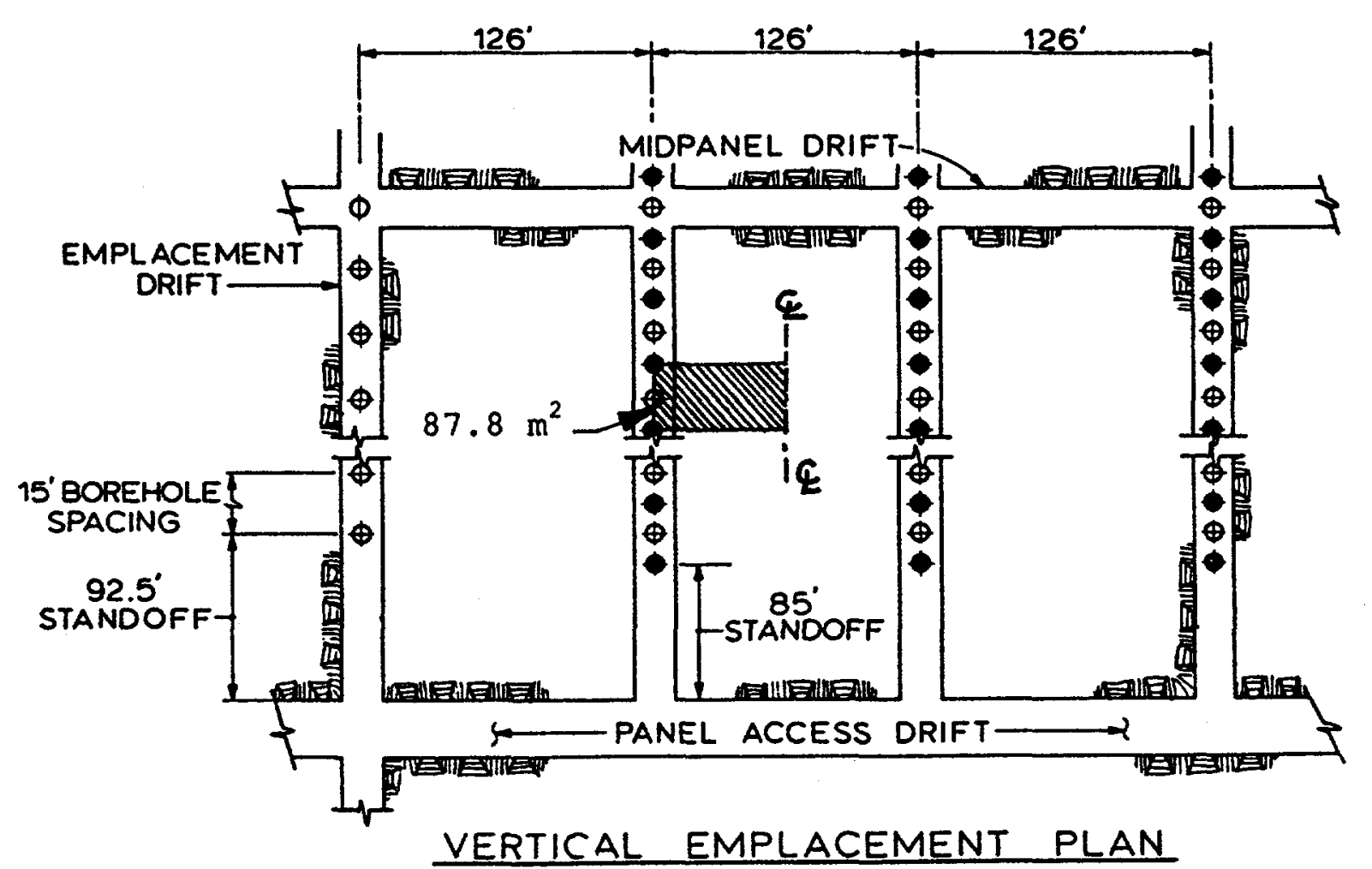

Fig. B-1 Layout of Waste Containers for Vertical Emplacement [after MacDougall et al., 1987, Chapter 4] 
In Fig. B-2, the lay-out of the waste is shown for horizontal emplacement (MacDougall et al., 1987, Chapter 4). The shaded area in the figure represents the unit area, over which the initial power of $28 \mathrm{SF}$ and 18 DHLW containers should be averaged. The shaded area is $4864 \mathrm{~m}^{2}$. With an initial power of $3200 \mathrm{~W}$ per SF container, and $420 \mathrm{~W}$ per $\mathrm{DHLW}$ container, the thermal loading is determined to be $20 \mathrm{~W} / \mathrm{m}^{2}$ or $80.8 \mathrm{~kW} /$ acre.

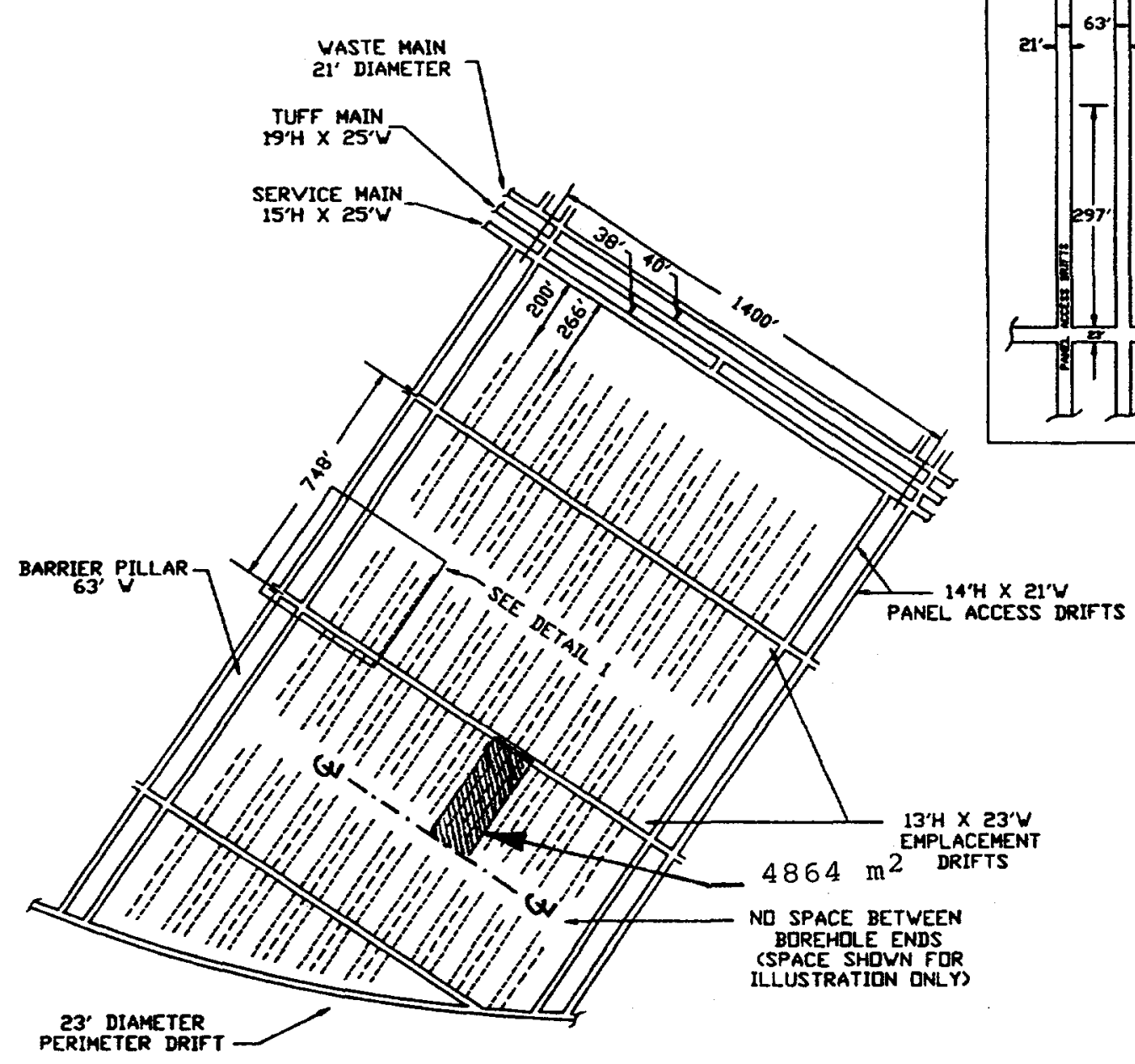

DETAIL 1 DF HORIZDNTAL EMPLACEMENT DIMENSIDNS

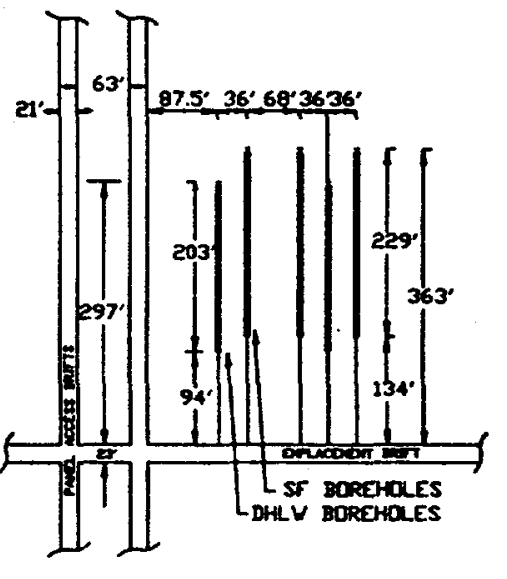
PERIMETER DRIFT

Fig. B-2 Layout of Waste Containers for Horizontal Emplacement [after MacDougall et al., 1987, Chapter 4] 


$$
\mathrm{B}-3
$$

\section{REFERENCE}

MacDougall, Hugh R., Leo W. Scully, and Joe R. Tillerson (Compilers). Site Characterization Plan Conceptual Design Report. SAND 84-2641. September 1987. 
APPENDIX C

DETERMINATION OF CONVECTIVE HEAT TRANSFER COEFFICIENTS

The convective heat transfer coefficient used to simulate forced ventilation of the disposal rooms is determined from the siederTate equation (Pitts and Sissom, 1977):

$$
\overline{\mathrm{Nu}} \cong \frac{\overline{\mathrm{h}} \mathrm{D}_{\mathrm{h}}}{\mathrm{k}}=0.023 \mathrm{Re}^{0.8} \mathrm{Pr}^{1 / 3}\left[\frac{\mu_{\mathrm{b}}}{\mu_{\mathrm{s}}}\right]^{0.14}
$$

where $\overline{\mathrm{Nu}}=$ the average Nusselt number,

$$
\begin{aligned}
\overline{\mathrm{h}} & =\text { the average convective heat transfer coefficient, } \\
\mathrm{D}_{\mathrm{h}} & =\text { the hydraulic diameter of the disposal room, } \\
\mathrm{k} & =\text { thermal conductivity of the air, } \\
\mathrm{Re} & =\text { Reynolds number, } \\
\mathrm{Pr} & =\text { Prandtl number, } \\
\mu_{\mathrm{b}}= & \text { dynamic viscosity of the bulk air, and } \\
\mu_{\mathrm{s}}= & \text { dynamic viscosity of the air at the convective bound- } \\
& \text { ary (the air is assumed to be } 50^{\circ} \mathrm{C} \text { at the boundary) }
\end{aligned}
$$

Equation $C-1$ is valid for $\operatorname{Re}>10,000$ and $1 / D>60$, where " $I$ " is the length of the duct (in this case, the disposal room). The properties of air used are taken from Pitts and Sissom (1977), p. 314 .

The Reynolds number, Re, for the disposal rooms is determined from

$$
\operatorname{Re}=\frac{V D_{h}}{v}
$$


where $\mathrm{V}=$ air velocity,

$D_{\mathrm{h}}=$ hydraulic diameter of the disposal rooms, and

$v=$ kinematic air viscosity.

Because the disposal rooms are not circular, the hydraulic diameter is determined from

$$
D_{h}=\frac{4 A}{P}
$$

where $\mathrm{A}$ = the cross-sectional area of the disposal room, and $P=$ length of the room perimeter.

The hydraulic diameter, $D_{h}$, determined for the disposal rooms of vertical and horizontal waste emplacement (MacDougall et al., 1987, Chapter 4) are given in Table C-1.

Table C-1

HYDRAULIC DIAMETER

Waste Emplacement Concept

Vertical

Horizontal
30.64
23.94

$\underset{\left(m^{2}\right)}{A}$

\section{$\mathrm{P}$ \\ (m)}

21.32

19.49
$D_{h}$

(m)

Reynolds number, Re, is determined from Eq. (C-2). An air velocity of $1 \mathrm{~m} / \mathrm{s}$ is assumed, and two air temperatures, $10^{\circ} \mathrm{C}$ and $20^{\circ} \mathrm{C}$, are considered. 
Table C-2

REYNOLDS NUMBER

\begin{tabular}{ccccc}
\hline $\begin{array}{c}\text { Waste Emplacement } \\
\text { Concept }\end{array}$ & $\begin{array}{c}\mathrm{V} \\
(\mathrm{m} / \mathrm{s})\end{array}$ & $\begin{array}{c}\mathrm{D}_{\mathrm{h}} \\
(\mathrm{m})\end{array}$ & $\begin{array}{c}\mathrm{v} \\
\left(\mathrm{m}^{2} / \mathrm{s}\right)\end{array}$ & $\mathrm{Re}$ \\
\hline $\begin{array}{c}\text { Vertical } \\
\mathrm{T}_{\text {air }}=10^{\circ} \mathrm{C}\end{array}$ & 1. & 5.75 & $1.36 \mathrm{e}-5$ & 423,469 \\
$\begin{array}{c}\text { Vertical } \\
\mathrm{T}_{\text {air }}=20^{\circ} \mathrm{C}\end{array}$ & 1. & 5.75 & $1.48 \mathrm{e}-5$ & 388,099 \\
$\begin{array}{c}\text { Horizontal } \\
\mathrm{T}_{\text {air }}=10^{\circ} \mathrm{C}\end{array}$ & 1. & 4.91 & $1.36 \mathrm{e}-5$ & 361,029 \\
$\begin{array}{c}\text { Horizontal } \\
\mathrm{T}_{\text {air }}=20^{\circ} \mathrm{C}\end{array}$ & 1. & 4.91 & $1.48 \mathrm{e}-5$ & 331,757 \\
\hline
\end{tabular}

The Reynolds numbers listed in Table $\mathrm{C}-2$ are all greater than 10,000 and, therefore, satisfy the conditions of Eq. (C-1). The second condition that must be satisfied to use Eq. $(C-1)$ is $1 / D_{h}>60$. The length, 1 , of the disposal rooms are approximately $400 \mathrm{~m}$ (MacDougall et al., 1987, Chapter 4). Table C-3 shows that this ratio is satisfied for the disposal rooms of vertical and horizontal waste emplacement. 


$$
\mathrm{C}-4
$$

Table C-3

RATIO OF I/D

Waste Emplacement Concept
1

(m)

400

400
$\mathrm{D}_{\mathrm{h}}$

(m)

5.75

70

Horizontal

4.91

81

The average Nusselt number and convective heat transfer coefficient determined are listed in Table $\mathrm{C}-4$.

Table $\mathrm{C}-4$

AVERAGE NUSSELT NUMBER AND CONVECTIVE HEAT TRANSFER COEFFICIENT

\begin{tabular}{|c|c|c|c|c|c|c|c|}
\hline $\begin{array}{c}\text { Waste } \\
\text { Emplacement } \\
\text { Concept }\end{array}$ & $\frac{\mu_{\mathrm{b}}}{\mu_{\mathrm{s}}}$ & $\operatorname{Pr}$ & $\mathrm{Re}$ & $\begin{array}{c}\mathrm{k} \\
(W / m-K) \\
x 10^{-2}\end{array}$ & $\mathrm{D}_{\mathrm{h}}$ & $\overline{\mathrm{Nu}}$ & $\frac{\bar{h}_{2}}{\left(W / m^{2}-K\right)}$ \\
\hline
\end{tabular}

Vertical

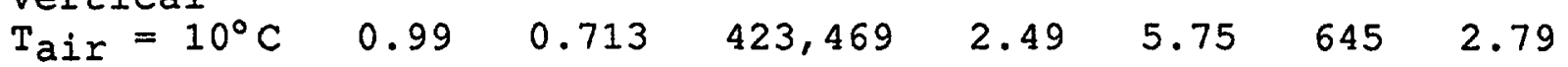

Vertical

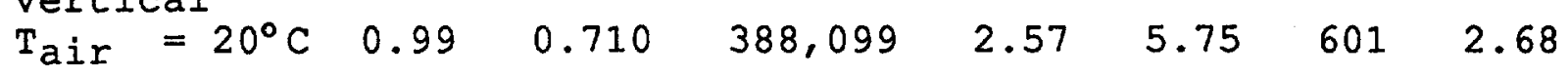

Horizontal

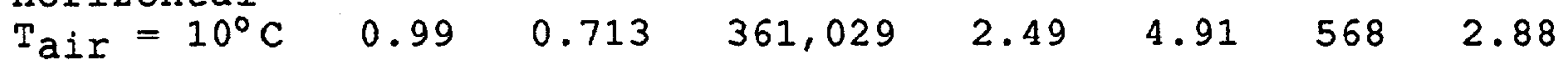

Horizontal

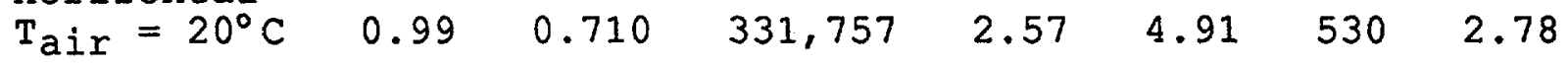




$$
\text { C-5 }
$$

\section{REFERENCE}

MacDougall, Hugh R., Leo W. Scully, and Joe R. Tillerson (Compilers). Site Characterization Plan Conceptual Design Report. SAND84-2641. September 1987.

Pitts, Donald R., and Leighton E. Sissom. Schaum's Outline of Theory and Problems of Heat Transfer. New York: McGraw-Hill Book Company, 1977, 
APPENDIX D

FLAC INPUT FILES

D-1. FLAC INPUT FILE FOR VERTICAL EMPLACEMENT

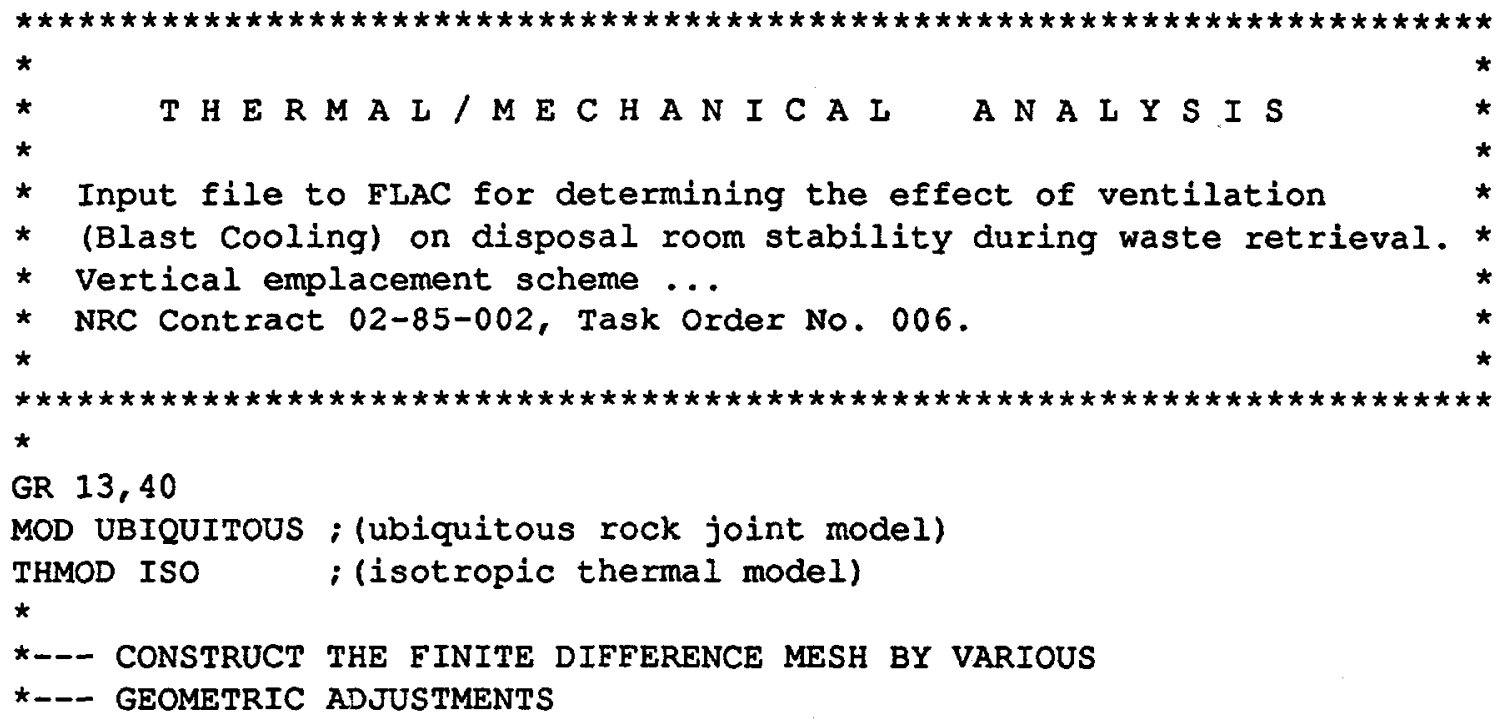

GEN $0 .,-150.0 ., 150,19.2,150,19.2,-150$.

GEN $0 ., 0.0 ., 6.712 .44,6.712 .44,0 . \quad I=1,6 \quad J=20,28$

GEN $2.44,0.2 .44,6.7119 .2,6.7119 .2,0$. R 1.5, $1 . \quad I=6,14 \quad J=20,28$ *

*--- The borehole above the waste container ...

GEN $0 .,-3.10 ., 0 . .37,0 . .37,-3.1 \mathrm{I}=1,2 \mathrm{~J}=15,20$

*-.- To the right of borehole and under floor ...

GEN . 37, -3.1 .37,0.2.44,0. 2.44, $-3.1 \mathrm{I}=2,6 \mathrm{~J}=15,20$

*--- The container inside the borehole ...

GEN $0 .,-7.620 .,-3.1 \quad .37,-3.1 \quad .37,-7.62 \mathrm{I}=1,2 \mathrm{~J}=10,15$

*-- To the right of the container and under floor .....

GEN .37, -7.62 .37, -3.1 2.44, -3.1 2.44,-7.62 I=2,6 J=10, 15

*--- To the right of borehole and under pillar ...

GEN $2.44,-3.102 .44,0.19 .2,0.19 .2,-3.1$ R $1.5,1 . I=6,14 \mathrm{~J}=15,20$

GEN 2.44,-7.62 2.44,-3.1 19.2,-3.1 19.2,-7.62 R 1.5, 1 . I=6,14 J=10,15

*--- Below the container and under pillar ...

GEN $0,,-30.0,-7.622 .44,-7.622 .44,-30$. R $1 ., .67 \mathrm{I}=1,6 \mathrm{~J}=5,10$

GEN $2.44,-30.2 .44,-7.6219 .2,-7.6219 .2,-30$. R $1.5, .67 \mathrm{I}=6,14 \mathrm{~J}=5,10$

GEN $0,,-150.0,,-30.19 .2,-30.19 .2,-150 . R 1,, .80 \mathrm{I}=1,14 \mathrm{~J}=1,5$

*--- Adjusting the lower part of mesh to achieve better 
* element aspect ratios ...

GEN R 1.2,1. I=1, $14 \mathrm{~J}=5$

GEN R 1.05, 1. I=1, $14 \mathrm{~J}=4$

GEN R 1.,1. $I=1,8 \mathrm{~J}=6$

*--- Adjusting the mesh above the disposal room ...

GEN $0 ., 7.0 ., 30.2 .44,30.2 .44,7$. R $1,, 1.7 \quad I=1,6 \quad J=29,35$

GEN 2.44,7.2.44,30.19.2,3019.2,7. R 1.51 .7 I=6, $14 \mathrm{~J}=29,35$

*-- Adjusting the mesh to the top of the model ...

GEN $0 ., 30.0 ., 150.19 .2,150.19 .2,30 . R 1 ., 1.3 \mathrm{I}=1,14 \mathrm{~J}=35,41$

GEN R 1.3, 1. I=1, $14 \mathrm{~J}=35$

GEN R 1.25,1. I=1, $14 \mathrm{~J}=36$

GEN R 1.2,1. I=1, $14 \mathrm{~J}=37$

GEN R 1.1, I. I=1, $14 \mathrm{~J}=38$

*

*-- Constructing the crown of the room by indiv. nodal adjustments ...

INI $X=2.44 \quad I=6 \quad J=26$

INI $Y=5.22 \quad I=6 \quad J=26$

INI $X=2.30 \quad I=6 \quad J=27$

INI $Y=5.50 \quad I=6 \quad J=27$

INI $X=2.10 \quad I=6, J=28$

INI $Y=5.90 \quad I=6 \quad J=28$

INI $X=1.65 \quad I=5 \quad J=28$

INI $Y=6.20 \quad I=5 \quad J=23$

INI $X=1.30 \quad I=4 \quad J=28$

INI $Y=6.40 \quad I=4 \quad J=28$

INI $X=1.00 \quad I=3 \quad J=28$

INI $Y=6.55 \quad I=3 \quad J=28$

INI $X=0.50 \quad I=2 \quad J=28$

INI $Y=6.65 \quad I=2 \quad J=28$

INI $X=2.50 \quad I=7 \quad J=28$

INI $Y=6.00 \quad I=7 \quad J=28$

INI $Y=6.43 \quad I=8 \quad J=28$

INI $Y=5.60 \quad I=7 \quad J=27$

INI $Y=5.15 \quad I=7 \quad J=26$

*

*--- Second row of nodal points above crown ...

INI $X=0.55 \quad I=2 \quad J=29$

INI $Y=6.95 \quad I=2 \quad J=29$

INI $X=1.10 \quad I=3 \quad J=29$

INI $Y=6.85 \quad I=3 \quad J=29$

INI $X=1.45 \quad I=4 \quad J=29$

INI $Y=6.70 \quad I=4, J=29$

INI $X=1.75 \quad I=5 \quad J=29$

INI $Y=6.55 \quad I=5 \quad J=29$

INI $X=2.10 \quad I=6 \quad J=29$

INI $Y=6.35 \quad I=6 \quad J=29$

INI $X=2.50 \quad I=7 \quad J=29$

INI $Y=6.35 \quad I=7 \quad J=29$ 
Third row of nodal points above crown ...

INI $Y=7.60 \quad I=1 \quad \mathrm{~J}=30$

INI $X=0.60 \quad I=2 \quad J=30$

INI $Y=7.55 \quad I=2, J=30$

INI $X=1.15 \quad I=3 \quad J=30$

INI $Y=7.50 \quad I=3, J=30$

INI $X=1.60 \quad I=4 \quad J=30$

INI $Y=7.40 \quad I=4 \quad J=30$

INI $X=2.00 \quad I=5 \quad J=30$

INI $Y=7.30 \quad I=5 \quad J=30$

INI $\mathrm{X}=2.40 \quad \mathrm{I}=6 \mathrm{~J}=30$

INI $Y=7.20 \quad I=6 \quad J=30$

INI $X=2.75 \quad I=7 \quad J=30$

INI $Y=7.30 \quad I=7 \quad \mathrm{~J}=30$

$\star$

*--- Forth row of nodal points above crown ...

GEN LINE $0 ., 8.6 \quad 2.78,8.3$

$\star$

*--- Some additional mesh adjustments ...

GEN LINE $3.291,6.4319 .2,6.43$

*

*--- ASSIGN MATERIAL PROPERTIES (REF: SCP-CDR CHAP. 2, SEC. 2.3.1)

*--- USING THE JOINT PROPERTIES AND "ROCK MASS" PROPERTIES.

*-- ALSO USING THE MOST RECENT RESULTS FROM DATA ANALYSIS,

*--- TABLES 2-4, 2-6, AND 2-7.

*--- THE ROCK IS CHARACTERIZED AS AN ELASTIC/PLASTIC MATERIAL

*--- WITH UBIQUITOUS JOINTS. A MOHR-COULOMB FAILURE CRITERION

*.-- IS USED FOR BOTH THE INTACT ROCK AND THE JOINTS ...

$\star$

*--- Rock Mass:

PROP SHEAR $=6.23 E 3$ BULK $=9.05 E 3 \mathrm{COH}=17.8 ;(\mathrm{MPa})$

PROP DENS $=2320$. ; $\left(\mathrm{kg} / \mathrm{m}^{\wedge} 3\right)$

PROP FRIC $=23.5 ;$ (degrees)

$\star$

*--- Rock Joints:

PROP JCOH $=0.1 ;(\mathrm{MPa})$

PROP JFRIC $=28.4$ JANG $=90$. ; (degrees)

*

*-- THERMAL PROPERTIES OE THE ROCK ...

* (Ref: SCP-CDR Chap. 2, Sec. 2.3.1.9, Table 2-9)

PROP $\mathrm{CON}=2.29 ;(\mathrm{W} / \mathrm{mK})$

PROP SPE $=931 . ;(\mathrm{J} / \mathrm{kgK})$

PROP THEX $=8.8 \mathrm{E}-6 ;(1 / \mathrm{K})$ 


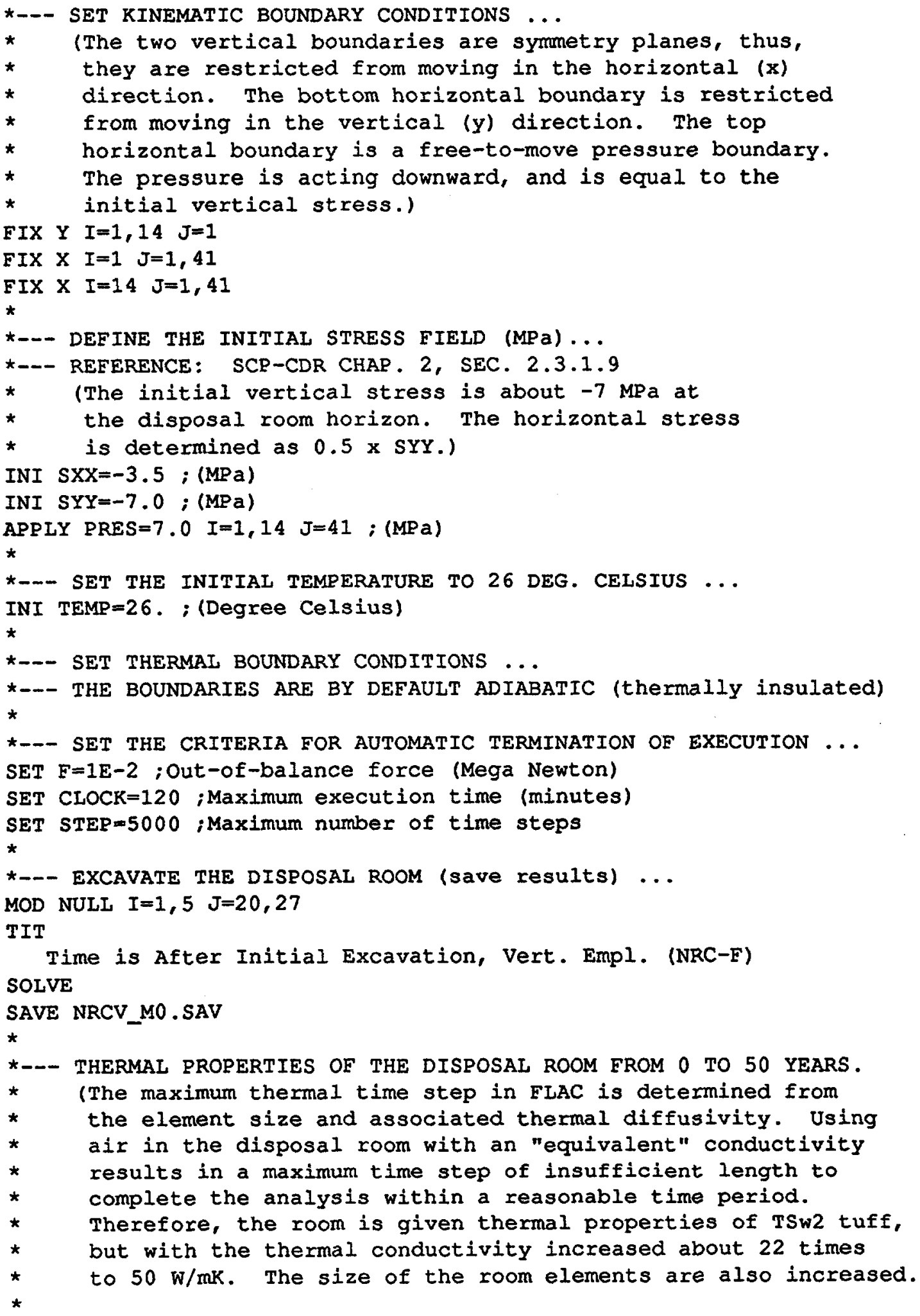




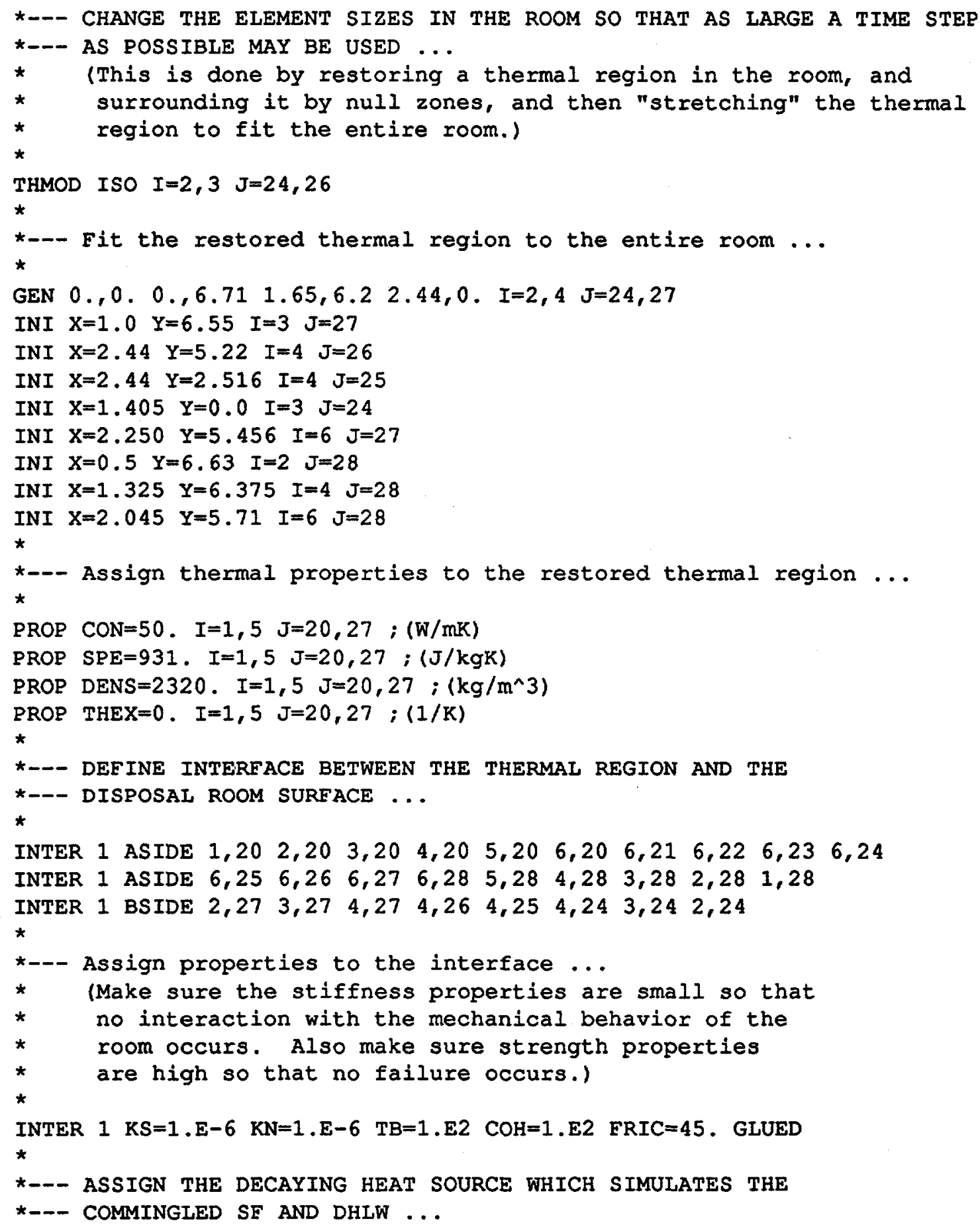


* (The thermal decay characteristics are from Peters, 1983,

* SAND-2497. The initial heat generating power per meter

* of room length is $792 \mathrm{~W}$. Because of symmetry only half

* of this power is applied. Note that the decay coefficients

* have dimension $1 / \mathrm{sec}$ and not $1 /$ year, which is commonly

* used in the literature ...

THAPP FLUX $41.8-2.46 \mathrm{E}-10 \quad \mathrm{I}=1 \mathrm{~J}=10,15$; (SPENT FUEL FIRST TERM)

THAPP FLUX $34.1-1.72 \mathrm{E}-9 \quad \mathrm{I}=1 \mathrm{~J}=10,15$; (SPENT FUEL SECOND TERM)

THAPP FLUX $8.8-6.43 E-10 \quad I=1 \mathrm{~J}=10,15$; (DHLW FIRST TERM)

THAPP FLUX $1.4-1.45 \mathrm{E}-9$ I=1 $\mathrm{J}=10,15$; (DHLW SECOND TERM)

*

*--- DEFINE NODAL POINTS FOR WHICH TEMP. HISTORIES ARE RECORDED ...

*

THIS NSTEP $=10$; Record results every 10 time steps ...

THIS TEMP I=1 $\mathrm{J}=20$; Location at the floor center ...

THIS TEMP $I=6 \mathrm{~J}=23$; Location at the rib center ...

THIS TEMP I=1 $\mathrm{J}=28$; Location at the crown center...

THIS TEMP I=1 $\mathrm{J}=12$; Location at the waste container center ...

*

*--- START THE HEAT TRANSFER SOLUTION USING THE EXPLICIT SCHEME ... THSOLVE $\mathrm{CLOCK}=6 . \mathrm{e} 3 \mathrm{TEMP}=5 . \mathrm{E} 2 \mathrm{STEP}=100000 \quad \mathrm{AGE}=7$

*

SET THDT $=14400$. ; Time step of 4 hrs.

THSOLVE CLOCK=6.E3 TEMP=5.E2 STEP=100000 AGE=30 IMPIICIT; 1 month

$\star$

SET THDT $=28800$. ; Time step of $8 \mathrm{hrs}$.

THSOLVE $C L O C K=6$.E3 TEMP $=5$.E2 STEP $=100000$ AGE=60 IMPLICIT; 2 months

*

SET THDT $=43200$. ; Time step of $12 \mathrm{hrs}$.

THSOLVE CLOCK=6.E3 TEMP=5.E2 STEP $=100000$ AGE=365 IMPLICIT; 1 year TIT

Predicted temperatures after 1 year, Vert. Empl. (NRC-F)

SAVE NRCV_T1.SAV

*

*--- PREDICT THE MECHANICAL RESPONSE OF 1 YeAR OF hEATING ...

SOLVE

TIT

Predicted $T / M$ response after 1 year. Vert. Empl. (NRC-F) SAVE NRCV_MI.SAV

*

*--- CONTINUE HEAT TRANSEER SOLUTION TO 2.5 YEARS $\ldots$

SET THDT $=64800$.; Time step of $18 \mathrm{hrs}$.

THSOLVE CLOCK=6.E3 TEMP=5.E2 STEP $=100000 \mathrm{AGE}=912.5$ IMPLICIT ; 2.5 years TIT

Predicted temperatures after 2.5 years, Vert. Empl. (NRC-F) SAVE NRCV_T2.SAV

* 


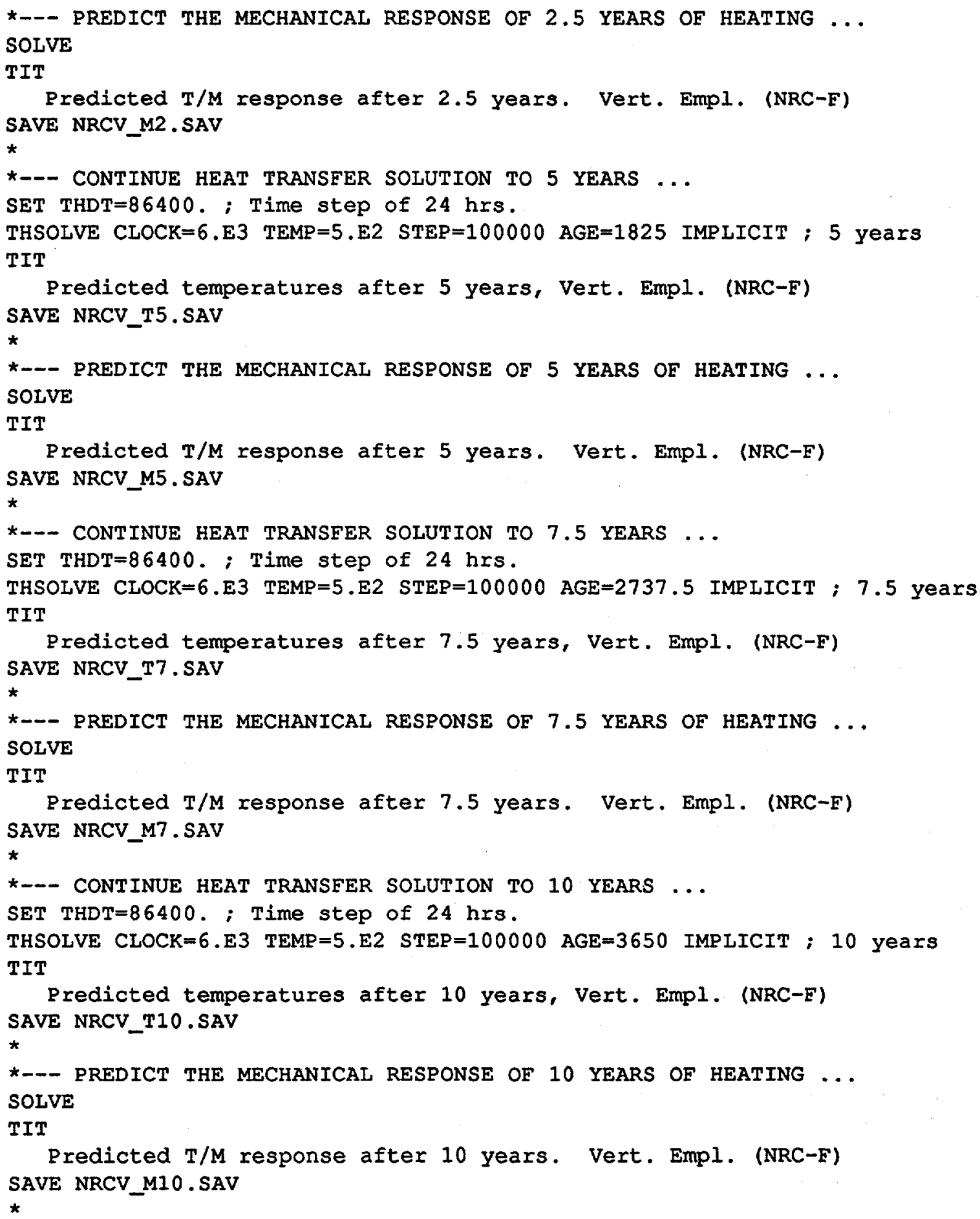


*-.- CONTINUE HEAT TRANSFER SOLUTION TO 15 YEARS ... SET THDT $=345600$. ; Time step of 4 days ...

THSOLVE CLOCK=6.E3 TEMP=5.E2 STEP=100000 AGE=5475 IMPLICIT; 15 years TIT

Predicted temperatures after 15 years, Vert. Empl. (NRC-F) SAVE NRCV_T15.SAV

*

*--- PREDICT THE MECHANICAI RESPONSE OF 15 YEARS OF HEATING ... SOLVE

TIT

Predicted $T / M$ response after 15 years. Vert. Empl. (NRC-F) SAVE NRCV_MI5.SAV

*

*--- CONTINUE heat transfer solution to 20 years ...

SET THDT $=604800$. ; Time step of 7 days ...

THSOLVE CLOCK=6.E3 TEMP=5.E2 STEP=100000 AGE=7300 IMPLICIT; 20 years TIT

Predicted temperatures after 20 years, Vert. Empl. (NRC-E)

SAVE NRCV_T20.SAV

*

*--- PREDICT THE MECHANICAL RESPONSE OF 20 YEARS OF HEATING ... SOLVE

TIT

Predicted $T / M$ response after 20 years. Vert. Empl. (NRC-F) SAVE NRCV_M20.SAV

*

CONTINUE HEAT TRANSFER SOLUTION TO 25 yEARS ...

SET THDT $=604800$.; Time step of 7 days ...

THSOLVE CLOCK=6.E3 TEMP=5.E2 STEP=100000 AGE=9125 IMPLICIT; 25 years TIT

Predicted temperatures after 25 years, Vert. Empl. (NRC-F) SAVE NRCV_T25.SAV

$\star$

*--- PREDICT THE MECHANICAI RESPONSE OE 25 YEARS OF HEATING ... SOLVE

TIT

Bredicted $T / M$ response after 25 years. Vert. Empl. (NRC-F) SAVE NRCV_M25.SAV

$\star$

*--- CONTINUE heAT TRANSFER SOLUTION TO 30 yeARS ...

SET THDT $=604800$. ; Time step of 7 days ...

THSOLVE CLOCK=6.E3 TEMP $=5 . E 2$ STEP $=100000$ AGE $=10950$ IMPLICIT ; 30 years TIT

Predicted temperatures after 30 years, Vert. Empl. (NRC-F) SAVE NRCV_T30.SAV 


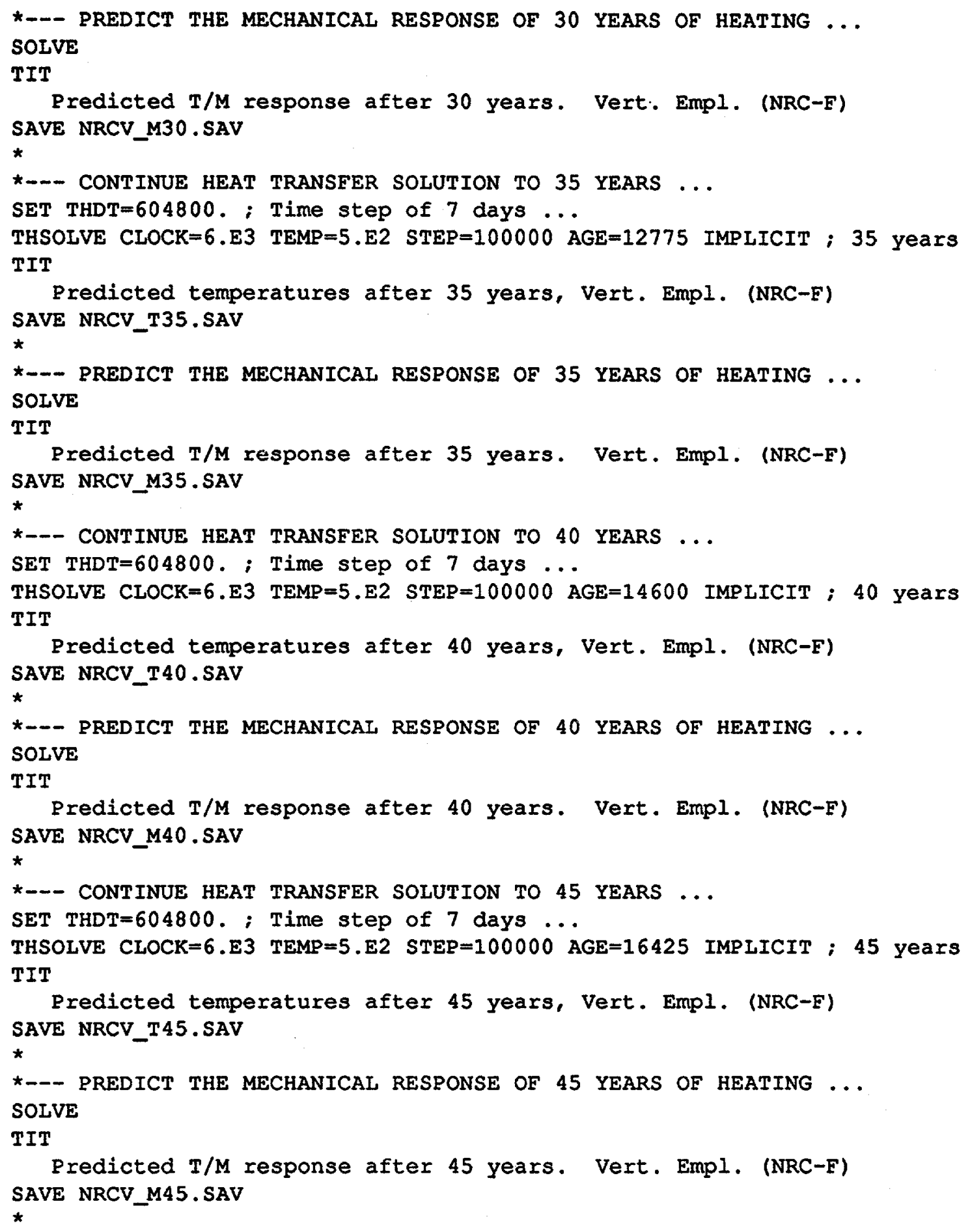




$$
\mathrm{D}-10
$$

CONTINUE HEAT TRANSFER SOLUTION TO 50 YEARS ...

SET THDT $=604800$. ; Time step of 7 days ...

THSOLVE CLOCK=6.E3 TEMP=5.E2 STEP=100000 AGE=18250 IMPLICIT ; 50 years TIT

Predicted temperatures after 50 years, Vert. Empl. (NRC-F) SAVE NRCV_T50.SAV

$\star$

* - - PREDICT THE MECHANICAL RESPONSE OF 50 YEARS OF HEATING ... SOLVE

TIT

Predicted $T / M$ response after 50 years. Vert. Empl. (NRC-F) SAVE NRCV_M50.SAV

$\star$ 


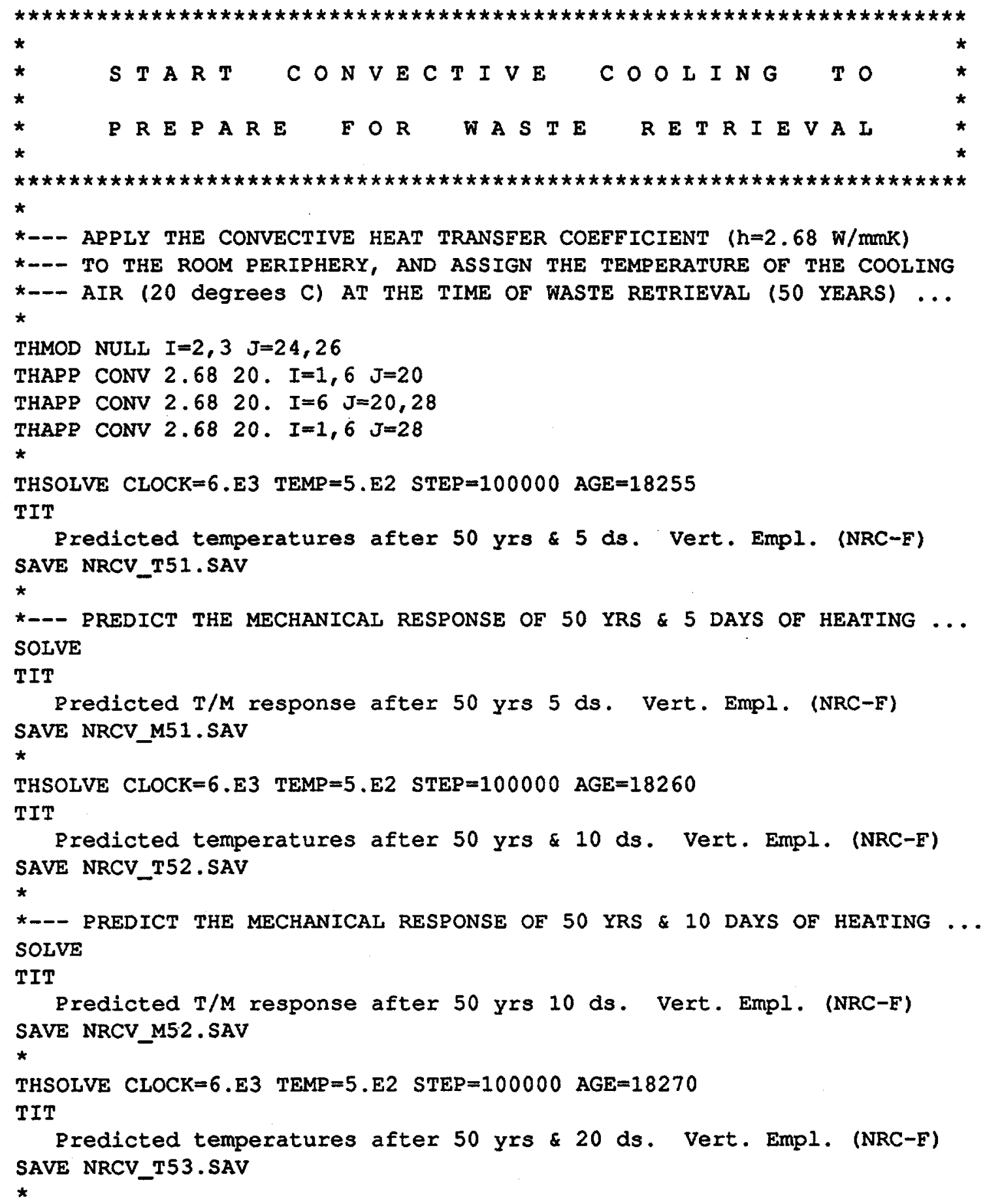


*--- PREDICT THE MECHANICAL RESPONSE OF 50 YRS \& 20 DAYS OF HEATING ... SOLVE

TIT

Predicted $T / M$ response after 50 yrs 20 ds. Vert. Empl. (NRC-F) SAVE NRCV_M53.SAV

*

THSOLVE CLOCK $=6 . E 3$ TEMP $=5 . E 2 \quad \mathrm{STEP}=100000 \quad \mathrm{AGE}=18290$

TIT

Predicted temperatures after 50 yrs \& 40 ds. Vert. Empl. (NRC-F) SAVE NRCV_T54.SAV

*

*--- PREDICT THE MECHANICAL RESPONSE OF 50 YRS \& 40 DAYS OF HEATING ... SOLVE

TIT

Predicted $T / M$ response after 50 yrs 40 ds. Vert. Empl. (NRC-F) SAVE NRCV_M54.SAV

$\star$

THSOLVE CLOCK $=6 . E 3$ TEMP $=5 . E 2$ STEP $=100000 \quad$ AGE $=18310$ TIT

Predicted temperatures after 50 yrs \&60 ds. Vert. Empl. (NRC-E) SAVE NRCV_T55.SAV

*

*-- PREDICT THE MECHANICAI RESPONSE OF 50 YRS \& 60 DAYS OF HEATING ... SOLVE

TIT

Predicted $T / M$ response after 50 yrs 60 ds. Vert. Empl. (NRC-F)

SAVE NRCV_M55.SAV

*

THSOLVE CLOCK $=6 . E 3$ TEMP $=5 . E 2$ STEP $=100000$ AGE $=18330$

TIT

Predicted temperatures after 50 yrs $\& 80$ ds. Vert. Empl. (NRC-F) SAVE NRCV_T56.SAV

*

*--- PREDICT THE MECHANICAL RESPONSE OF 50 YRS \& 80 DAYS OF HEATING ... SOLVE

TIT

Predicted $T / M$ response after 50 yrs 80 ds. Vert. Empl. (NRC-F) SAVE NRCV_M56.SAV

*

THSOLVE $\mathrm{CLOCK}=6 . \mathrm{E} 3 \mathrm{TEMP}=5 . \mathrm{E} 2$ STEP $=100000 \mathrm{AGE}=18350$

TIT

Predicted temperatures after 50 yrs \& 100 ds. Vert. Empl. (NRC-F) SAVE NRCV_T57.SAV

* 
*-.- PREDICT THE MECHANICAL RESPONSE OF 50 YRS \& 100 DAYS OF HEATING ... SOLVE

TIT

Predicted $T / M$ response after 50 yrs 100 ds. Vert. Empl. (NRC-F) SAVE NRCV_M57.SAV

$\star$

THSOLVE CLOCK=6.E3 TEMP=5.E2 STEP=100000 AGE $=18370$

TIT

Predicted temperatures after 50 yrs \& 120 ds. Vert. Empl. (NRC-E) SAVE NRCV_T58.SAV

$\star$

*--- PREDICT THE MECHANICAL RESPONSE OF 50 YRS \& 120 DAYS OF HEATING ... SOLVE

TIT

Predicted $T / M$ response after 50 yrs 120 ds. Vert. Empl. (NRC-E) SAVE NRCV_M58.SAV

$$
\text { * }
$$

* 


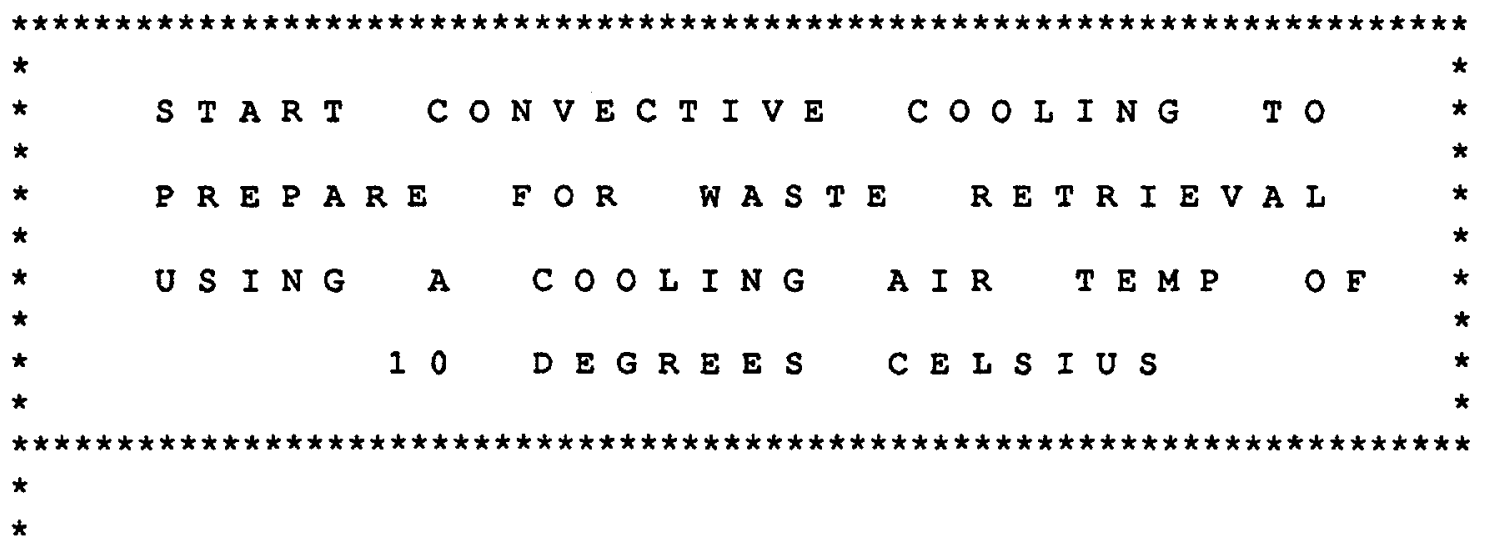

*--- Restart the thermomechanical analysis performed up to 50 years ...

$\star$

res nrcv_m50.sav

*

*

*--- APPLY THE CONVECTIVE HEAT TRANSFER COEFFICIENT ( $\mathrm{h}=2.79 \mathrm{w} / \mathrm{mmK}$ )

*-.- TO THE ROOM PERIPHERY, AND ASSIGN THE TEMPERATURE OF THE COOLING

*--- AIR (10 degrees C) AT THE TIME OF WASTE RETRIEVAL (50 YEARS) ...

*--- NOTE THAT THE CONVECTIVE HEAT TRANSFER COEFFICIENT IS DIFFERENT

*--- FOR DIFEERENT TEMPERATURES OF THE COOLING AIR ...

*

THMOD NULL $I=2,3 \mathrm{~J}=24,26$

THAPP CONV 2.79 10. I=1,6 J=20

THAPP CONV 2.79 10. I=6 J=20,28

THAPP CONV 2.7910 . I $=1,6 \mathrm{~J}=28$

*

THSOLVE CLOCK $=6 . E 3$ TEMP $=5 . E 2$ STEP $=100000$ AGE $=18255$

TIT

Predicted temperatures after 50 yrs \&5 ds. $10^{\circ} \mathrm{C}$ Vert. Empl. (NRC-F) SAVE NRCV_T61.SAV

*

*--- PREDICT THE MECHANICAL RESPONSE OF 50 YRS \& 5 DAYS OF HEATING ... SOLVE

TIT

Predicted $T / M$ response after 50 yrs 5 ds. $10^{\circ} \mathrm{C}$ Vert. Empl. (NRC-F) SAVE NRCV_M61.SAV

*

THSOLVE CLOCK=6.E3 TEMP=5.E2 STEP $=100000$ AGE $=18260$

TIT

Predicted temperatures after 50 yrs \& 10 ds.. $10^{\circ} \mathrm{C}$ Vert. Empl. (NRC-F) SAVE NRCV_T62.SAV

$\star$ 


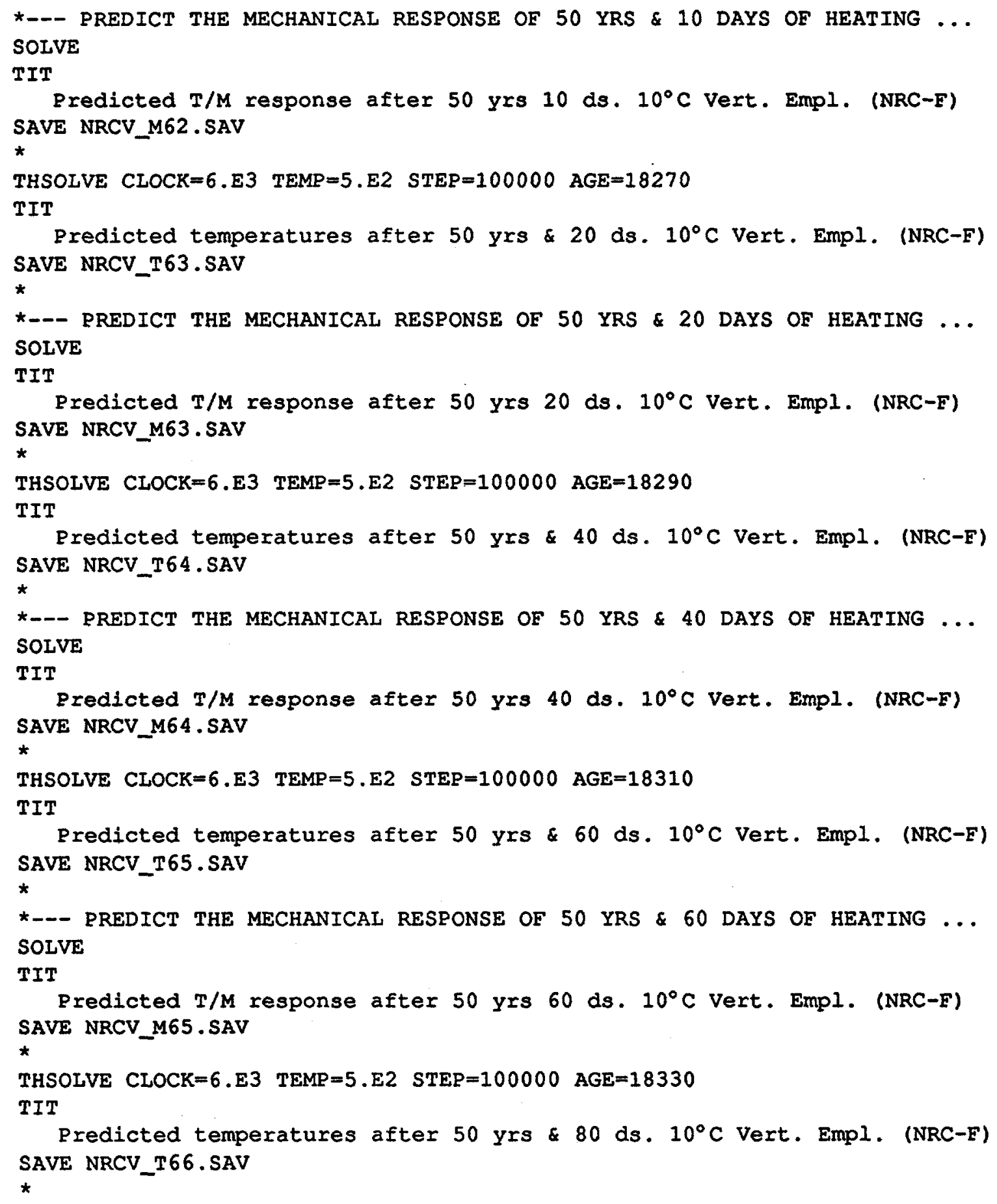$$
\text { THSOLVE CLOCK }=6 . E 3 \quad \text { TEMP }=5 . E 2 \text { STEP }=100000 \quad \text { AGE }=18330
$$
TIT

Predicted temperatures after 50 yrs \& 80 ds. $10^{\circ} \mathrm{C}$ Vert. Empl. (NRC-F) SAVE NRCV_T66.SAV 


$$
D-16
$$

*--- PREDICT THE MECHANICAL RESPONSE OF 50 YRS \& 80 DAYS OF HEATING ... SOLVE

TIT

Predicted $T / M$ response after 50 yrs 80 ds. $10^{\circ} \mathrm{C}$ Vert. Empl. (NRC-F) SAVE NRCV_M66.SAV

THSOLVE $C L O C K=6 . E 3 \quad T E M P=5 . E 2 \quad S T E P=100000 \quad A G E=18350$

TIT

Predicted temperatures after 50 yrs \& 100 ds. $10^{\circ} \mathrm{C}$ Vert. Empl. (NRC-F) SAVE NRCV_T67.SAV

$$
\text { * }
$$

*--- PREDICT THE MECHRICAL RESPONSE OF 50 YRS \& 100 DAYS OF HEATING ... SOLVE

TIT

Predicted $\mathrm{T} / \mathrm{M}$ response after 50 yrs $100 \mathrm{ds} .10^{\circ} \mathrm{C}$ Vert. Empl. (NRC-F) SAVE IRCV_M67.SAV

$\star$

THSOLVE $\mathrm{CLOCK}=6 . \mathrm{E} 3$ TEMP $=5 . \mathrm{E} 2$ STEP $=100000$ AGE $=18370$

TIT

Predicted temperatures after 50 yrs $\& 120$ ds. $10^{\circ} \mathrm{C}$ Vert. Empl. (NRC-F) SAVE NRCV_T68.SAV

*

*--- PREDICT THE MECHANICAL RESPONSE OF 50 YRS \& 120 DAYS OF hEATING ... SOLVE

TIT

Predicted $\mathrm{T} / \mathrm{M}$ response after 50 yrs 120 ds. $10^{\circ} \mathrm{C}$ Vert. Empl. (NRC-F) SAVE NRCV_M68.SAV 
D-2 FLAC Input File for Horizontal Emplacement

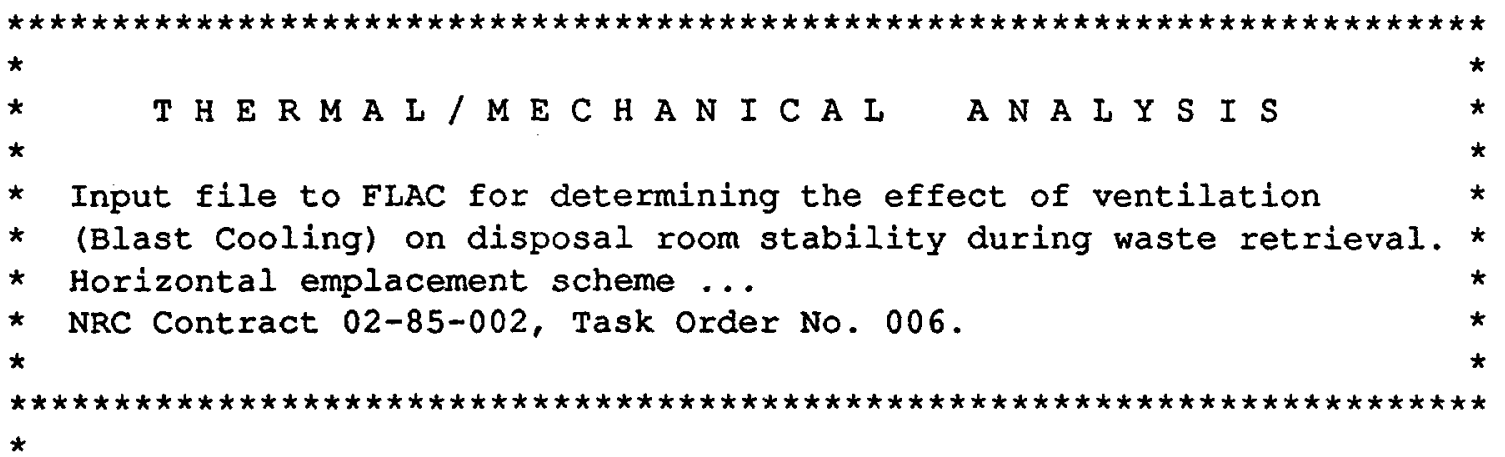

GR 25,32

MOD UBIQUITOUS ; (ubiquitous rock joint model)

THMOD ISO ; (isotropic thermal model)

*

*--- CONSTRUCT THE FINITE DIFFERENCE MESH BY VARIOUS

*--- GEOMETRIC ADJUSTMENTS

gen $0,,-150,0,150,114,150,114,,-150$.

$\star$

*--- Generate the room region ...

gen $0 ., 0.0,2,114,2,114,0 . j=1,26 j=15,19$

$\star$

*-- Generate the region $50 \mathrm{~m}$ above the room ...

gen $0 ., 2.0 ., 50.3 .51,50.3 .51,2 . r .9,1.4 i=1,6 j=19,27$

*

*-- Generate the region $50 \mathrm{~m}$ below the room ...

gen $0 .,-500,0.3 .51,0.3 .51,-50$ × $0.9,0.65 i=1,6 j=7,15$

*

*-- Generate the region off the roof/wall corner...

gen $3.51,2.3 .51,50.17 .5,5017.5,2, r 1.5,1.4 i=6,12 j=19,27$

$\star$

*--- Generate the disposal room ...

gen $0,0,0 ., 2,3.51,2,3.51,0, r 0.9,1 i=1,6 j=15,19$

$\star$

*--- Generate the region off the wall/floor corner ...

gen $3.51,-50.3 .51,0.17 .5,0.17 .5,-50 . r 1.5, .65 i=6,12 j=7,15$

*

*--- Generate the region next to the wall ...

gen $3.51,0.3 .51,2.17 .5,2.17 .5,0 . R 1.5,1 . \mathrm{I}=6,12 \mathrm{~J}=15,19$

$\star$

*-- Generate the region above borehole ...

gen $17.5,2.17,5,50.32 .16,50.32 .16,2 . \quad x \quad 0.7,1.4 \quad i=12,15 j=19,27$ * 


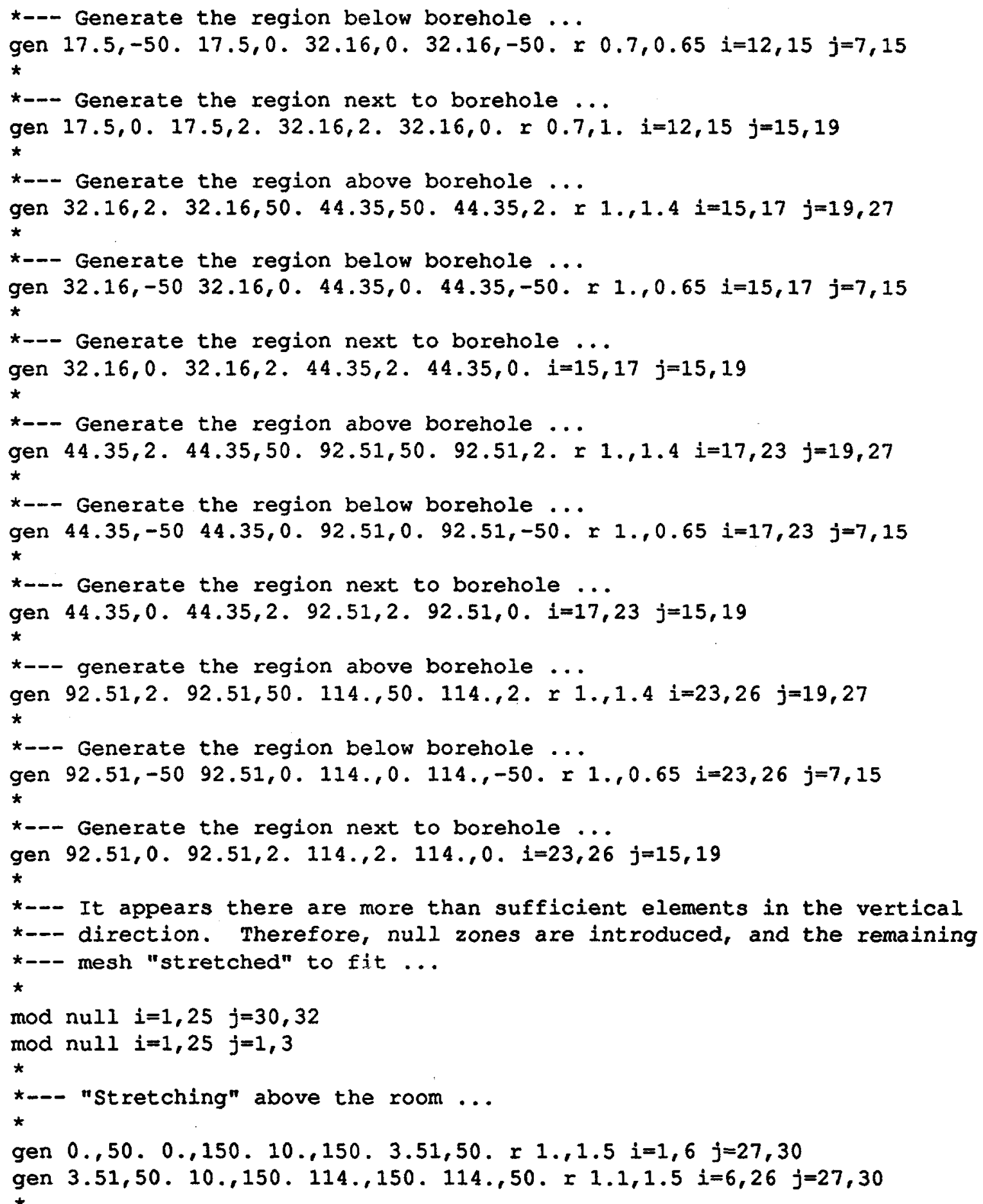




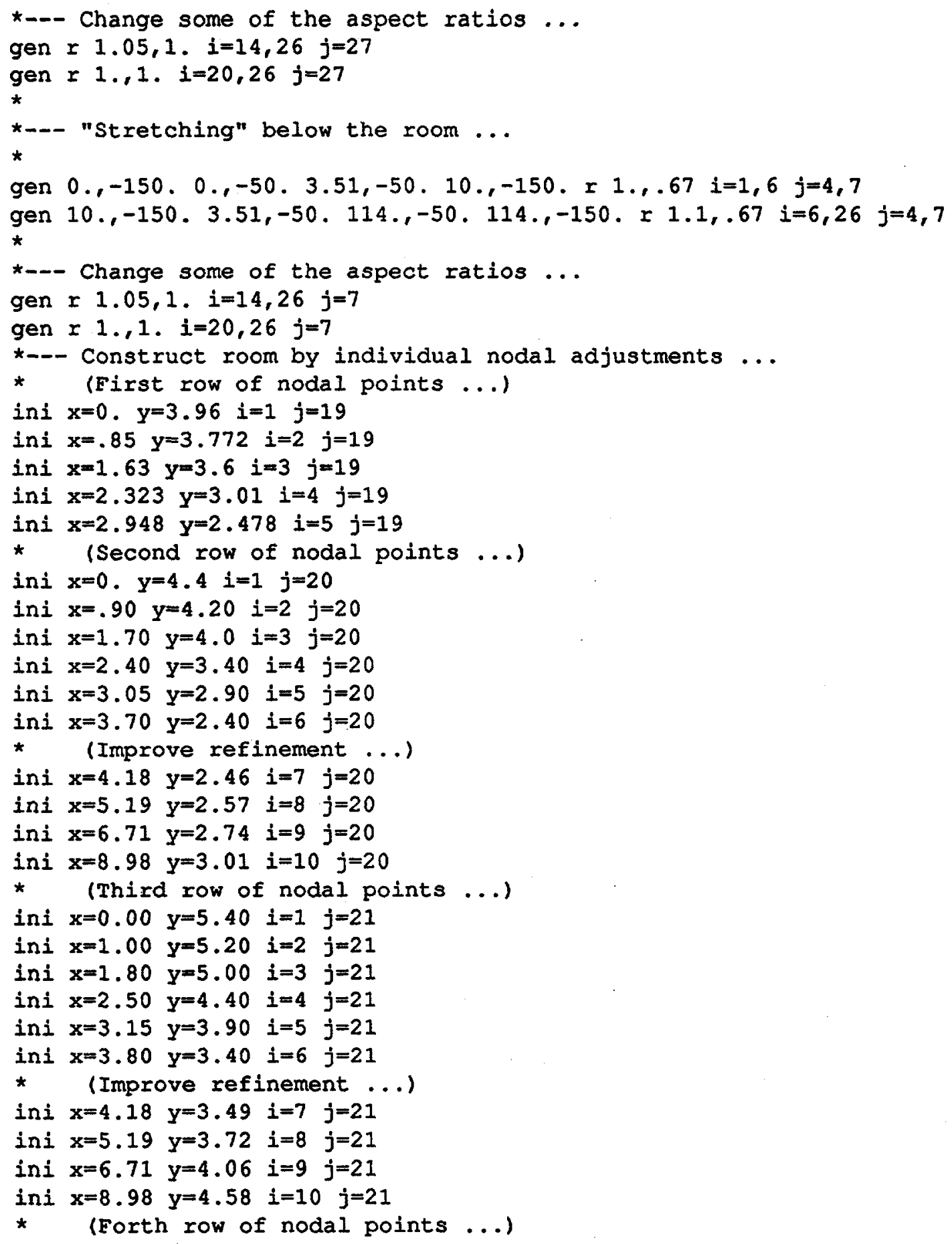




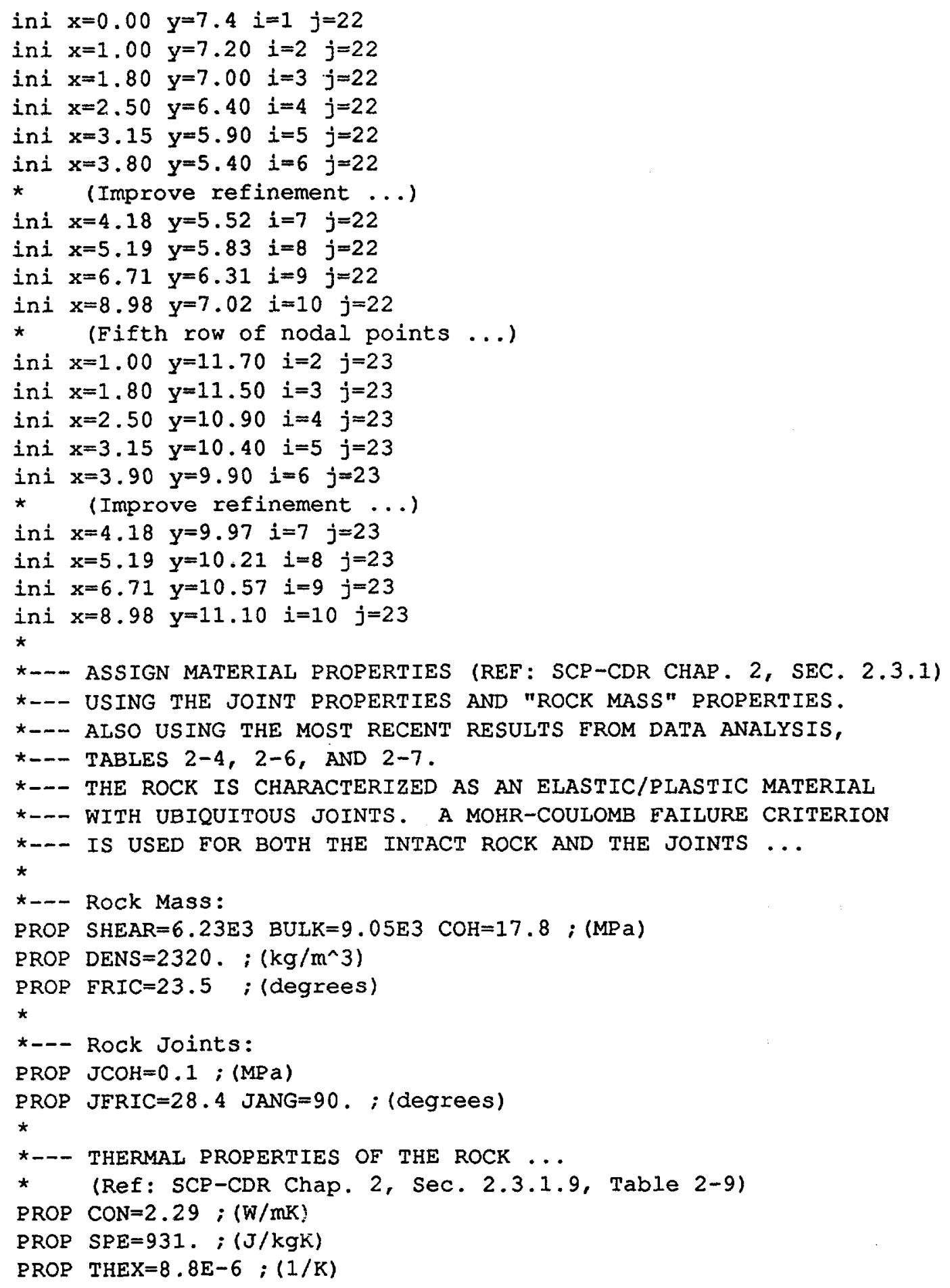




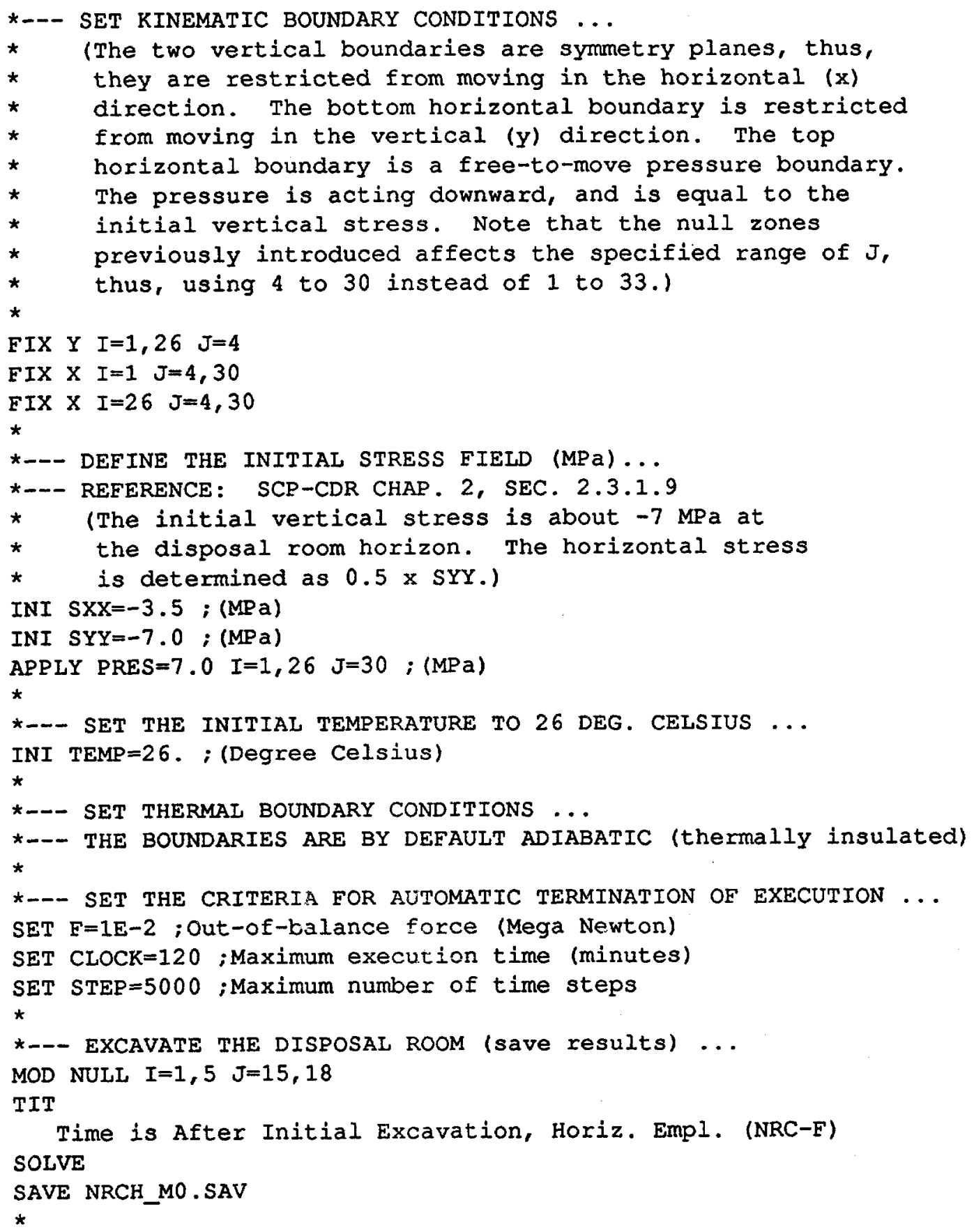


*--- THERMAL PROPERTIES OF THE DISPOSAL ROOM FROM 0 TO 50 YEARS. (The maximum thermal time step in FLAC is determined from the element size and associated thermal diffusivity. Using air in the disposal room with an "equivalent" conductivity results in a maximum time step of insufficient length to complete the analysis within a reasonable time period. Therefore, the room is given thermal properties of TSw2 tuff, but with the thermal conductivity increased about 22 times to $50 \mathrm{w} / \mathrm{mk}$. The size of the room elements are also increased.

- CHANGE THE ELEMENT SIZES IN THE ROOM SO THAT AS LARGE A TIME STEP AS POSSIBLE MAY BE USED ...

* This is done by restoring a thermal region in the room, and * surrounding it by null zones, and then "stretching" the thermal * region to fit the entire room.)

*

THMOD ISO $\mathrm{I}=2,3 \mathrm{~J}=17$

*

*-.- Fit the restored thermal region to the entire room ...

*

ini $x=0.00 \quad y=0.00 \quad i=2 \quad j=17$

ini $x=0.00 \quad y=3.96 \quad i=2 \quad j=18$

ini $x=1.629 \quad y=0.00 \quad i=3 \quad j=17$

ini $x=1.630 \quad y=3.60 \quad i=3 \quad j=18$

ini $x=3.51 \quad y=0.00 \quad i=4 \quad j=17$

ini $x=3.51 \quad y=2.00 \quad i=4 \quad j=18$

*

*--- Assign thermal properties to the restored thermal region ...

*

PROP CON $=50 . \quad I=2,3 \mathrm{~J}=17 ;(\mathrm{W} / \mathrm{mK})$

PROP SPE $=931$. I $=2,3 \mathrm{~J}=17 ;(\mathrm{J} / \mathrm{kgK})$

PROP DENS $=2320 . \quad \mathrm{I}=2,3 \mathrm{~J}=17 ;\left(\mathrm{kg} / \mathrm{m}^{\wedge} 3\right)$

PROP THEX $=0 . \mathrm{I}=2,3 \mathrm{~J}=17 ;(1 / \mathrm{K})$

*

*--- DEFINE INTERFACES BETWEEN THE THERMAL REGION AND THE

*.-- DisPosal ROOM SURFACE ...

*

INTER 1 ASIDE $1,15 \quad 2,15 \quad 3,15 \quad 4,15 \quad 5,15 \quad 6,15 \quad 6,16 \quad 6,17 \quad 6,18 \quad 6,19$

INTER 1 ASIDE 5,19 4,19 3,19 2,19 1,19

INTER 1 BSIDE $2,18 \quad 3,18 \quad 4,18 \quad 4,17 \quad 3,17 \quad 2,17$

* 


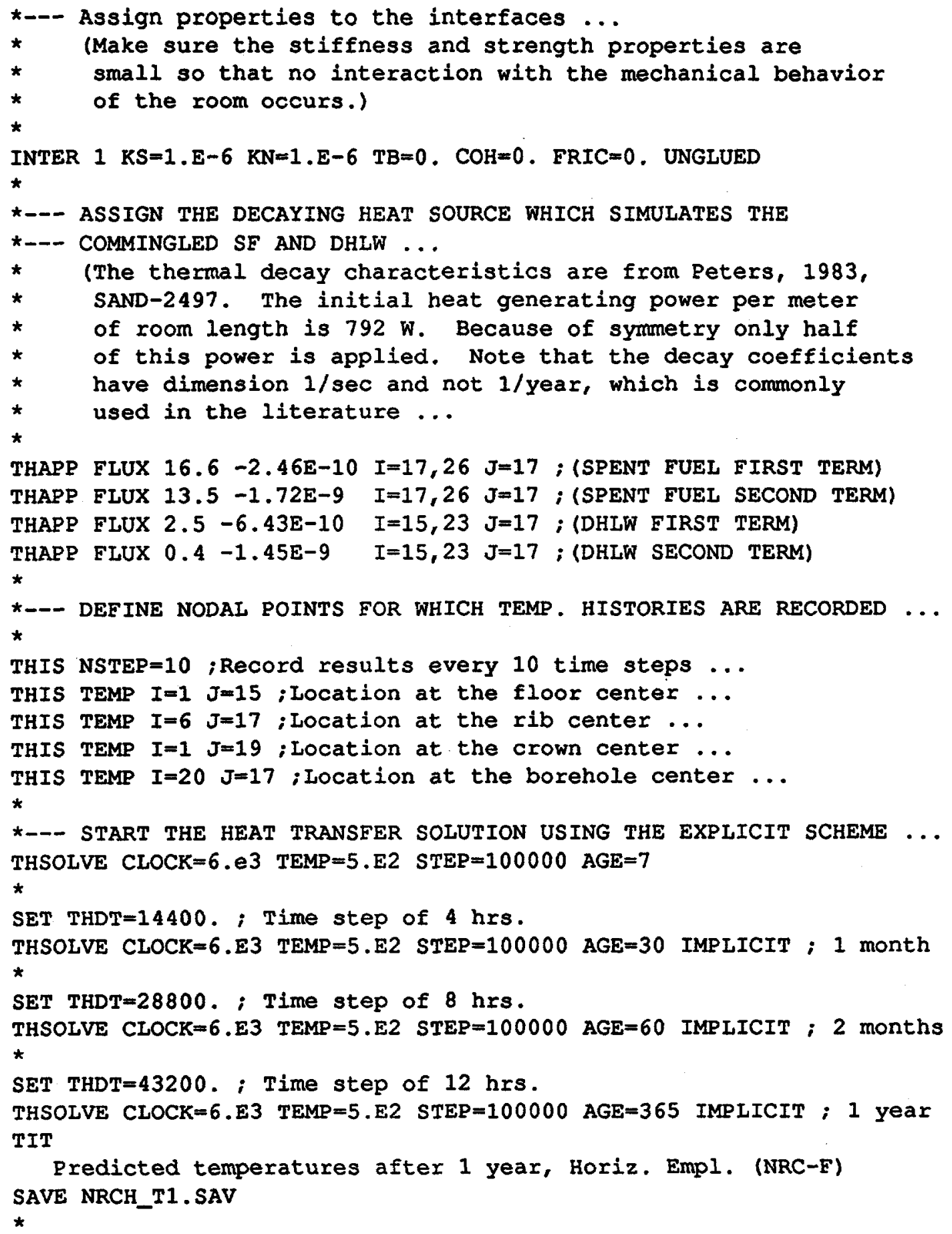




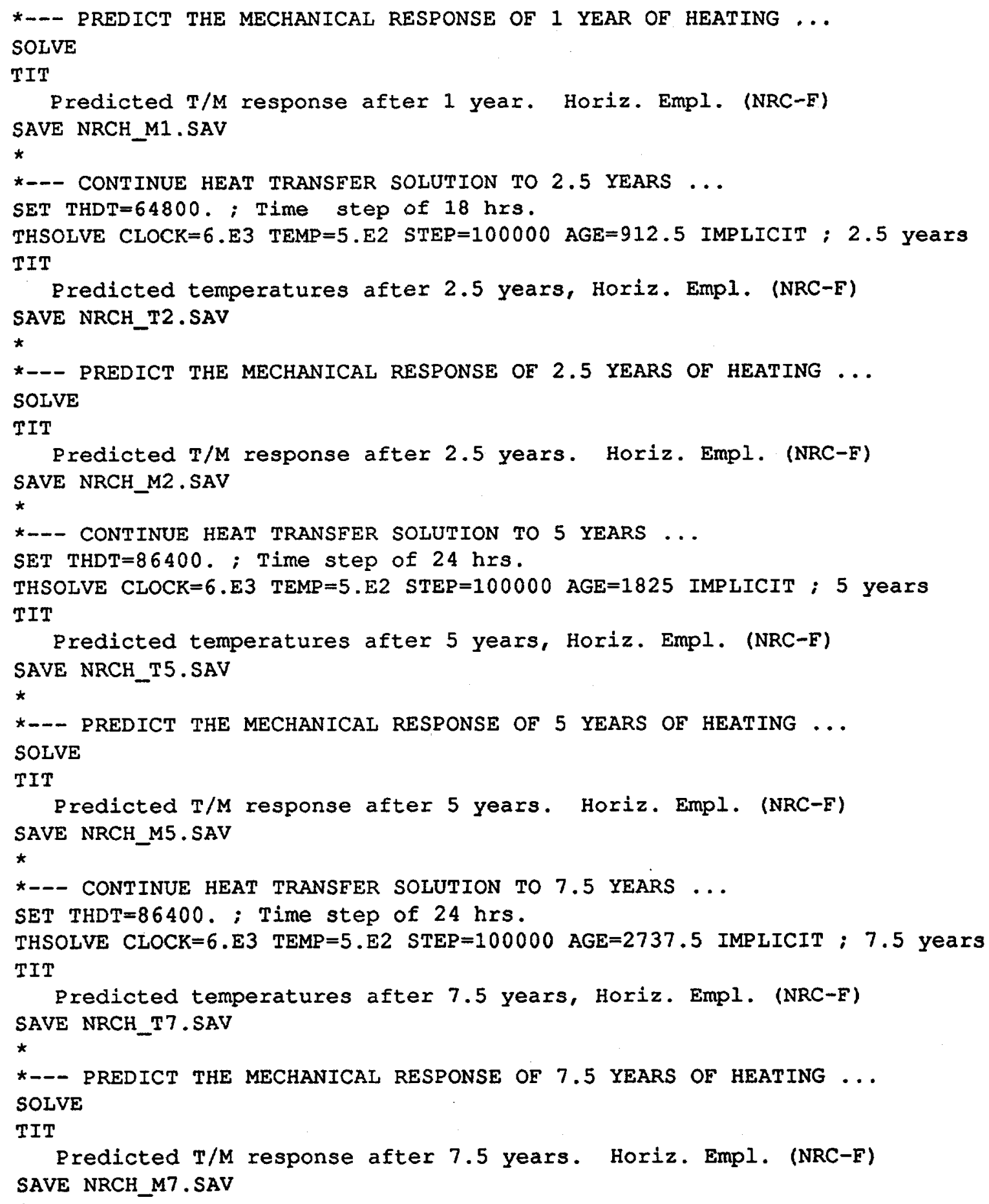




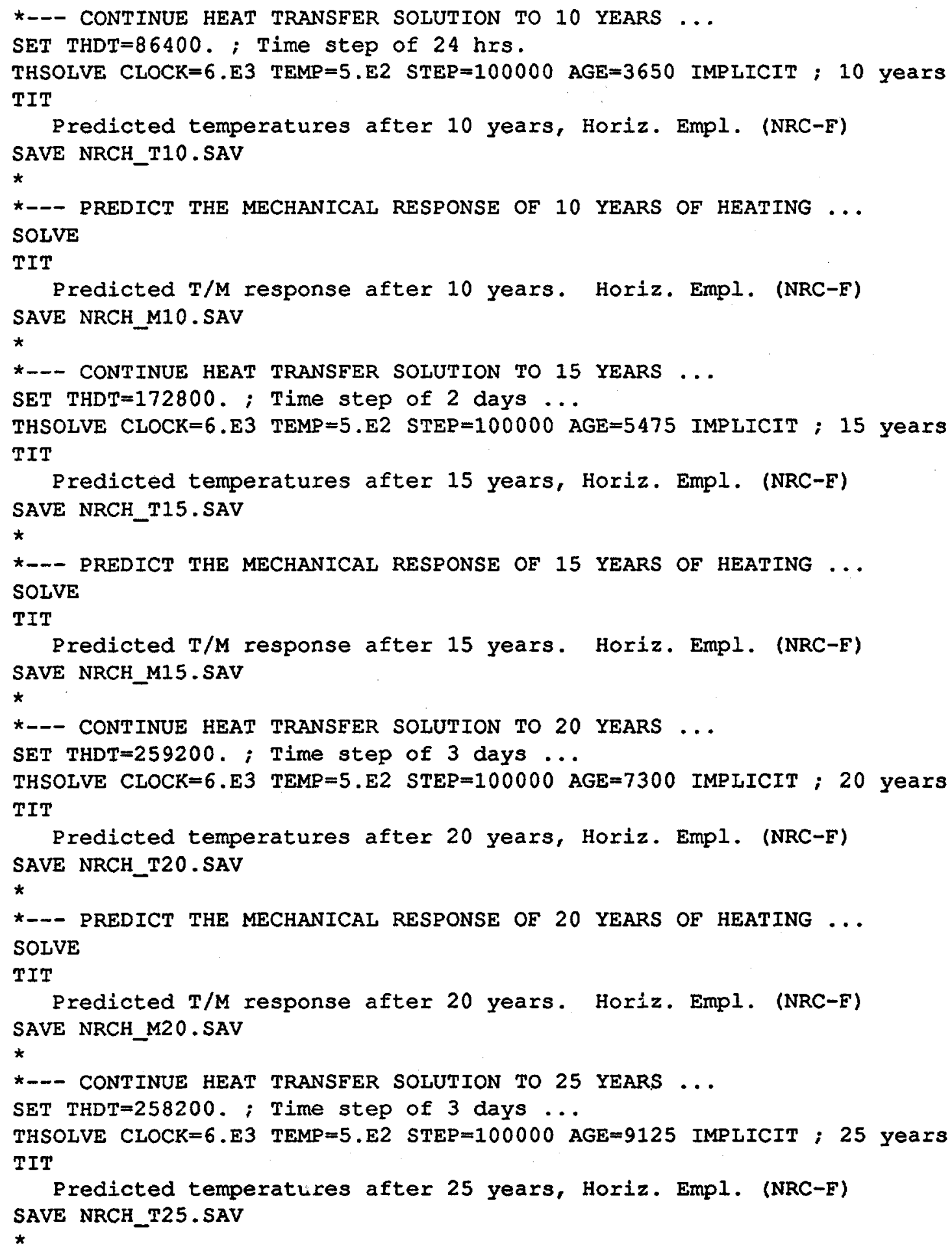




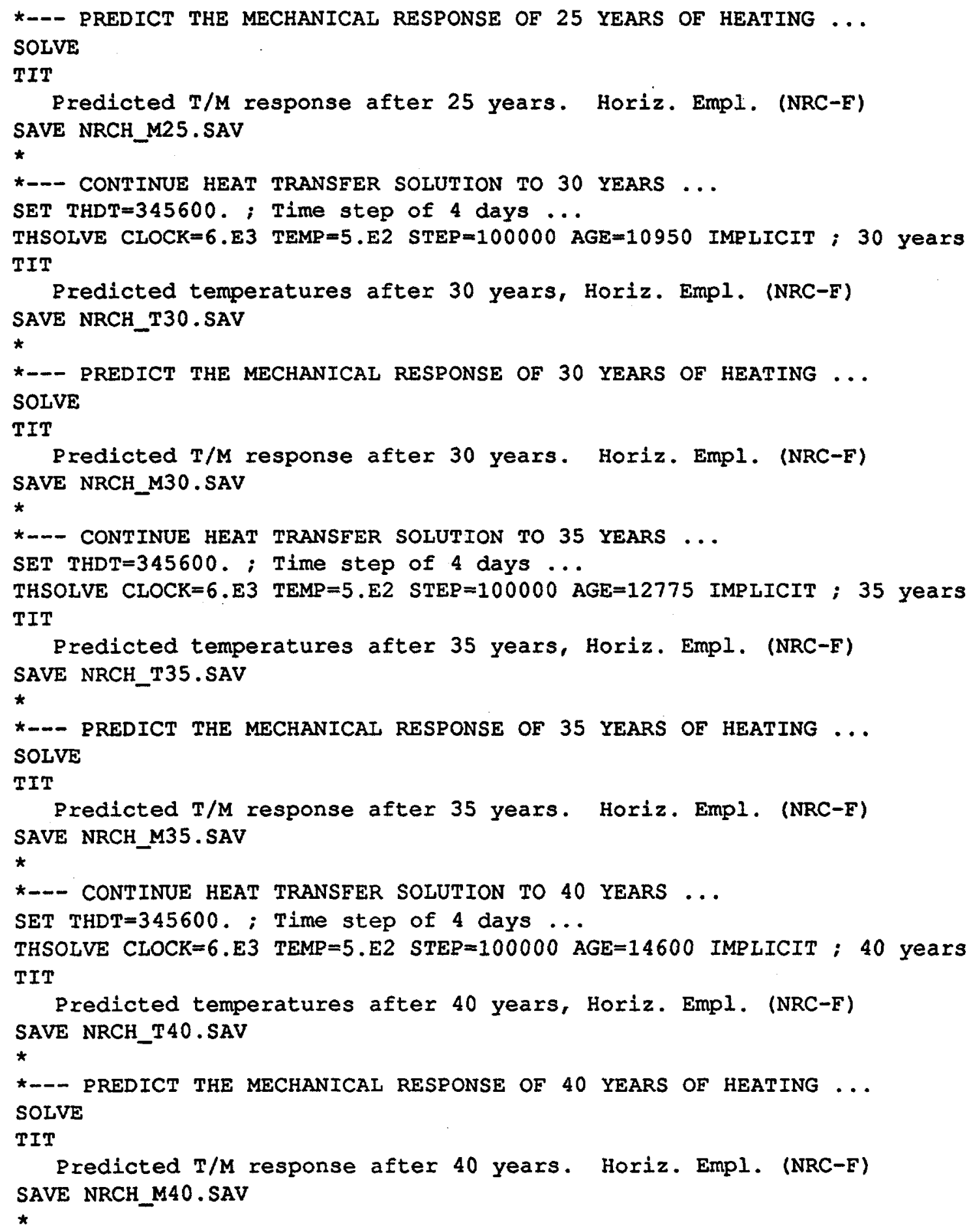




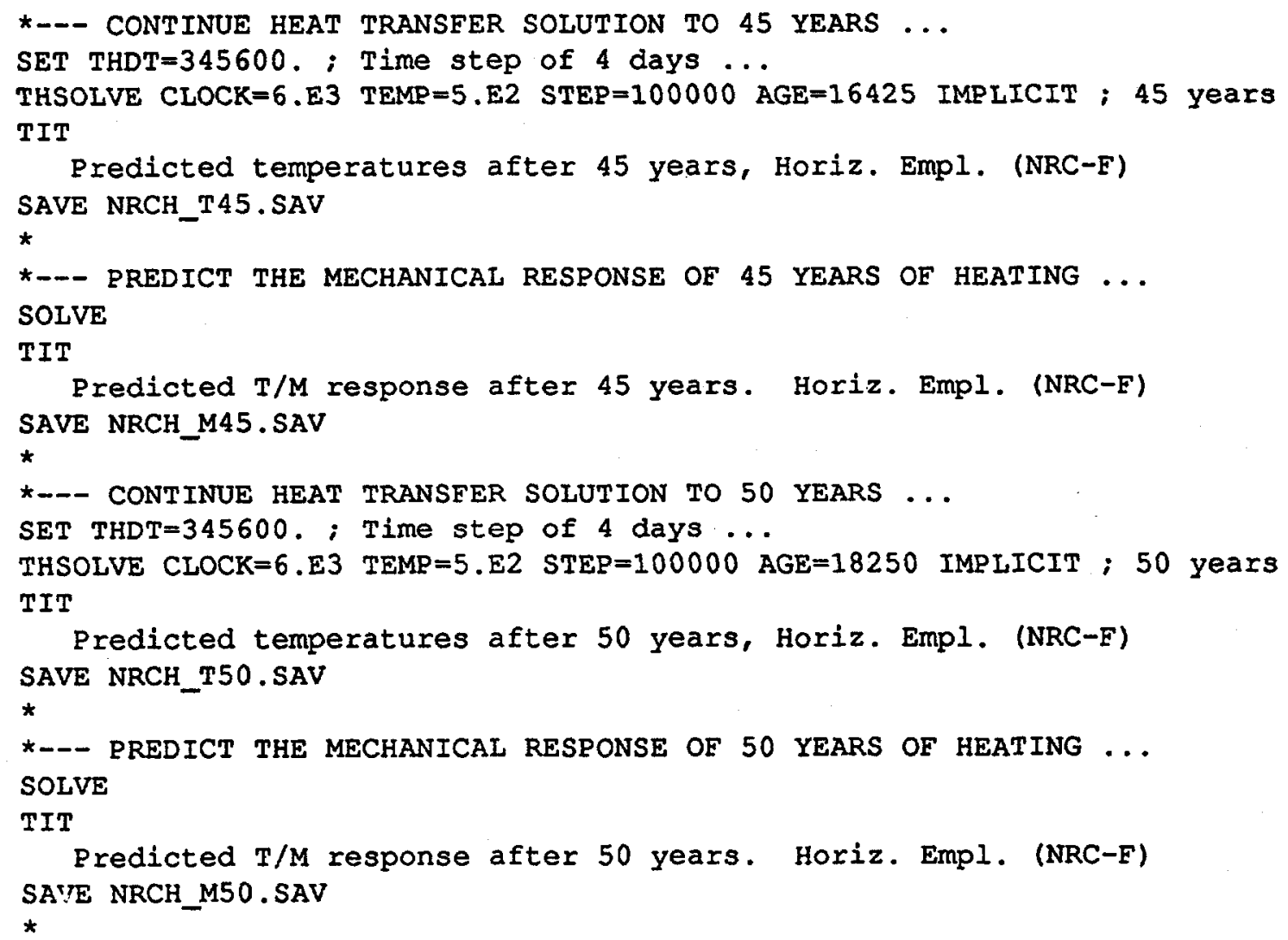




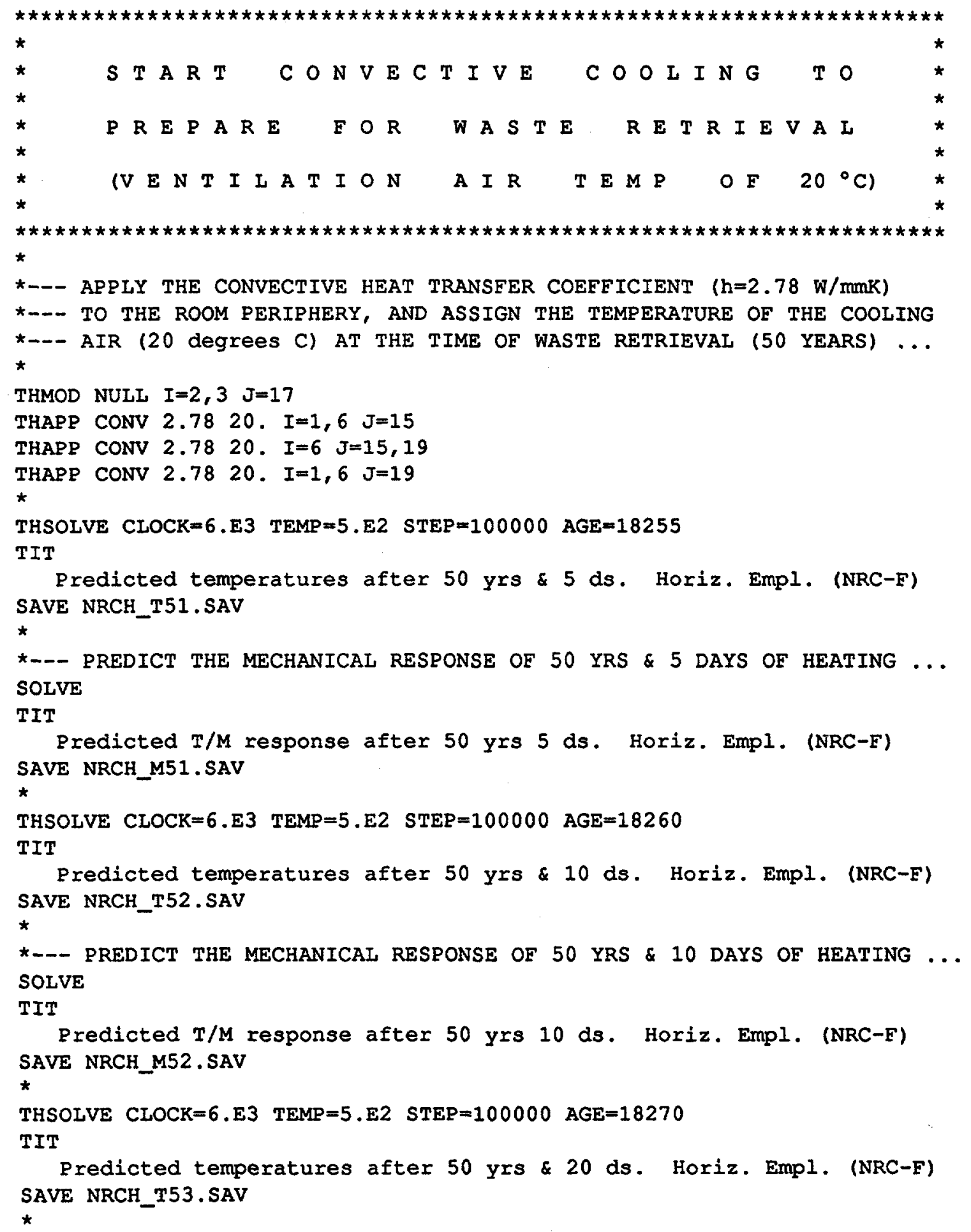


*--- PREDICT THE MECHANICAL RESPONSE OE 50 YRS \& 20 DAYS OF HEATING ... SOLVE

TIT

Predicted $T / M$ response after 50 yrs 20 ds. Horiz. Empl. (NRC-F) SAVE NRCH_M53.SAV

*

THSOLVE CLOCK=6.E3 TEMP $=5 . E 2$ STEP $=100000$ AGE $=18290$

TIT

Predicted temperatures after 50 yrs \& 40 ds. Horiz. Empl. (NRC-E) SAVE NRCH_T54.SAV

*

*--- PREDICT THE MECHANICAL RESPONSE OF 50 YRS \& 40 DAYS OF hEATING ... SOLVE

TIT

Predicted $T / M$ response after 50 yrs 40 ds. Horiz. Empl. (NRC-F) SAVE NRCH_M54.SAV

*

THSOLVE CLOCK=6.E3 TEMP=5.E2 STEP=100000 AGE $=18310$

TIT

Predicted temperatures after 50 yrs \& 60 ds. Horiz. Empl. (NRC-F) SAVE NRCH_T55.SAV

*

*--- PREDICT THE MECHANICAL RESPONSE OF 50 YRS \& 60 DAYS OF hEATING ... SOLVE

TIT

Predicted $T / M$ response after 50 yrs 60 ds. Horiz. Empl. (NRC-F) SAVE NRCH_M55.SAV

*

THSOLVE CLOCK $=6 . E 3$ TEMP $=5$.E2 STEP $=100000$ AGE $=18330$ TIT

Predicted temperatures after 50 yrs \& 80 ds. Horiz. Empl. (NRC-F) SAVE NRCH_T56.SAV

*

*--- PREDICT THE MECHANICAI RESPONSE OF 50 YRS \& 80 DAYS OF HEATING ... SOLVE

TIT

Predicted $T / M$ response after 50 yrs 80 ds. Horiz. Empl. (NRC-F) SAVE NRCH_M56.SAV

*

THSOLVE CLOCK $=6 . E 3$ TEMP $=5 . E 2$ STEP $=100000$ AGE $=18350$

TIT

Predicted temperatures after 50 yrs \& $100 \mathrm{ds}$. Horiz. Empl. (NRC-F) SAVE NRCH_T57.SAV

* 


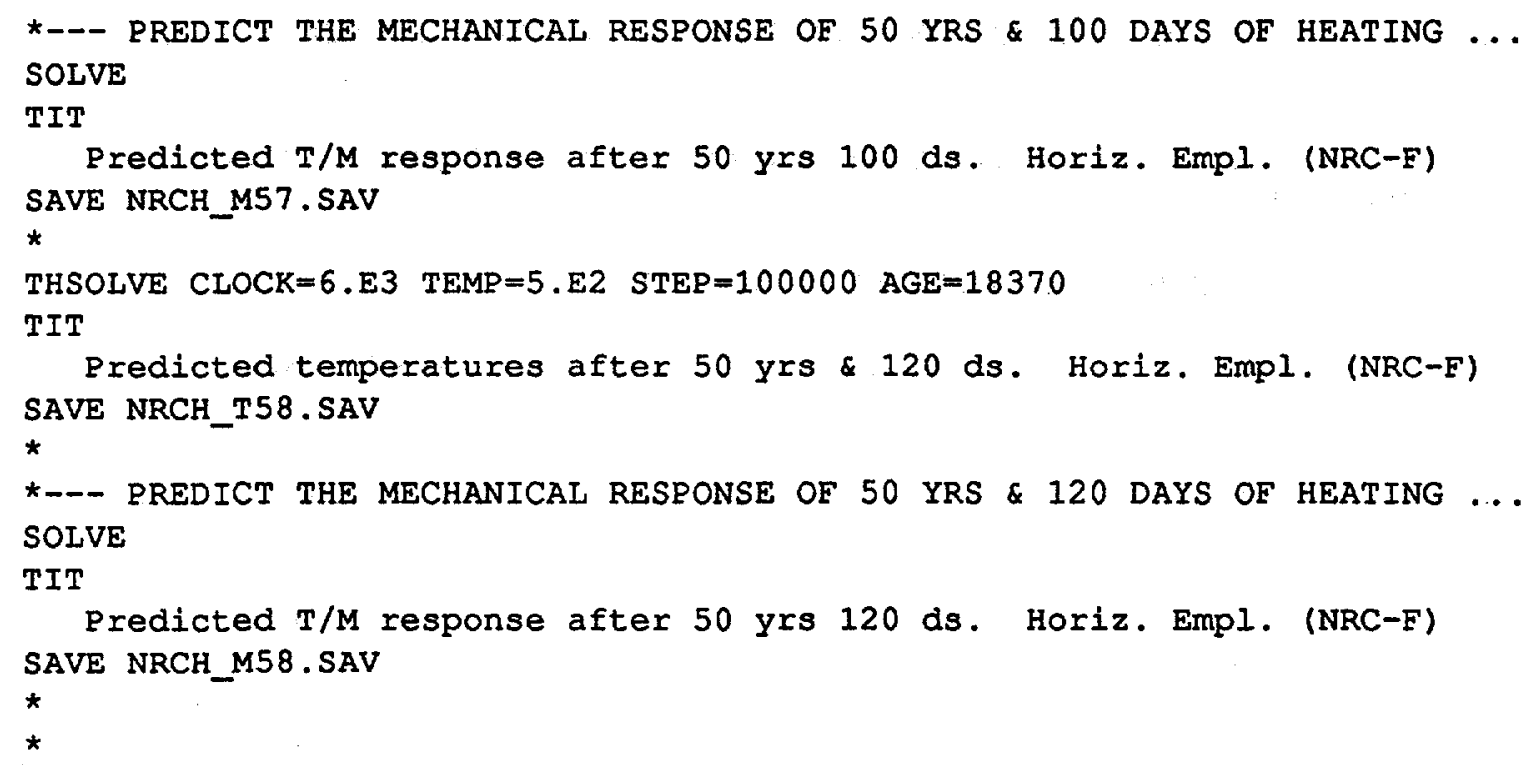




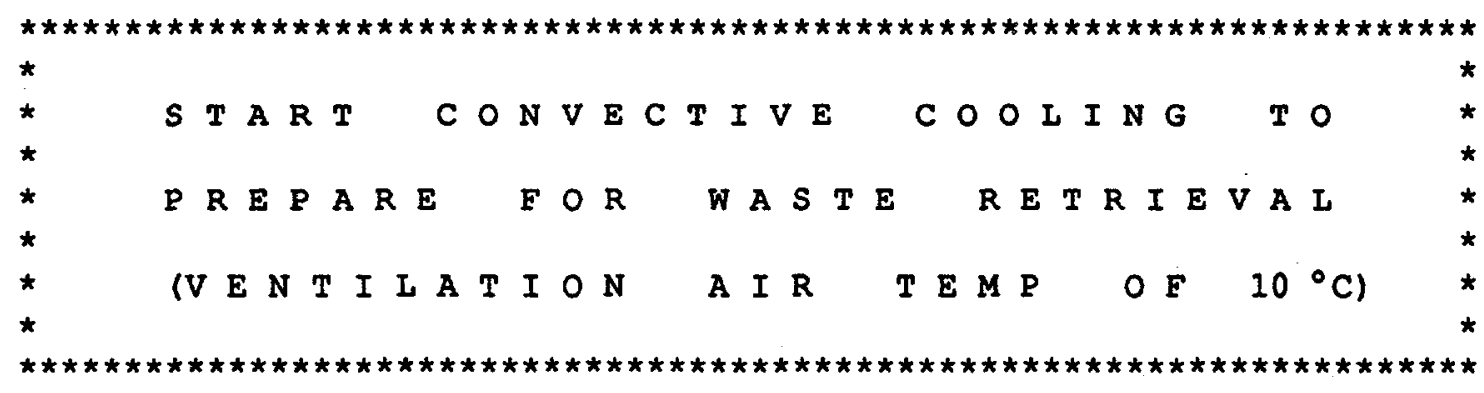

$\star$ RES NRCH_M50.SAV

$\star$

*--- APPLY THE CONVECTIVE HEAT TRANSFER COEFEICIENT ( $\mathrm{h}=2.88 \mathrm{w} / \mathrm{mmK}$ )

*--- TO THE ROOM PERIPHERY, AND ASSIGN THE TEMPERATURE OF THE COOLING

*--- AIR ( 10 degrees C) AT THE TIME OF WASTE RETRIEVAL (50 YEARS) ...

*--- Note that the convective heat transfer coefficient is different

*--- for different air temperatures and different room geometries ...

$\star$

THMOD NULL $I=2,3 \mathrm{~J}=17$

THAPP CONV 2.88 10. I=1,6 J=15

THAPP CONV 2.88 10. I=6 J=15,19

THAPP CONV 2.88 10. I=1, $6 \quad \mathrm{~J}=19$

*

THSOLVE CLOCK=6.E3 TEMP=5.E2 STEP=100000 AGE $=18255$

TIT

Predicted temperatures after 50 yrs \& 5 ds. $10^{\circ} \mathrm{C}$ Horiz. Empl. (NRC-F) SAVE NRCH_T61.SAV

*

*--- PREDICT THE MECHANICAL RESPONSE OF 50 YRS \& 5 DAYS OF HEATING ... SOLVE

TIT

Predicted $T / M$ response after 50 yrs 5 ds. $10^{\circ} \mathrm{C}$ Horiz. Empl. (NRC-F) SAVE NRCH_M61.SAV

*

THSOLVE CLOCK $=6 . E 3$ TEMP $=5$. E2 STEP $=100000$ AGE $=18260$

TIT

Predicted temperatures after 50 yrs \& 10 ds. $10^{\circ} \mathrm{C}$ Horiz. Empl. (NRC-F) SAVE NRCH_T62.SAV

$\star$ 
*-.- PREDICT THE MECHANICAL RESPONSE OE 50 YRS \& 10 DAYS OF HEATING ... SOLVE

TIT

Predicted $\mathrm{T} / \mathrm{M}$ response after 50 yrs $10 \mathrm{ds}, 10^{\circ} \mathrm{C}$ Horiz. Empl. (NRC-F) SAVE NRCH_M62.SAV

*

THSOLVE CLOCK $=6$.E3 TEMP $=5$. E2 STEP $=100000$ AGE $=18270$

TIT

Predicted temperatures after 50 yrs \& 20 ds. $10^{\circ} \mathrm{C}$ Horiz. Empl. (NRC-F) SAVE NRCH_T63.SAV

*

*--- PREDICT THE MECHANICAL RESPONSE OF 50 YRS \& 20 DAYS OF HEATING ... SOLVE

TIT

Predicted $T / M$ response after 50 yrs 20 ds. $10^{\circ} \mathrm{C}$ Horiz. Empl. (NRC-F) SAVE NRCH_M63.SAV

*

THSOLVE CLOCK=6.E3 TEMP $=5$.E2 STEP $=100000$ AGE $=18290$

TIT

Predicted temperatures after 50 yrs \& 40 ds. $10^{\circ} \mathrm{C}$ Horiz. Empl. (NRC-F) SAVE NRCH_T64.SAV

$\star$

*--- PREDICT THE MECHANICAL RESPONSE OF 50 YRS \& 40 DAYS OF HEATING ... SOLVE

TIT

Predicted $\mathrm{T} / \mathrm{M}$ response after 50 yrs 40 ds. $10^{\circ} \mathrm{C}$ Horiz. Empl. (NRC-F) SAVE NRCH_M64.SAV

*

THSOLVE CLOCK=6.E3 TEMP=5.E2 STEP=100000 AGE=18310

TIT

Predicted temperatures after 50 yrs \& 60 ds. $10^{\circ} \mathrm{C}$ Horiz. Empl. (NRC-F) SAVE NRCH_T65.SAV

$\star$

*--- PREDICT THE MECHANICAL RESPONSE OF 50 YRS \& 60 DAYS OF HEATING ... SOLVE

TIT

Predicted T/M response after 50 yrs 60 ds. $10^{\circ} \mathrm{C}$ Horiz. Empl. (NRC-F) SAVE NRCH_M65.SAV

$\star$

THSOLVE CLOCK=6.E3 TEMP $=5 . E 2$ STEP $=100000 \quad A G E=18330$

TIT

Predicted temperatures after 50 yrs \& 80 ds. $10^{\circ} \mathrm{C}$ Horiz. Empl. (NRC-F) SAVE NRCH_T66.SAV

* 


$$
\text { D-33 }
$$

*--- PREDICT THE MECHANICAL RESPONSE OF 50 YRS \& 80 DAYS OF HEATING ... SOLVE

TIT

Predicted $T / M$ response after 50 yrs 80 ds. $10^{\circ} \mathrm{C}$ Horiz. Empl. (NRC-F) SAVE NRCH_M66.SAV

*

THSOLVE CLOCK $=6 . E 3$ TEMP $=5 . E 2$ STEP $=100000 \quad$ AGE $=18350$

TIT

Predicted temperatures after 50 yrs \& 100 ds. 10' Horiz. Empl. (NRC-F) SAVE NRCH_T67.SAV

*

*--- PREDICT THE MECHANICAI RESPONSE OF 50 YRS \& 100 DAYS OF hEATING ... SOLVE

TIT

Predicted $T / M$ response after 50 yrs 100 ds. $10^{\circ} \mathrm{C}$ Horiz. Empl. (NRC-F) SAVE NRCH_M67.SAV

*

THSOLVE CLOCK $=6 . E 3 \quad \mathrm{TEMP}=5 . \mathrm{E} 2 \mathrm{STEP}=100000 \quad \mathrm{AGE}=18370$

TIT

Predicted temperatures after 50 yrs \& 120 ds. $10^{\circ} \mathrm{C}$ Horiz. Empl. (NRC-F) SAVE NRCH_T68.SAV

*

*--- PREDICT THE MECHANICAL RESPONSE OF 50 YRS \& 120 DAYS OF HEATING ... SOLVE

TIT

Predicted $\mathrm{T} / \mathrm{M}$ response after 50 yrs 120 ds. $10^{\circ} \mathrm{C}$ Horiz. Empl. (NRC-F) SAVE NRCH_M68.SAV 


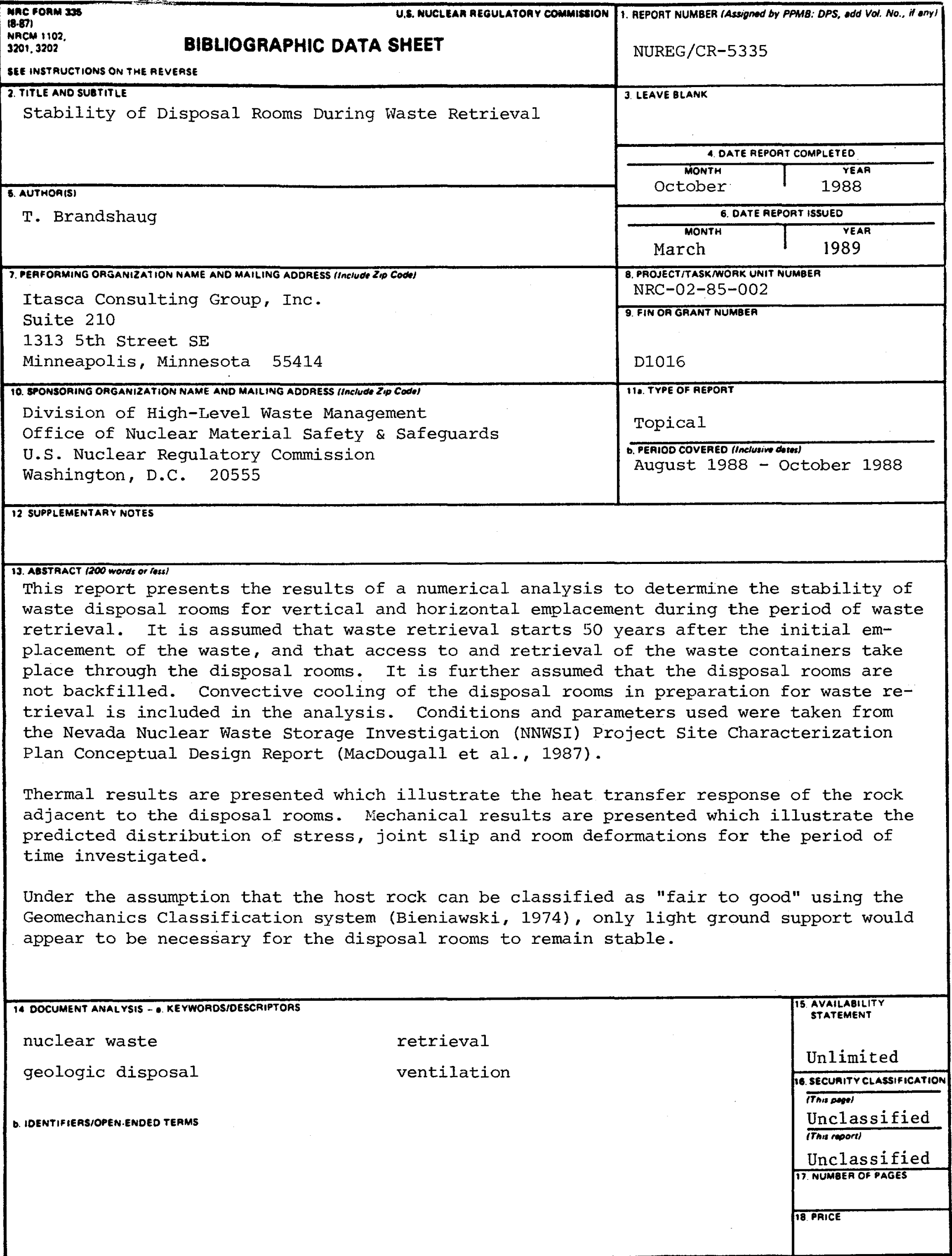

